Article

\title{
Asymmetric Synthesis of Photophore-Containing Lactisole Derivatives to Elucidate Sweet Taste Receptors
}

\author{
Tomoya Nakagita ${ }^{1,2,+} \oplus$, Akiko Ishida ${ }^{3,+}$, Zetryana Puteri Tachrim ${ }^{3,4}$, Lei Wang ${ }^{3,5}$, \\ Takumi Misaka ${ }^{1}$ and Makoto Hashimoto ${ }^{3, *}$ \\ 1 Department of Applied Biological Chemistry, Graduate School of Agricultural and Life Sciences, \\ The University of Tokyo, Tokyo 113-8657, Japan; nakagita.tomoya.eo@ehime-u.ac.jp (T.N.); \\ amisaka@mail.ecc.u-tokyo.ac.jp (T.M.) \\ 2 Proteo-Science Center, Ehime University, Ehime 791-8577, Japan \\ 3 Division of Applied Bioscience, Graduate School of Agriculture, Hokkaido University, Kita 9, Nishi 9, \\ Kita-ku, Sapporo 060-8589, Japan; a-ishida@frontier.hokudai.ac.jp (A.I.); zetry@chem.itb.ac.id (Z.P.T.); \\ leiwang@dlut.edu.cn (L.W.) \\ 4 Program Study of Chemistry, Faculty of Mathematics and Natural Sciences, Institut Teknologi Bandung, \\ Jalan Ganesha 10, Bandung 40132, Indonesia \\ 5 Department of Pharmacy, School of Chemical Engineering, Dalian University of Technology, \\ Dalian 116023, China \\ * Correspondence: hasimoto@abs.agr.hokudai.ac.jp; Tel.: +81-11-7063849 \\ + These authors contributed equally to this work.
}

Received: 29 May 2020; Accepted: 16 June 2020; Published: 17 June 2020

\begin{abstract}
Lactisole, which has a 2-phenoxy propionic acid skeleton, is well-known as an inhibitor of sweet taste receptors. We recently revealed some of the structure-activity relationships of the aromatic ring and chiral center of lactisole. Photoaffinity labeling is one of the common chemical biology methods to elucidate the interaction between bioactive compounds and biomolecules. In this paper, the novel asymmetric synthesis of lactisole derivatives with common photophores (benzophenone, azide and trifluoromethyldiazirine) for photoaffinity labeling is described. The synthetic compounds are subjected to cell-based sweet taste receptors, and the substitution with trifluoromethyldiazirinyl photophore shows the highest affinity to the receptor of the synthesized compounds.
\end{abstract}

Keywords: lactisole; photoaffinity label; sweet taste; diazirine; azide; benzophenone

\section{Introduction}

Lactisole (2-(4-methoxyphenoxy)propanoic acid) [1,2] is well-known as an inhibitor of sweet taste receptors and has been shown to interact with the transmembrane domain of the T1R3 subunit (T1R3-TMD) of the receptor [3]. The mother skeleton, 2-phenoxypropanoic acid, is found in several phenoxy herbicides, such as 2-(2,4-dichlorophenoxy)propanoic acid (dichlorprop, 2,4-DP) 2-(4-chlorophenoxy)propanoic acid (4-CPP) [4], and (R)-isomers of them have herbicide activities. We recently reported that the $(S)$-isomers at the 2-position of lactisole and 2,4-DP at the 2-position have higher affinity for sweet taste receptor than $(R)$-isomers [5]. These results are inconsistent with the herbicide activity for 2-phenoxypropanoic acid [6]. The detailed functional analysis of the stereocenter may be important to elucidate sweet taste receptors.

Photoaffinity labeling [7-10] is a useful biochemical method for the analysis of biological interactions between low-molecular-weight bioactive compounds and biomolecules. The methodology may afford other information near the binding sites which cannot be obtained from 
structure-activity relationship studies. Three major photophores-phenylazide, benzophenone and (trifluoromethyl)phenyldiazirine-are used for photoaffinity labeling [11]. We reported several preparations of gustatory ligands to elucidate gustatory receptors [12-20]; however, there are few studies on the synthesis of photoreactive lactisole derivatives which have aimed to elucidate their biological activities. In this paper, we describe the comprehensive synthesis of photoreactive lactisole derivatives (Figure 1), which we then used in an inhibitory activity assay for cell-based human sweet taste receptors.
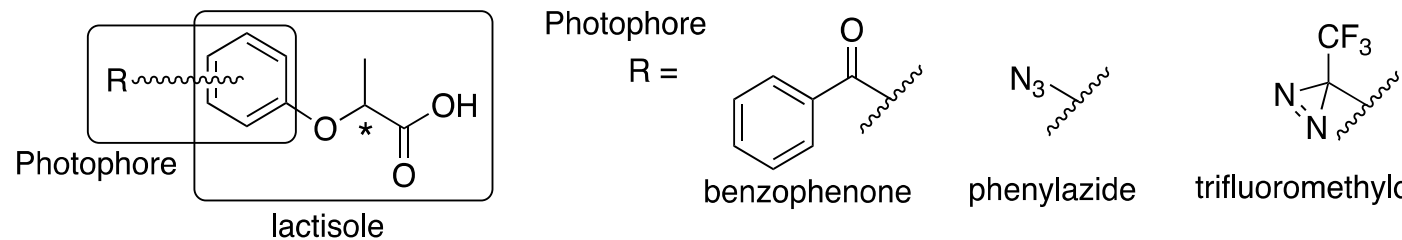

lactisole

phenylazide

trifluoromethyldiazirine

Figure 1. Structures of photoreactive lactisole derivatives in this study.

\section{Results}

\subsection{Synthesis}

The key steps to construct a lactisole skeleton in an asymmetric manner are achieved by the Mitsunobu reaction for optically pure methyl lactate and phenol derivatives of photophore precursors. Details for each photophore are described below.

\subsubsection{Benzophenone-Based Lactisole Derivatives}

A few reports have described the preparations of racemic benzophenone-based lactisole derivatives and their separation by chromatography [21-25]. However, to date, the asymmetric synthesis of benzophenone-modified lactisole derivatives has not been reported. Hydroxybenzophenone derivatives (1-3), optically pure methyl lactate (4 and 5, 1.5 equiv.) and triphenylphosphine (1.2 equiv.) were preincubated at $0{ }^{\circ} \mathrm{C}$ for $10 \mathrm{~min}$ in dichloromethane and diethyl azodicarboxylate (1.5 equiv.) was slowly added to the solution. The reaction mixture was stirred at room temperature overnight and worked up with a general procedure. Purification with column chromatography afforded the optically pure methyl 2-benzoylphenoxypropionate derivatives 6-8 with a good yield. The methyl esters were subjected to chiral high-performance liquid chromatography (HPLC) with Chiralpak IG [2] to ensure the configuration of the chiral center. The methyl esters were hydrolyzed under reflux in the presence of $\mathrm{K}_{2} \mathrm{CO}_{3}$ to afford derivatives 9-13 in high yields (Figure 2).

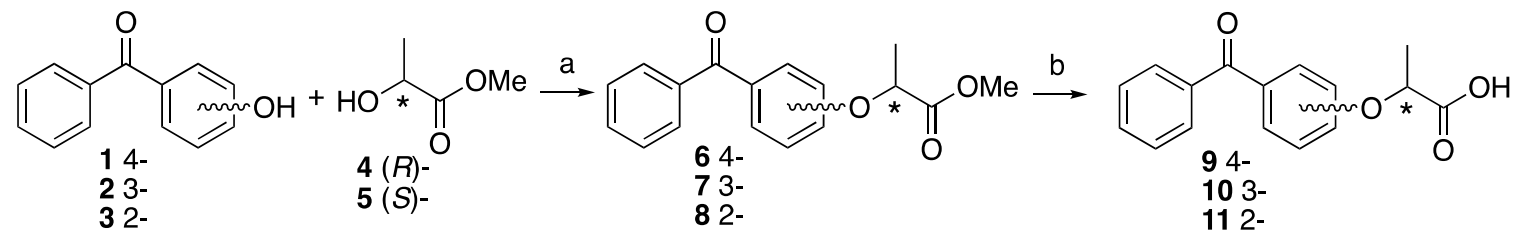

Figure 2. Synthesis of benzophenone-containing lactisole derivatives. (a) (1) $\mathrm{PPh}_{3}, \mathrm{CH}_{2} \mathrm{Cl}_{2}, 0{ }^{\circ} \mathrm{C}$, $10 \mathrm{~min}$; (2) diethyl azodicarboxylate (DEAD), $\mathrm{CH}_{2} \mathrm{Cl}_{2}, \mathrm{rt}, 8 \mathrm{~h},(S)-688 \%$, (R)-6 quant., (S)-7 quant., (R)-7 quant, (S)-8 88\%, (R)-8 82\%; (b) $\mathrm{K}_{2} \mathrm{CO}_{3}, \mathrm{CH}_{3} \mathrm{OH}, \mathrm{H}_{2} \mathrm{O}$, reflux, $2 \mathrm{~h}$, (S)-9 quant, (R)-9 quant., $(S)-\mathbf{1 0} 80 \%$, (R)-10 quant, $(S)-\mathbf{1 1} 87 \%$, $(R)-\mathbf{1 1} 88 \%$.

\subsubsection{Azide-Based Lactisole Derivatives}

An example of the synthesis of racemic azide-based lactisole ethyl ester has been reported previously [26], but to date, the asymmetric synthesis of azide modified on the aromatic ring of the lactisole skeleton has not been reported. Akazome et al. reported the asymmetric synthesis of $(R)$-2-nitro $(R)-23$ [27] and $(R)-3-n i t r o(R)-15$ [28,29]-substituted lactisole methyl ester. Our retrosynthesis 
for comprehensive preparations of azide-based lactisole derivatives was based on the asymmetric synthesis of nitro-substituted lactisole skeletons, followed by the conversion of the nitro group to azide derivatives. First, 4- and 3- Nitrophenol 12 and 13, and optically pure methyl lactate 4 and 5 (1.5 equiv.) and triphenylphosphine (1.2 equiv.) were preincubated at $0{ }^{\circ} \mathrm{C}$ for $10 \mathrm{~min}$ in dichloromethane. Diethyl azodicarboxylate (1.5 equiv.) was slowly added to the solution to construct nitro-substituted methyl lactisole 14 and 15. Nitro groups were reduced under a hydrogen atmosphere in the presence of $5 \%$ $\mathrm{Pd} / \mathrm{C}$ to afford amino derivatives 16 and 17. The aniline derivatives were subjected to diazotization followed by azidation to obtain azide-substituted methyl lactisole derivatives 18 and 19, which were checked by chiral center configuration. The methyl esters were hydrolyzed with sodium hydroxide under reflux condition to afford 20 and 21 in high yields (Figure 3).

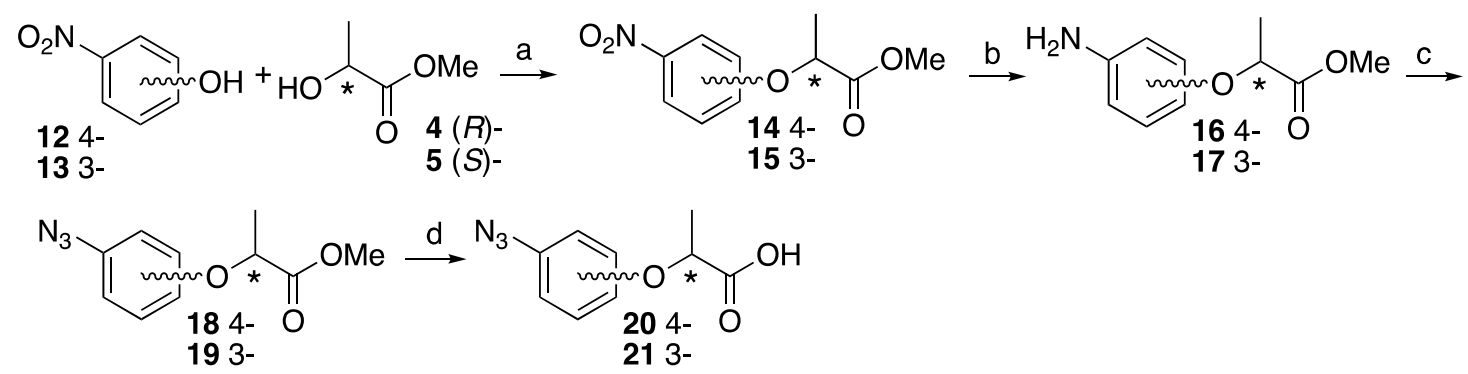

Figure 3. Synthesis of 4- and 3- azide-substituted lactisole derivatives. (a) (1) $\mathrm{PPh}_{3}, \mathrm{CH}_{2} \mathrm{Cl}_{2}, 0{ }^{\circ} \mathrm{C}$, 10 min; (2) DEAD, $\mathrm{CH}_{2} \mathrm{Cl}_{2}$, rt, 8 h, (S)-14 99\%, (R)-14 quant., (S)-15 quant., (R)-15 quant, (b) $\mathrm{H}_{2}, \mathrm{Pd} / \mathrm{C}$, $\mathrm{CH}_{3} \mathrm{OH}$, rt, 2 h, (S)-16 quant., (R)-16 quant., (S)-17 quant., (R)-17 87\%, (c) (1) $\mathrm{NaNO}_{2}, \mathrm{HCl}_{2} \mathrm{H}_{2} \mathrm{O}, 0{ }^{\circ} \mathrm{C}$; (2) $\mathrm{NaN}_{3}, 0{ }^{\circ} \mathrm{C}, 30 \mathrm{~min}$, then rt, $30 \mathrm{~min},(S)-\mathbf{1 8}$ quant., (R)-18 93\%., (S)-19 92\%., (R)-19 85\%, (d) NaOH, $\mathrm{CH}_{3} \mathrm{OH}, \mathrm{H}_{2} \mathrm{O}$, reflux, $5 \mathrm{~h},(S)-20$ 91\%, (R)-20 96\%, (S)-21 quant., (R)-21 81\%.

Then, 2-Nitrophenol 22 was also subjected to the Mitsunobu reaction in an identical manner with another isomer to make nitro methyl lactate skeleton 23. The hydrogenation of the nitro group promoted subsequent intramolecular cyclization between the amino and methyl ester to afford 2-methyl-2H-benzo[b][1,4]oxazin-3(4H)-one as the sole product [27]. To prevent intramolecular cyclization, the methyl ester hydrolyzed 24, then converted to tert-butyl ester 25 . The hydrogenation of nitro group of $\mathbf{2 5}$ proceeded smoothly to isolate aniline derivative $\mathbf{2 6}$ within an hour. Although tert-butyl ester was selected, intramolecular cyclization between the aniline and ester proceeded with a longer reaction time $(>4 \mathrm{~h}$ ). Compound 26 was subjected to diazotization followed by azidation to construct phenylazide moiety 27 , which was checked by chiral center configuration.

The deprotection of tert-butyl group of $\mathbf{2 7}$ with trifluoroacetic acid in dichloromethane afforded a complex mixture because the azide group was not stable under this condition. Mild acidic deprotection with $4 \mathrm{M} \mathrm{HCl}$ in dioxane was acceptable, but the partial decomposition of starting material 27 was observed over an hour. The starting material 27 could be recovered by partition within $1 \mathrm{~h}$, and the hydrolysis was repeated for the recovered 27 three times to afford compound $\mathbf{2 8}$ in a moderate yield (Figure 4). The reaction with 2-nitrophenol 22 and optical pure tert-butyl lactate was also conducted to construct compound 25 directly, but unfortunately, the Mitsunobu reaction did not proceed for the tert-butyl lactate.

\subsubsection{Trifluotromethyldiazirine-Based Lactisole Derivatives}

To date, trifluoromethyldiazirine-based lactisole derivatives have not been reported. The three-membered azi $(\mathrm{N}=\mathrm{N})$ partial structure of trifluoromethyldiazirine is not stable for the Mitsunobu condition because the reactant, diethyl azodicarboxylate DEAD also has an azo group in its structure. The reaction with diazirinyl phenol derivatives and 1'-hydroxy peracetylsucrose with DEAD or Tsuda reagents did not occur in our previous study [14]. The synthetic plan was based on the preparation of trifluoroacetyl modified on the aromatic ring of lactisole; then we constructed a diazirinyl three-membered ring on the trifluoroacetyl group. The reagent of liquid ammonia is essential to the construction of the 
diazirine moiety, but the reagent also reacts with methyl ester to form amide. tert-Butyl ester was utilized for this purpose. $p$-Trifluoroacetyl anisole and $m$-trifluoroacetyl anisole $\mathbf{2 9}$ and $\mathbf{3 0}$ were selected as the starting material for 4 and 3-substituted lactisoles. Compound 29 was treated with lithium chloride under a reflux condition to obtain trifluoroacetyl phenol 31 [30,31]. $m$-Trifluoroacetyl phenol 32 was synthesized with a boron tribromide treatment of $\mathbf{3 0}$ at room temperature [32]. Mitsunobu reactions for these phenols with chiral methyl lactate were archived in an identical manner to construct lactisole methyl ester skeletons 33 and 34. After the hydrolysis of methyl esters with $\mathrm{K}_{2} \mathrm{CO}_{3}$ under the reflux condition, corresponding trifluoroacetyl-substituted carboxylic acids $\mathbf{3 5}$ and $\mathbf{3 6}$ were subjected to diazirine formation. However, it was difficult to construct diazirine moiety for $\mathbf{3 5}$ and $\mathbf{3 6}$ directly. The carboxylic acids were converted to tert-butyl esters with tert-butyl bromide in the presence of $\mathrm{K}_{2} \mathrm{CO}_{3}$ and tetrabutylammonium bromide (TBAB) under reflux conditions. Although the reactions were not completed within $5 \mathrm{~h}$, the decompositions of the diazirinyl moiety of the starting material were observed over $5 \mathrm{~h}$. tert-Butyl derivatives 37 and 38 were obtained with moderate yields and the starting materials could be recovered from the reaction mixture (Figure 5). The tert-butyl thioester formations [33] were also conducted for the carboxylic acids to improve the chemical yields of the protection. The chemical yields were almost identical with tert-butyl ester, but the recovery of the starting material was very difficult from the reaction mixture. Mitsunobu reactions for trifluoroacetyl phenol 31 and 32 with chiral tert-butyl lactate were also conducted, but no reactions were observed.

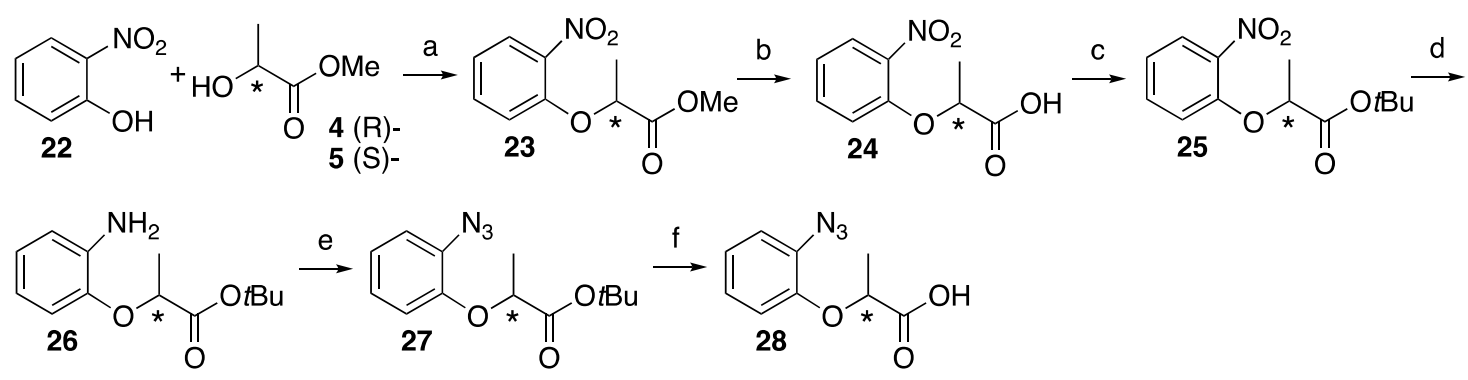

Figure 4. Synthesis of 2-azide-substituted lactisole derivatives. (a) (1) $\mathrm{PPh}_{3}, \mathrm{CH}_{2} \mathrm{Cl}_{2}, \mathrm{O}^{\circ} \mathrm{C}, 10 \mathrm{~min}$; (2) DEAD, $\mathrm{CH}_{2} \mathrm{Cl}_{2}$, rt, 8 h, (S)-23 quant., (R)-23 quant., (b) $\mathrm{NaOH}, \mathrm{CH}_{3} \mathrm{OH}$, reflux, $1 \mathrm{~h}$, (S)-24 quant., (R)-24 quant., (c) $t$-Butyl bromide, $\mathrm{K}_{2} \mathrm{CO}_{3}$, tetrabutylammonium bromide, dimethyl acetamide, $55{ }^{\circ} \mathrm{C}$, 2.5 h, (S)-25 77\%, (R)-25 82\%, (d) $\mathrm{H}_{2}, \mathrm{Pd} / \mathrm{C}, \mathrm{CH}_{3} \mathrm{OH}, \mathrm{rt}, 1$ h, (S)-26 73\%, (R)-26 89\%, (e) $\mathrm{NaNO}_{2}, \mathrm{HCl}$, $\mathrm{H}_{2} \mathrm{O}, 0{ }^{\circ} \mathrm{C}$; (2) $\mathrm{NaN}_{3}, 0{ }^{\circ} \mathrm{C}, 30 \mathrm{~min}$, then rt, $30 \mathrm{~min}$, (S)-27 quant., (R)-27 89\%, (f) $4 \mathrm{M} \mathrm{HCl}$, dioxane, rt, $1 \mathrm{~h},(S)-28$ 68\%, (R)-26 65\%

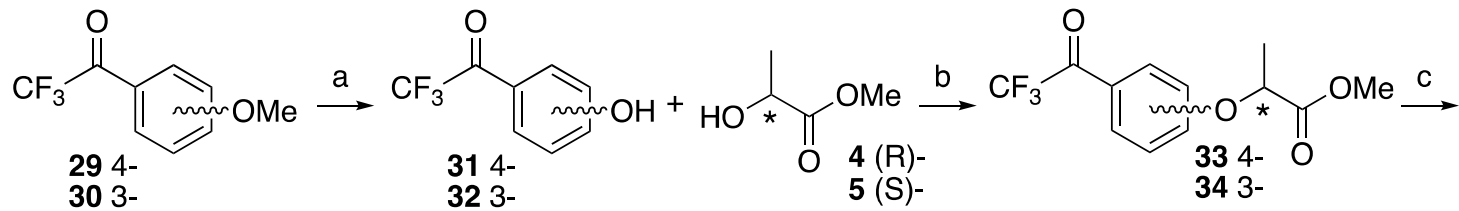<smiles>CCCCOC(=O)C(C)Oc1ccc(C(=O)C(C)(C)CCCC)cc1</smiles>

Figure 5. Synthesis of 3- and 4-trifluoroacetyl lactisole derivatives. (a) $\mathrm{LiCl}, \mathrm{DMF}$, reflux, $5 \mathrm{~h}$ for 31 $82 \%, \mathrm{BBr}_{3}, \mathrm{CH}_{2} \mathrm{Cl}_{2}, \mathrm{rt}, 2 \mathrm{~h}$ for 32 quant. (b) (1) $\mathrm{PPh}_{3}, \mathrm{CH}_{2} \mathrm{Cl}_{2}, 0{ }^{\circ} \mathrm{C}, 10 \mathrm{~min}$; (2) DEAD, $\mathrm{CH}_{2} \mathrm{Cl}_{2}, \mathrm{rt}$, $8 \mathrm{~h},(S)-33$ 78\%, (R)-33 74\%, (S)-34 71\%, (R)-34 75\%. (c) $\mathrm{K}_{2} \mathrm{CO}_{3}, \mathrm{MeOH}, \mathrm{H}_{2} \mathrm{O}$, reflux, 2 h, (S)-35 quant., (R)-35 95\%, (S)-36 99\%, (R)-36 97\%. (d) $t$-BuBr, $\mathrm{K}_{2} \mathrm{CO}_{3}$, tetrabutylammonium bromide (TBAB), DMA, $55^{\circ} \mathrm{C}, 5 \mathrm{~h},(S)-3766 \%$, (R)-37 70\%, (S)-38 38\%, (R)-38 37\%. 
Then, 2-trifluoroactyl phenol, which was prepared by the Fries rearrangement of phenyl 2,2,2-trifluoroacetate with $\mathrm{AlCl}_{3}$ [34], was subjected to Mitsunobu reaction with chiral methyl lactate 4 and did not afford a 2-trifluoroacetyl lactisole skeleton. The Mitsunobu reaction of salicylaldehyde and methyl lactate 4 followed by the conversion of aldehyde to the trifluoroacetyl group also failed due to the instability of methyl ester for the condition of trifluoroacetyl construction. Protected salicylaldehyde was selected for trifluoroacetyl substitution at the 2-position of lactisole. The carbonyl group was protected by thioacetal 40 [35], then subjected to a Mitsunobu reaction with chiral methyl lactate 4 and $\mathbf{5}$ to construct lactisole methyl ester $\mathbf{4 1}$ in an identical manner to that described above. After the hydrolysis of methyl esters with methanolic $\mathrm{NaOH}$ under the reflux condition, carboxylic acid 42 was converted to lactisole tert-butyl ester 43, then thioacetal was deprotected with methyl iodide. Aldehyde 44 was treated with TMS- $\mathrm{CF}_{3}$ followed by oxidation with Dess-Martin periodinane [20] to afford 2-trifluoroacetyl-substituted lactisole tert-butyl ester 45 (Figure 6).<smiles></smiles>

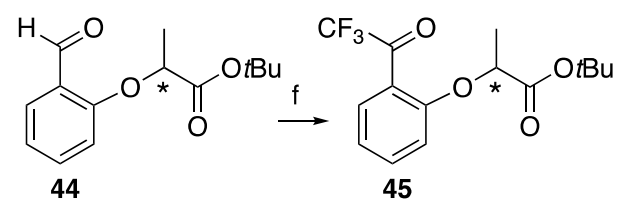

Figure 6. Synthesis of 2-trifluoroacetyl lactisole derivative. (a) 1,3-propanedithiol, $\mathrm{I}_{2}, \mathrm{CH}_{2} \mathrm{Cl}_{2}, \mathrm{rt}, 1 \mathrm{~h}$, 95\%, (b) (1) 4 or 5, $\mathrm{PPh}_{3}, \mathrm{CH}_{2} \mathrm{Cl}_{2}, 0{ }^{\circ} \mathrm{C}, 10 \mathrm{~min}$; (2) DEAD, $\mathrm{CH}_{2} \mathrm{Cl}_{2}, \mathrm{rt}, 8$ h, (S)-41 98\%, (R)-41 98\%, (c) $\mathrm{K}_{2} \mathrm{CO}_{3}, \mathrm{MeOH}, \mathrm{H}_{2} \mathrm{O}$, reflux, $1 \mathrm{~h}$, (S)-42 quant., (R)-42 quant, (d) $t-\mathrm{BuBr}, \mathrm{K}_{2} \mathrm{CO}_{3}, \mathrm{TBAB}, \mathrm{DMA}, 55^{\circ} \mathrm{C}$, 2.5 h, (S)-43 83\%, (R)-43 82\%, (e) $\mathrm{CH}_{3} \mathrm{I}, \mathrm{NaHCO}_{3}, \mathrm{CH}_{3} \mathrm{CN}, \mathrm{H}_{2} \mathrm{O}$, rt, 24 h, (S)-44 78\%, (R)-44 79\%, (f) (1) TMS- $\mathrm{CF}_{3}, \mathrm{~K}_{2} \mathrm{CO}_{3}, \mathrm{DMF}, \mathrm{rt}, 4 \mathrm{~h}$, (2) $1 \mathrm{M} \mathrm{HCl}, \mathrm{rt}, 4 \mathrm{~h}$; (3) Dess-Martin periodinane, $\mathrm{CH}_{2} \mathrm{Cl}_{2}, \mathrm{rt}, 3 \mathrm{~h}$, (S) $-4585 \%$, (R)-45 89\%.

Each trifluoroacetyl-substituted lactisole tert-butyl esters $(37,38,45)$ was subjected to diazirine constructions, oximation with hydroxylamine hydrochloride 46-48, tosylation for hydroxyl group of oxime 49-51, diaziridine formation with liquid ammonia 52-54, and oxidation with activated $\mathrm{MnO}_{2}$ to obtain 55-57, which were checked by chiral center configuration. tert-Butyl esters were hydrolyzed with trifluoroacetic acid to afford trifluoromethyldiazirine-based lactisole derivatives in moderate yields. The one-pot conversion of the tosyl oxime 49 to diazirine 55 [36] was also acceptable for the preparation with an identical yield (Figure 7).

\subsection{Cell-Based Sweet Taste Assay}

The synthesized photoreactive lactisole derivatives were administrated to the Flp-In 293 cell line and were expressed as inhibitors to the human sweet taste receptors, with less than $3.2 \mathrm{mM}$ comprising the final concentration. (S)-configurations of all photoreactive lactisole derivatives were preferred for sweet taste inhibition, and the results were consistent with our previous studies for lactisole and 2,4-dichlorophenoxy propanoic acid (2,4-DP) [5]. Benzophenone photophore (9-11) is too bulky to substitute for sweet taste receptors. Azide-substituted lactisoles (20, 21 and 28), which feature the linear linkage of three nitrogen atoms, had slightly higher affinity for the receptor than benzophenone derivatives. Trifluoromethyldiazirinyl substitution (58-60) had the highest affinity for sweet taste receptors among the photoreactive lactisole derivatives. The positions of photophores on aromatic rings are also influenced the activity, and the 4-position was preferred as a substitute. Fifty percent inhibitory concentration ( $\left.\mathrm{IC}_{50}\right)$ values $(\mu \mathrm{M})$ for $(S)-58$ and $(S)-59$ are almost identical with that of (S)-lactisole (Table 1, Supplementary Materials). 


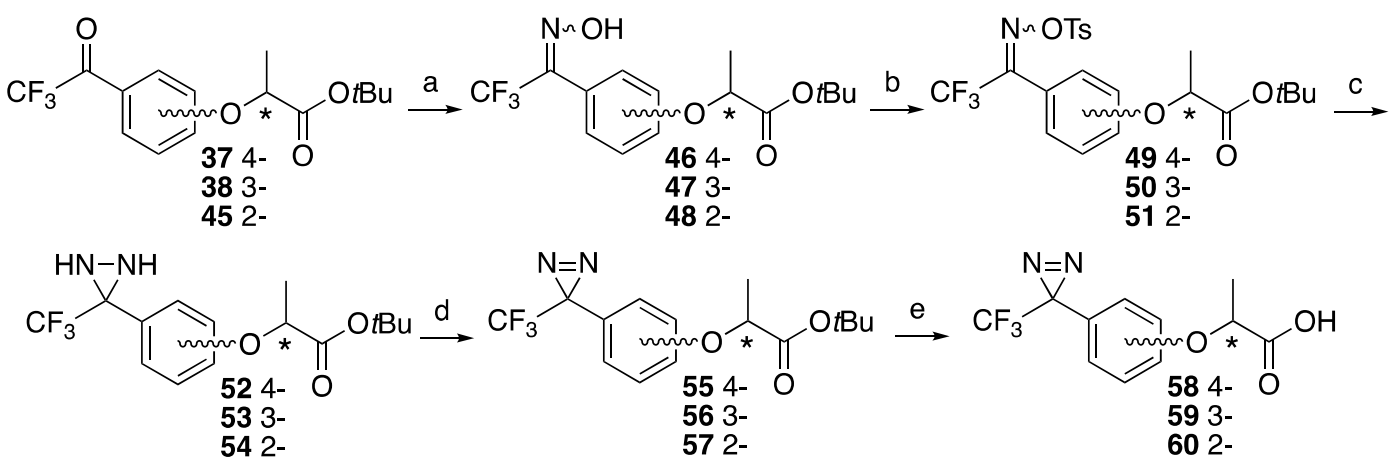

Figure 7. Synthesis of 2-, 3- and 4-trifluoromethyl diazirinyl lactisole derivatives. (a) $\mathrm{NH}_{2} \mathrm{OH} \mathrm{HCl,}$ pyridine, EtOH, $60{ }^{\circ} \mathrm{C}, 12$ h, (S)-46 quant., (R)-46 quant., (S)-47 quant., (R)-47 85\%, (S)-48 quant., $(R)-48$ 98\%, (b) Tosyl chloride, DMAP, $\mathrm{CH}_{2} \mathrm{Cl}_{2}, \mathrm{rt}, 45 \mathrm{~min}$, (S)-49 quant., (R)-49 98\%, (S)-50 quant., (R)-50 93\%, (S)-51 94\%, (R)-51 quant., (c) $\mathrm{NH}_{3}$ (l), $\mathrm{Et}_{2} \mathrm{O}, \mathrm{rt}, 12$ h, (S)-52 88\%, (R)-52 88\%, (S)-53 92\%, (R)-53 quant., (S)-54 76\%, (R)-54 80\%, (d) $\mathrm{MnO}_{2}, \mathrm{CH}_{2} \mathrm{Cl}_{2}, \mathrm{rt}, 2$ h, (S)-55 91\%, (R)-55 92\%, (S)-56 82\%, (R)-56 82\%, (S)-57 89\%, (R)-57 96\%, (e) $\mathrm{CF}_{3} \mathrm{COOH}, \mathrm{CH}_{2} \mathrm{Cl}_{2}, \mathrm{rt}, 4 \mathrm{~h}$, (S)-58 98\%, (R)-58 92\%, (S)-59 quant., (R)-59 $89 \%,(S)-60$ quant., (R)-60 quant.

Table 1. Inhibitory activities of photophore containing lactisole derivatives. $\mathrm{IC}_{50}: 50 \%$ inhibitory concentration.

\begin{tabular}{|c|c|c|c|c|c|c|}
\hline $\begin{array}{l}\text { Position of } \\
\text { Photophore }\end{array}$ & Benzophenone & $\mathrm{IC}_{50}(\mu \mathrm{M})$ & Azide & $\mathrm{IC}_{50}(\mu \mathrm{M})$ & Diazirine & $\mathrm{IC}_{50}(\mu \mathrm{M})$ \\
\hline \multirow{2}{*}{$4-$} & $(S)-9$ & $970 \pm 11$ & $(S)-\mathbf{2 0}$ & $100 \pm 0.77$ & $(S)-58$ & $12 \pm 0.067$ \\
\hline & $(R)-9$ & $2200 \pm 32$ & $(R)-20$ & $1800 \pm 24$ & $(R)-58$ & $250 \pm 1.8$ \\
\hline \multirow{2}{*}{ 3- } & $(S)-\mathbf{1 0}$ & $1100 \pm 10$ & $(S)-\mathbf{2 1}$ & $100 \pm 0.83$ & $(S)-59$ & $19 \pm 0.14$ \\
\hline & $(R)-10$ & $1100 \pm 11$ & $(R)-21$ & $2400 \pm 23$ & $(R)-59$ & $250 \pm 1.7$ \\
\hline \multirow{2}{*}{$2-$} & $(S)-\mathbf{1 1}$ & $1200 \pm 20$ & $(S)-\mathbf{2 8}$ & $280 \pm 5.2$ & $(S)-60$ & $37 \pm 0.28$ \\
\hline & $(R)-\mathbf{1 1}$ & $1200 \pm 18$ & $(R)-28$ & $1200 \pm 18$ & $(R)-60$ & $300 \pm 1.8$ \\
\hline \multirow{2}{*}{ Control } & rac-lactisole $\mathbf{6 1}$ & $82 \pm 0.44$ & $(S)-61$ & $20 \pm 4.3$ & $(R)-61$ & nd \\
\hline & rac-2,4-DP 62 & $7.9 \pm 0.067$ & $(S)-62$ & $2.6 \pm 0.51$ & $(R)-62$ & $45 \pm 6.1$ \\
\hline
\end{tabular}

nd: not determined.

\section{Discussion}

The 2-phenoxypropanoic acid skeleton has a unique bioactivity and is known as a pesticide and sweetener inhibitor. It seems that the stereochemistry at the 2-position may play an important role in its biological activity. We reported a comparison of the biological activity of optically pure lactisole and 2,4-dichlorophenoxy propanoic acid, which were synthesized in an asymmetric manner. Photoaffinity labeling is one of the most reliable methods for functional analysis between small ligands and biomolecules. It is essential to prepare photophore-substituted ligand derivatives. In this paper, we achieved the asymmetric synthesis of benzophenone, azide and trifluoromethyldiazirine modified derivatives on the aromatic ring of lactisole. The Mitsunobu reaction was utilized to construct a lactisole skeleton in an asymmetric manner. Although benzophenone skeletons were acceptable for the Mitsunobu reaction conditions, azide and trifluoromethyldiazirine moieties are not suitable for the condition because of the nitrogen-nitrogen multiple bonds in their structures. The phenol derivatives of precursors for these photophores were utilized for the asymmetric synthesis of the lactisole skeleton, followed by the construction of photophores on these derivatives. Several instabilities of the intermediates to the reaction condition were found, which were overcome with improvements of the reaction condition or protecting groups. Human sweet receptor assays for the photophore-containing lactisole derivatives revealed that (S)-isomers at the 4-position of lactisole 
derivatives are important and that the trifluoromethyldiazirine-substituted derivatives have identical affinity to optically pure lactisole. These results indicated that photoaffinity labeling with synthetic lactisole derivatives will be useful for the functional analysis of sweet taste receptors.

\section{Materials and Methods}

\subsection{General Procedures}

All reagents used were of analytical grade. Nuclear magnetic resonance (NMR) spectra were measured by an EX 270 spectrometer (JEOL, Tokyo, Japan). Optical rotations were measured at $23^{\circ} \mathrm{C}$ on a JASCO DIP370 polarimeter (JASCO, Tokyo, Japan). HRMS-ESI spectra were obtained with a Waters (Waters, Milford, CT, USA). Chiral lactisoles ((S)- and (R)-61) and 2,4-DPs ((S)- and $(R)-62)$ were synthesized previously [5]. The chirality of ester derivatives was determined by a Chiralcel IG column $(250 \times 4.6 \mathrm{~mm})$ with $n$-hexane and 2-propanol.

\subsection{Synthesis of Benzophenone-Based Lactisole Derivatives}

Methyl (S)-2-(4-benzoylphenoxy)propanoate ((S)-6). To 4-hydroxybenzophenone 1 (182 mg, $0.92 \mathrm{mmol})$ in dry $\mathrm{CH}_{2} \mathrm{Cl}_{2}(6 \mathrm{~mL})$, methyl D-(+)-lactate $4(144 \mathrm{mg}, 1.38 \mathrm{mmol})$ and $\mathrm{PPh}_{3}(290 \mathrm{mg}$, $1.10 \mathrm{mmol})$ was added at $0{ }^{\circ} \mathrm{C}$. After the reaction mixture was stirred for $10 \mathrm{~min}$ at $0{ }^{\circ} \mathrm{C}, \mathrm{DEAD}(240 \mathrm{mg}$, $1.38 \mathrm{mmol}$ ) was slowly added at same temperature. The reaction mixture was stirred overnight at room temperature and partitioned between water and $\mathrm{CH}_{2} \mathrm{Cl}_{2}$. The organic layer was washed with brine, dried over $\mathrm{MgSO}_{4}$, filtered and concentrated. The residue was purified by column chromatography (ethyl acetate/ $n$-hexane, 1:9) to give methyl (S)-2-(4-benzoylphenoxy)propanoate ((S)-6) (230 mg, 88\%). $[\alpha]_{\mathrm{D}}-42\left(c 1, \mathrm{CHCl}_{3}\right) .{ }^{1} \mathrm{H}-\mathrm{NMR}\left(270 \mathrm{MHz}, \mathrm{CDCl}_{3}\right): \delta=7.81(\mathrm{~d}, J=8.6 \mathrm{~Hz}, 2 \mathrm{H}), 7.75(\mathrm{~d}, J=7.4 \mathrm{~Hz}, 2 \mathrm{H})$, $7.56(\mathrm{t}, J=7.4 \mathrm{~Hz}, 1 \mathrm{H}), 7.46(\mathrm{t}, J=7.4 \mathrm{~Hz}, 2 \mathrm{H}), 6.93(\mathrm{~d}, J=8.6 \mathrm{~Hz}, 2 \mathrm{H}), 4.87(\mathrm{q}, J=6.8 \mathrm{~Hz}, 1 \mathrm{H}), 3.78(\mathrm{~s}, 3 \mathrm{H})$, $1.67(\mathrm{~d}, J=6.8 \mathrm{~Hz}, 3 \mathrm{H}) .{ }^{13} \mathrm{C}-\mathrm{NMR}\left(67.5 \mathrm{MHz}, \mathrm{CDCl}_{3}\right): \delta=195.4,171.9,161.0,138.0,132.5,131.9,130.9$, 129.7, 128.1, 114.4, 72.4, 52.4, 18.3. HRMS (ESI): $m / z$ calculated for $\mathrm{C}_{17} \mathrm{H}_{16} \mathrm{O}_{4}+\mathrm{H}^{+}\left[\mathrm{M}+\mathrm{H}^{+}\right]: 285.1127$. Found: 285.1120. Chiral HPLC ( $n$-hexane/2-propanol 90:10): $t_{\mathrm{R}} 25.8 \mathrm{~min}$.

Methyl (R)-2-(4-benzoylphenoxy)propanoate ((R)-6). The similar treatment of 4-hydroxybenzophenone $1(361 \mathrm{mg}, 1.82 \mathrm{mmol})$ and methyl L-(-)-lactate $5(284 \mathrm{mg}, 2.72 \mathrm{mmol})$ as that just described gave (R)-6 (542 mg, quant). $[\alpha]_{\mathrm{D}}+42\left(c 1, \mathrm{CHCl}_{3}\right) .{ }^{1} \mathrm{H}-\mathrm{NMR}\left(270 \mathrm{MHz}, \mathrm{CDCl}_{3}\right): \delta=7.80(\mathrm{~d}, J=8.9 \mathrm{~Hz}, 2 \mathrm{H}), 7.74(\mathrm{~d}$, $J=7.3 \mathrm{~Hz}, 2 \mathrm{H}), 7.55(\mathrm{t}, J=7.3 \mathrm{~Hz}, 1 \mathrm{H}), 7.46(\mathrm{t}, J=7.3 \mathrm{~Hz}, 2 \mathrm{H}), 7.46(\mathrm{t}, J=7.3 \mathrm{~Hz}, 2 \mathrm{H}), 6.92(\mathrm{~d}, J=8.9 \mathrm{~Hz}$, $2 \mathrm{H}), 4.87(\mathrm{q}, J=6.8 \mathrm{~Hz}, 1 \mathrm{H}), 3.77(\mathrm{~s}, 3 \mathrm{H}), 1.66(\mathrm{~d}, J=6.8 \mathrm{~Hz}, 3 \mathrm{H}) .{ }^{13} \mathrm{C}-\mathrm{NMR}\left(67.5 \mathrm{MHz}, \mathrm{CDCl}_{3}\right): \delta=195.2$, 171.9, 160.9, 138.0, 132.4, 131.9, 130.8, 129.6, 128.2, 114.3, 72.3, 52.3, 18.3. HRMS (ESI): $m / z$ calculated for $\mathrm{C}_{17} \mathrm{H}_{16} \mathrm{O}_{4}+\mathrm{H}^{+}\left[\mathrm{M}+\mathrm{H}^{+}\right]$: 285.1127. Found: 285.1132. Chiral HPLC (n-hexane/2-propanol 90:10): $t_{\mathrm{R}} 28.0 \mathrm{~min}$.

Methyl (S)-2-(3-benzoylphenoxy)propanoate ((S)-7). The similar treatment of 3-hydroxybenzophenone $2(200 \mathrm{mg}, 1.01 \mathrm{mmol})$ and methyl D-(+)-lactate $4(157 \mathrm{mg}, 1.51 \mathrm{mmol})$ as that just described gave (S)-7 (288 mg, quant). $[\alpha]_{\mathrm{D}}-28\left(c \mathrm{1}, \mathrm{CHCl}_{3}\right) .{ }^{1} \mathrm{H}-\mathrm{NMR}\left(270 \mathrm{MHz}, \mathrm{CDCl}_{3}\right): \delta=7.79(\mathrm{~d}, J=7.4 \mathrm{~Hz}, 2 \mathrm{H})$, $7.59(\mathrm{t}, J=7.4 \mathrm{~Hz}, 1 \mathrm{H}), 7.47(\mathrm{t}, J=7.4 \mathrm{~Hz}, 2 \mathrm{H}), 7.38(\mathrm{~m}, 2 \mathrm{H}), 7.30(\mathrm{~m}, 1 \mathrm{H}), 7.12(\mathrm{~m}, 1 \mathrm{H}), 4.83(\mathrm{q}, J=6.8 \mathrm{~Hz}$, $1 \mathrm{H}), 3.76(\mathrm{~s}, 3 \mathrm{H}), 1.64(\mathrm{~d}, J=6.8 \mathrm{~Hz}, 3 \mathrm{H}) .{ }^{13} \mathrm{C}-\mathrm{NMR}\left(67.5 \mathrm{MHz}, \mathrm{CDCl}_{3}\right): \delta=196.1,172.2,157.4,138.9$, 137.4, 132.4, 130.0, 129.4, 128.2, 123.5, 119.6, 115.8, 72.5, 52.3, 18.4. HRMS (ESI): $m / z$ calculated for $\mathrm{C}_{17} \mathrm{H}_{16} \mathrm{O}_{4}+\mathrm{H}^{+}\left[\mathrm{M}+\mathrm{H}^{+}\right]$: 285.1127. Found: 285.1127. Chiral HPLC (n-hexane/2-propanol 90:10): $t_{\mathrm{R}} 19.6 \mathrm{~min}$.

Methyl (R)-2-(3-benzoylphenoxy)propanoate ((R)-7). The similar treatment of 3-hydroxybenzophenone $2(360 \mathrm{mg}, 1.82 \mathrm{mmol})$ and methyl L-(-)-lactate $5(284 \mathrm{mg}, 2.72 \mathrm{mmol})$ as that just described gave $(R)-7$ (517 mg, quant). $[\alpha]_{\mathrm{D}}+28\left(c 1, \mathrm{CHCl}_{3}\right) .{ }^{1} \mathrm{H}-\mathrm{NMR}\left(270 \mathrm{MHz}, \mathrm{CDCl}_{3}\right): \delta=7.71(\mathrm{~d}, J=7.4 \mathrm{~Hz}, 2 \mathrm{H}), 7.51(\mathrm{t}$, $J=7.4 \mathrm{~Hz}, 1 \mathrm{H}), 7.39(\mathrm{t}, J=7.4 \mathrm{~Hz}, 2 \mathrm{H}), 7.31(\mathrm{~m}, 2 \mathrm{H}), 7.22(\mathrm{~m}, 1 \mathrm{H}), 7.04(\mathrm{~m}, 1 \mathrm{H}), 4.75(\mathrm{q}, J=6.8 \mathrm{~Hz}, 1 \mathrm{H})$, $3.68(\mathrm{~s}, 3 \mathrm{H}), 1.56(\mathrm{~d}, J=6.8 \mathrm{~Hz}, 3 \mathrm{H}) .{ }^{13} \mathrm{C}-\mathrm{NMR}\left(67.5 \mathrm{MHz}, \mathrm{CDCl}_{3}\right): \delta=196.1,172.2$ 157.4, 138.9, 137.4, 132.4, 129.7, 128.2, 123.5, 119.6, 115.9, 72.6, 52.3, 18.5. HRMS (ESI): $m / z$ calculated for $\mathrm{C}_{17} \mathrm{H}_{16} \mathrm{O}_{4}+\mathrm{H}^{+}$ $\left[\mathrm{M}+\mathrm{H}^{+}\right]$: 285.1127. Found: 285.1122. Chiral HPLC (n-hexane/2-propanol 90:10): $t_{\mathrm{R}} 18.9 \mathrm{~min}$. 
Methyl (S)-2-(2-benzoylphenoxy)propanoate ((S)-8). The similar treatment of 2-hydroxybenzophenone $3(210 \mathrm{mg}, 1.06 \mathrm{mmol})$ and methyl D-(+)-lactate $4(165 \mathrm{mg}, 1.59 \mathrm{mmol})$ as that just described gave (S)-8 (263 mg, 88\%). [ $\alpha]_{\mathrm{D}}+11\left(\mathrm{c} 1, \mathrm{CHCl}_{3}\right) .{ }^{1} \mathrm{H}-\mathrm{NMR}\left(270 \mathrm{MHz}, \mathrm{CDCl}_{3}\right): \delta=7.84(2 \mathrm{H}, \mathrm{d}, J=8.2 \mathrm{~Hz})$, $7.54(1 \mathrm{H}, \mathrm{t}, J=7.4 \mathrm{~Hz}), 7.43(1 \mathrm{H}, \mathrm{d}, J=7.6 \mathrm{~Hz}), 7.42(3 \mathrm{H}, \mathrm{t}, J=7.4 \mathrm{~Hz}), 7.08(1 \mathrm{H}, \mathrm{t}, J=7.4 \mathrm{~Hz})$, $6.80(1 \mathrm{H}, \mathrm{d}, J=8.2 \mathrm{~Hz}), 4.66(1 \mathrm{H}, \mathrm{q}, J=6.8 \mathrm{~Hz}), 3.68(3 \mathrm{H}, \mathrm{s}), 1.24(3 \mathrm{H}, \mathrm{d}, J=6.8 \mathrm{~Hz}) .{ }^{13} \mathrm{C}-\mathrm{NMR}$ $\left(67.5 \mathrm{MHz}, \mathrm{CDCl}_{3}\right): \delta=196.3,172.0,155.3,138.0,132.7,131.9,130.0,129.7,129.7,128.0,121.6,113.0$, 73.2, 52.2, 18.0. HRMS (ESI): $m / z$ calculated for $\mathrm{C}_{17} \mathrm{H}_{16} \mathrm{O}_{4}+\mathrm{H}^{+}\left[\mathrm{M}+\mathrm{H}^{+}\right]$: 285.1127. Found: 285.1119 . Chiral HPLC ( $n$-hexane:2-propanol $=90: 10) t_{\mathrm{R}} 15.4 \mathrm{~min}$.

Methyl (R)-2-(2-benzoylphenoxy)propanoate ((R)-8). The similar treatment of 2-hydroxybenzophenone 3 (372 mg, $1.87 \mathrm{mmol}$ ) and methyl L-(-)-lactate $5(293 \mathrm{mg}, 2.81 \mathrm{mmol})$ as that just described gave $(R)-8(435 \mathrm{mg}, 82 \%) . \quad[\alpha]_{\mathrm{D}}-11$ (c 1, $\left.\mathrm{CHCl}_{3}\right) .{ }^{1} \mathrm{H}-\mathrm{NMR}\left(270 \mathrm{MHz}, \mathrm{CDCl}_{3}\right)$ : $\delta=7.83(\mathrm{~d}, J=8.2 \mathrm{~Hz}, 2 \mathrm{H}), 7.54(\mathrm{t}, J=7.4 \mathrm{~Hz}, 1 \mathrm{H}), 7.43(\mathrm{~d}, J=7.6 \mathrm{~Hz}, 1 \mathrm{H}), 7.42(\mathrm{t}, J=7.9 \mathrm{~Hz}, 3 \mathrm{H}), 7.08$ $(\mathrm{t}, J=7.4 \mathrm{~Hz}, 1 \mathrm{H}), 6.80(\mathrm{~d}, J=8.2 \mathrm{~Hz}, 1 \mathrm{H}), 4.66(\mathrm{q}, J=6.8 \mathrm{~Hz}, 1 \mathrm{H}), 3.68(\mathrm{~s}, 3 \mathrm{H}), 1.24(\mathrm{~d}, J=6.8 \mathrm{~Hz}, 3 \mathrm{H})$. ${ }^{13} \mathrm{C}-\mathrm{NMR}\left(67.5 \mathrm{MHz}, \mathrm{CDCl}_{3}\right): \delta=196.3,172.0,155.3,138.0,132.7,131.8,130.0,129.7,129.7,128.0,121.6$, 113.0, 73.2, 52.1, 17.9. HRMS (ESI): $m / z$ calculated for $\mathrm{C}_{17} \mathrm{H}_{16} \mathrm{O}_{4}+\mathrm{H}^{+}\left[\mathrm{M}+\mathrm{H}^{+}\right]$: 285.1127. Found: 285.1132. Chiral HPLC ( $n$-hexane:2-propanol $=90: 10) t_{\mathrm{R}} 17.7 \mathrm{~min}$.

(S)-2-(4-benzoylphenoxy)propanoic acid ((S)-9). Methyl (S)-2-(4-benzoylphenoxy)-propanoate (S)-6 (212 mg, $0.75 \mathrm{mmol})$ was dissolved in $\mathrm{MeOH}(14.4 \mathrm{~mL})$ and $\mathrm{H}_{2} \mathrm{O}(1.6 \mathrm{~mL})$, and then $\mathrm{K}_{2} \mathrm{CO}_{3}$ $(309 \mathrm{mg}, 2.24 \mathrm{mmol}$ ) was added. After the reaction mixture was stirred at reflux for $2 \mathrm{~h}$, cooled to room temperature and then partitioned between ethyl acetate and water. The water layer was acidified by $1 \mathrm{M}$ $\mathrm{HCl}$ and extracted by ethyl acetate. The organic layer was washed by $\mathrm{H}_{2} \mathrm{O}$ and brine, and dried over $\mathrm{MgSO}_{4}$, filtrated and concentrated to give (S)-2-(2-benzoylphenoxy)propanoic acid (S)-9 (206 mg, quant). $[\alpha]_{\mathrm{D}}-22\left(c 1, \mathrm{CHCl}_{3}\right) .{ }^{1} \mathrm{H}-\mathrm{NMR}\left(270 \mathrm{MHz} \mathrm{CDCl}_{3}\right): \delta=7.82(\mathrm{~d}, J=8.9 \mathrm{~Hz}, 2 \mathrm{H}), 7.75(\mathrm{~d}, J=7.4 \mathrm{~Hz}, 2 \mathrm{H})$, $7.57(\mathrm{t}, J=7.4 \mathrm{~Hz}, 1 \mathrm{H}), 7.47(\mathrm{t}, J=7.4 \mathrm{~Hz}, 2 \mathrm{H}), 6.95(\mathrm{~d}, J=8.9 \mathrm{~Hz}, 2 \mathrm{H}), 4.91(\mathrm{q}, J=6.8 \mathrm{~Hz}, 1 \mathrm{H}), 1.72$ $(\mathrm{d}, J=6.8 \mathrm{~Hz}, 3 \mathrm{H}) .{ }^{13} \mathrm{C}-\mathrm{NMR}\left(67.5 \mathrm{MHz}, \mathrm{CDCl}_{3}\right): \delta=195.9,176.4,160.9,137.8,132.6,132.1,130.8$, 129.8, 128.2, 114.4, 71.9, 18.3. HRMS (ESI): $m / z$ calculated for $\mathrm{C}_{16} \mathrm{H}_{14} \mathrm{O}_{4}+\mathrm{H}^{+}\left[\mathrm{M}+\mathrm{H}^{+}\right]: 271.0970$. Found: 271.0970.

(R)-2-(4-benzoylphenoxy)propanoic acid ((R)-9). The similar treatment of methyl (R)-2-(4-benzoylphenoxy)propanoate $(R)-6(517 \mathrm{mg}, 1.82 \mathrm{mmol})$ as that just described gave $(R)-9$ (511 mg, quant). $[\alpha]_{\mathrm{D}}+22\left(c 1, \mathrm{CHCl}_{3}\right) .{ }^{1} \mathrm{H}-\mathrm{NMR}\left(270 \mathrm{MHz}, \mathrm{CDCl}_{3}\right): \delta=7.82(\mathrm{~d}, J=8.9 \mathrm{~Hz}, 2 \mathrm{H})$, $7.75(\mathrm{~d}, J=7.4 \mathrm{~Hz}, 2 \mathrm{H}), 7.57(\mathrm{t}, J=7.4 \mathrm{~Hz}, 1 \mathrm{H}), 7.47(\mathrm{t}, J=7.4 \mathrm{~Hz}, 2 \mathrm{H}), 6.96(\mathrm{~d}, J=8.9 \mathrm{~Hz}, 2 \mathrm{H})$, $4.91(\mathrm{q}, J=6.8 \mathrm{~Hz}, 1 \mathrm{H}), 1.72(\mathrm{~d}, J=6.8 \mathrm{~Hz}, 3 \mathrm{H}) .{ }^{13} \mathrm{C}-\mathrm{NMR}\left(67.5 \mathrm{MHz}, \mathrm{CDCl}_{3}\right): \delta=196.0,175.8,161.0$, $137.8,132.6,132.1,130.8,129.8,128.2,114.5,72.0,18.3$. HRMS (ESI): $m / z$ calculated for $\mathrm{C}_{16} \mathrm{H}_{14} \mathrm{O}_{4}+\mathrm{H}^{+}$ $\left[\mathrm{M}+\mathrm{H}^{+}\right]:$271.0970. Found: 271.0950 .

(S)-2-(3-benzoylphenoxy)propanoic acid ((S)-10). The similar treatment of methyl (S)-2-(3-benzoylphenoxy)propanoate $(S)-7(159 \mathrm{mg}, 0.56 \mathrm{mmol})$ as that just described gave $(S)-10$ $(144 \mathrm{mg}, 95 \%) .[\alpha]_{\mathrm{D}}-9\left(\mathrm{c} 1, \mathrm{CHCl}_{3}\right) .{ }^{1} \mathrm{H}-\mathrm{NMR}\left(270 \mathrm{MHz}, \mathrm{CDCl}_{3}\right): \delta=7.78(\mathrm{~d}, J=7.3 \mathrm{~Hz}, 2 \mathrm{H})$, $7.57(\mathrm{t}, J=7.3 \mathrm{~Hz}, 1 \mathrm{H}), 7.46(\mathrm{t}, J=7.3 \mathrm{~Hz}, 2 \mathrm{H}), 7.40(\mathrm{~m}, 2 \mathrm{H}), 7.3(\mathrm{~m}, 1 \mathrm{H}), 7.15(\mathrm{~m}, 1 \mathrm{H}), 4.88(\mathrm{q}, J=6.8 \mathrm{~Hz}$, $1 \mathrm{H}), 1.68(\mathrm{~d}, J=6.8 \mathrm{~Hz}, 3 \mathrm{H}) .{ }^{13} \mathrm{C}-\mathrm{NMR}\left(67.5 \mathrm{MHz} \mathrm{CDCl}_{3}\right): \delta=196.3,177.0,157.2,139.0,137.3,132.6,130.0$, 129.6, 128.3, 123.9, 119.7, 116.0, 72.1, 18.3. HRMS (ESI): $m / z$ calculated for $\mathrm{C}_{16} \mathrm{H}_{14} \mathrm{O}_{4}+\mathrm{H}^{+}\left[\mathrm{M}+\mathrm{H}^{+}\right]$: 271.0970. Found: 271.0952. Chiral HPLC (n-hexane:2-propanol $=90: 10) t_{\mathrm{R}} 25.8 \mathrm{~min}$.

(R)-2-(3-benzoylphenoxy)propanoic acid ((R)-10). The similar treatment of methyl (R)-2-(3-benzoylphenoxy)propanoate $(R)-7(413 \mathrm{mg}, 1.45 \mathrm{mmol})$ as that just described gave $(R)-10$ (465 mg, quant). $[\alpha]_{\mathrm{D}}+9\left(\mathrm{c} 1, \mathrm{CHCl}_{3}\right) .{ }^{1} \mathrm{H}-\mathrm{NMR}\left(270 \mathrm{MHz}, \mathrm{CDCl}_{3}\right): \delta=7.78(\mathrm{~d}, J=7.4 \mathrm{~Hz}$, $2 \mathrm{H}), 7.57(\mathrm{t}, J=7.4 \mathrm{~Hz}, 1 \mathrm{H}), 7.45(\mathrm{t}, J=7.4 \mathrm{~Hz}, 2 \mathrm{H}), 7.39(\mathrm{~m}, 2 \mathrm{H}), 7.33(\mathrm{~m}, 1 \mathrm{H}), 7.14(\mathrm{~m}, 1 \mathrm{H})$, $4.88(\mathrm{q}, J=6.8 \mathrm{~Hz}, 1 \mathrm{H}), 1.68(\mathrm{~d}, J=6.8 \mathrm{~Hz}, 3 \mathrm{H}) .{ }^{13} \mathrm{C}-\mathrm{NMR}\left(67.5 \mathrm{MHz}, \mathrm{CDCl}_{3}\right): \delta=196.5,176.5$, $157.2,138.8,137.2,132.6,130.0,129.5,128.2,123.8,119.7,115.9,72.1,18.3$. HRMS (ESI): $m / z$ calculated for $\mathrm{C}_{16} \mathrm{H}_{14} \mathrm{O}_{4}+\mathrm{H}^{+}\left[\mathrm{M}+\mathrm{H}^{+}\right]$: 271.0970. Found: 271.0960. Chiral HPLC ( $n$-hexane:2-propanol = 90:10) $t_{\mathrm{R}} 28.0 \mathrm{~min}$. 
(S)-2-(2-benzoylphenoxy)propanoic acid ((S)-11). The similar treatment of methyl (S)-2-(3-benzoylphenoxy)propanoate $(S)-8(229 \mathrm{mg}, 0.80 \mathrm{mmol})$ as that just described gave $(S)-\mathbf{1 1}$ $(187 \mathrm{mg}, 87 \%) .[\alpha]_{\mathrm{D}}-40\left(\mathrm{c} 1, \mathrm{CHCl}_{3}\right) .{ }^{1} \mathrm{H}-\mathrm{NMR}\left(270 \mathrm{MHz}, \mathrm{CDCl}_{3}\right): \delta=7.87(\mathrm{~d}, J=7.3 \mathrm{~Hz}, 2 \mathrm{H})$, $7.64(\mathrm{t}, J=7.3 \mathrm{~Hz}, 1 \mathrm{H}), 7.50(\mathrm{~m}, 4 \mathrm{H}), 7.12(\mathrm{~m}, 2 \mathrm{H}), 5.00(\mathrm{q}, J=6.8 \mathrm{~Hz}, 1 \mathrm{H}), 1.65(\mathrm{~d}, J=6.8 \mathrm{~Hz}, 3 \mathrm{H})$. ${ }^{13} \mathrm{C}-\mathrm{NMR}\left(67.5 \mathrm{MHz}, \mathrm{CDCl}_{3}\right): \delta=197.1,173.1,156.6,137.0,133.8,132.1,130.7,128.5,127.3,121.9,115.1$, 75.2, 18.6. HRMS (ESI): $m / z$ calculated for $\mathrm{C}_{16} \mathrm{H}_{14} \mathrm{O}_{4}+\mathrm{H}^{+}\left[\mathrm{M}+\mathrm{H}^{+}\right]:$271.0970. Found: 271.0950.

(R)-2-(2-benzoylphenoxy)propanoic acid ((R)-11). The similar treatment of methyl (S)-2-(2-benzoylphenoxy)propanoate $(R)-8(392 \mathrm{mg}, 1.38 \mathrm{mmol})$ as that just described gave $(R)-\mathbf{1 1}$ $(326 \mathrm{mg}, 88 \%) .[\alpha]_{\mathrm{D}}+40\left(\mathrm{c} 1, \mathrm{CHCl}_{3}\right) .{ }^{1} \mathrm{H}-\mathrm{NMR}\left(270 \mathrm{MHz}, \mathrm{CDCl}_{3}\right): \delta=7.87(\mathrm{~d}, J=6.9 \mathrm{~Hz}, 2 \mathrm{H})$, $7.64(\mathrm{t}, J=7.4 \mathrm{~Hz}, 1 \mathrm{H}), 7.50(\mathrm{~m}, 4 \mathrm{H}), 7.12(\mathrm{~m}, 2 \mathrm{H}), 5.01(\mathrm{q}, J=6.9 \mathrm{~Hz}, 1 \mathrm{H}), 1.66(\mathrm{~d}, J=6.9 \mathrm{~Hz}, 3 \mathrm{H})$. ${ }^{13} \mathrm{C}-\mathrm{NMR}\left(67.5 \mathrm{MHz}, \mathrm{CDCl}_{3}\right): \delta=197.1,173.0,156.6,137.0,133.8,132.1,130.7,128.5,127.3,121.9,115.0$, 75.2, 18.6. HRMS (ESI): $m / z$ calculated for $\mathrm{C}_{16} \mathrm{H}_{14} \mathrm{O}_{4}+\mathrm{H}^{+}\left[\mathrm{M}+\mathrm{H}^{+}\right]$: 271.0970. Found: 271.0950.

\subsection{Synthesis of 3- or 4-Azidephenoxy-Based Lactisole Derivatives}

Methyl (S)-2-(4-nitrophenoxy)propanoate ((S)-14). To 4-nitrophenol 12 (437 $\mathrm{mg}, 3.14 \mathrm{mmol})$ in dry $\mathrm{CH}_{2} \mathrm{Cl}_{2}(6 \mathrm{~mL}), \mathrm{D}-(+)$-lactate $4(491 \mathrm{mg}, 4.71 \mathrm{mmol})$ and $\mathrm{PPh}_{3}(989 \mathrm{mg}, 3.77 \mathrm{mmol})$ was added at $0{ }^{\circ} \mathrm{C}$ After the reaction mixture was stirred for $10 \mathrm{~min}$ at $0{ }^{\circ} \mathrm{C}$, DEAD $(820 \mathrm{mg}, 4.71 \mathrm{mmol})$ was slowly added at same temperature. The reaction mixture was stirred overnight at room temperature and partitioned between water and $\mathrm{CH}_{2} \mathrm{Cl}_{2}$. The organic layer was washed with brine, dried over $\mathrm{MgSO}_{4}$, filtered and concentrated. The residue was purified by column chromatography (ethyl acetate $/ n$-hexane, $1: 9)$ to give $\left.(S)-14(700 \mathrm{mg}, 99 \%) .[\alpha]_{\mathrm{D}}-64(c), \mathrm{CHCl}_{3}\right) .{ }^{1} \mathrm{H}-\mathrm{NMR}(270 \mathrm{MHz}$, $\left.\mathrm{CDCl}_{3}\right): \delta=8.20(\mathrm{~d}, J=8.9 \mathrm{~Hz}, 2 \mathrm{H}), 6.93(\mathrm{~d}, J=8.9 \mathrm{~Hz}, 2 \mathrm{H}), 4.88(\mathrm{q}, J=6.8 \mathrm{~Hz}, 1 \mathrm{H}), 3.78(\mathrm{~s}, 3 \mathrm{H})$, $1.68(\mathrm{~d}, J=6.8 \mathrm{~Hz}, 3 \mathrm{H}) .{ }^{13} \mathrm{C}-\mathrm{NMR}\left(67.5 \mathrm{MHz}, \mathrm{CDCl}_{3}\right): \delta=171.4,162.4,142.0,125.9,114.9,72.9,52.6$, 18.4. HRMS (ESI): $m / z$ calculated for $\mathrm{C}_{10} \mathrm{H}_{11} \mathrm{NO}_{5}+\mathrm{H}^{+}\left[\mathrm{M}+\mathrm{H}^{+}\right]$: 226.0715. Found: 226.0720 .

Methyl (R)-2-(4-nitrophenoxy)propanoate ((R)-14). The similar treatment of 4-nitrophenol 12 $(128 \mathrm{mg}, 0.92 \mathrm{mmol})$ and methyl L-(-)-lactate $5(144 \mathrm{mg}, 1.38 \mathrm{mmol})$ as that just described gave $(R)-14$ (213 mg, quant). $[\alpha]_{\mathrm{D}}+64\left(\right.$ c 1, $\left.\mathrm{CHCl}_{3}\right)$, (ref. $[\alpha]_{\mathrm{D}}+64.4\left(\right.$ c $\left.\left.0.10, \mathrm{CHCl}_{3}\right)[29]\right) .{ }^{1} \mathrm{H}-\mathrm{NMR}(270 \mathrm{MHz}$, $\left.\mathrm{CDCl}_{3}\right): \delta=8.18(\mathrm{~d}, J=8.6 \mathrm{~Hz}, 2 \mathrm{H}), 6.93(\mathrm{~d}, J=9.2 \mathrm{~Hz}, 2 \mathrm{H}), 4.90(\mathrm{q}, J=6.8 \mathrm{~Hz}, 1 \mathrm{H}), 3.78(\mathrm{~s}, 3 \mathrm{H}), 1.68$ $\mathrm{d}, J=6.8 \mathrm{~Hz}, 3 \mathrm{H}) .{ }^{13} \mathrm{C}-\mathrm{NMR}\left(67.5 \mathrm{MHz}, \mathrm{CDCl}_{3}\right): \delta=171.2,162.3,141.9,125.8,114.8,72.7,52.5,18.2$. HRMS (ESI): $m / z$ calculated for $\mathrm{C}_{10} \mathrm{H}_{11} \mathrm{NO}_{5}+\mathrm{H}^{+}\left[\mathrm{M}+\mathrm{H}^{+}\right]$: 226.0715. Found: 226.0720.

Methyl (S)-2-(3-nitrophenoxy)propanoate ((S)-15). The similar treatment of 3-nitrophenol 13 (301 mg, $2.16 \mathrm{mmol})$ and methyl D-(+)-lactate $4(338 \mathrm{mg}, 3.24 \mathrm{mmol})$ as that just described gave $(S)-15$ (490 mg, quant). [ $\alpha]_{\mathrm{D}}-59\left(\mathrm{c} 1, \mathrm{CHCl}_{3}\right) .{ }^{1} \mathrm{H}-\mathrm{NMR}\left(270 \mathrm{MHz}, \mathrm{CDCl}_{3}\right): \delta=7.85(\mathrm{dd}, J=8.1,2.3 \mathrm{~Hz}, 1 \mathrm{H})$, $7.69(\mathrm{t}, J=2.3 \mathrm{~Hz}, 1 \mathrm{H}), 7.44(\mathrm{t}, J=8.1 \mathrm{~Hz}, 1 \mathrm{H}), 7.22(\mathrm{dd}, J=8.1,2.3 \mathrm{~Hz}, 1 \mathrm{H}), 4.87(\mathrm{q}, J=6.8 \mathrm{~Hz}, 1 \mathrm{H})$, $3.79(\mathrm{~s}, 3 \mathrm{H}), 1.67(\mathrm{~d}, J=6.8 \mathrm{~Hz}, 3 \mathrm{H}) .{ }^{13} \mathrm{C}-\mathrm{NMR}\left(67.5 \mathrm{MHz} \mathrm{CDCl}_{3}\right): \delta=171.5,158.0,149.1,130.1,121.8$, 116.5, 109.7, 72.9, 52.5, 18.3. HRMS (ESI): $m / z$ calculated for $\mathrm{C}_{10} \mathrm{H}_{11} \mathrm{NO}_{5}+\mathrm{H}^{+}\left[\mathrm{M}+\mathrm{H}^{+}\right]: 226.0715$. Found: 226.0730 .

Methyl (R)-2-(3-nitrophenoxy)propanoate ((R)-15). The similar treatment of 3-nitrophenol 13 (422 $\mathrm{mg}, 3.04 \mathrm{mmol})$ and methyl L-(-)-lactate $5(474 \mathrm{mg}, 4.55 \mathrm{mmol})$ as that just described gave $(R)-15$ (711 mg, quant). $[\alpha]_{\mathrm{D}}+59\left(\mathrm{c} 1, \mathrm{CHCl}_{3}\right) .{ }^{1} \mathrm{H}-\mathrm{NMR}\left(270 \mathrm{MHz}, \mathrm{CDCl}_{3}\right): \delta=7.85(\mathrm{dd}, J=8.2,2.3 \mathrm{~Hz}, 1 \mathrm{H})$, $7.69(\mathrm{t}, J=2.3 \mathrm{~Hz}, 1 \mathrm{H}), 7.44(\mathrm{t}, J=8.2 \mathrm{~Hz}, 1 \mathrm{H}), 7.22(\mathrm{dd}, J=8.2,2.3 \mathrm{~Hz}, 1 \mathrm{H}), 4.87(\mathrm{q}, J=6.8 \mathrm{~Hz}, 1 \mathrm{H})$, $3.79(\mathrm{~s}, 3 \mathrm{H}), 1.67(\mathrm{~d}, J=6.8 \mathrm{~Hz}, 3 \mathrm{H}) .{ }^{13} \mathrm{C}-\mathrm{NMR}\left(67.5 \mathrm{MHz}, \mathrm{CDCl}_{3}\right): \delta=171.5,158.0,149.1,130.1,121.8$, 116.5, 109.7, 72.9, 52.5, 18.3. HRMS (ESI): $m / z$ calculated for $\mathrm{C}_{10} \mathrm{H}_{11} \mathrm{NO}_{5}+\mathrm{H}^{+}\left[\mathrm{M}+\mathrm{H}^{+}\right]: 226.0715$. Found: 226.0710.

Methyl (S)-2-(4-aminophenoxy)propanoate ((S)-16). Methyl (S)-2-(4-nitrophenoxy)-propanoate (S)-15 (700 mg, $3.11 \mathrm{mmol})$ and 5\% Pd/C (35.0 mg) were suspended in MeOH (10 mL). The reaction mixture was stirred vigorously at room temperature for $2 \mathrm{~h}$ under $\mathrm{H}_{2}$ atmosphere. The residue was filtrated using Celite and concentrated to give $(S)-16\left(607 \mathrm{mg}\right.$, quant). $[\alpha]_{\mathrm{D}}-50\left(c 1, \mathrm{CHCl}_{3}\right) .{ }^{1} \mathrm{H}-\mathrm{NMR}$ $\left(270 \mathrm{MHz} \mathrm{CDCl}_{3}\right): \delta=6.73(\mathrm{~d}, J=8.9 \mathrm{~Hz}, 2 \mathrm{H}), 6.59(\mathrm{~d}, J=8.9 \mathrm{~Hz}, 2 \mathrm{H}), 4.63(\mathrm{q}, J=6.8 \mathrm{~Hz}, 1 \mathrm{H})$, $3.73(\mathrm{~s}, 3 \mathrm{H}), 3.46(\mathrm{~s}, 2 \mathrm{H}), 1.57(\mathrm{~d}, J=6.8 \mathrm{~Hz}, 3 \mathrm{H}) .{ }^{13} \mathrm{C}-\mathrm{NMR}\left(67.5 \mathrm{MHz}, \mathrm{CDCl}_{3}\right): \delta=173.0,150.4,141.0$, 
116.7, 116.1, 73.7, 52.1, 18.5. HRMS (ESI): $m / z$ calculated for $\mathrm{C}_{10} \mathrm{H}_{13} \mathrm{NO}_{3}+\mathrm{H}^{+}\left[\mathrm{M}+\mathrm{H}^{+}\right]$: 196.0974 . Found: 196.0960 .

Methyl (R)-2-(4-aminophenoxy)propanoate ((R)-16). The similar treatment of methyl $(R)-2-(4-$ nitrophenoxy)propanoate $(R)-\mathbf{1 5}(575 \mathrm{mg}, 2.56 \mathrm{mmol})$ as that just described gave $(R)-\mathbf{1 6}(500 \mathrm{mg}$, quant). $[\alpha]_{\mathrm{D}}+50\left(\mathrm{c} 1, \mathrm{CHCl}_{3}\right) .{ }^{1} \mathrm{H}-\mathrm{NMR}\left(270 \mathrm{MHz}, \mathrm{CDCl}_{3}\right): \delta=6.73(\mathrm{~d}, J=8.9 \mathrm{~Hz}, 2 \mathrm{H}), 6.66(\mathrm{~d}, J=8.9 \mathrm{~Hz}, 2 \mathrm{H})$, $4.64(\mathrm{q}, J=6.8 \mathrm{~Hz}, 1 \mathrm{H}), 4.24(\mathrm{~s}, 2 \mathrm{H}), 3.73(\mathrm{~s}, 3 \mathrm{H}), 1.57(3 \mathrm{H}, \mathrm{d}, J=6.8 \mathrm{~Hz}, 3 \mathrm{H}) .{ }^{13} \mathrm{C}-\mathrm{NMR}(67.5 \mathrm{MHz}$, $\mathrm{CDCl}_{3}$ ): $\delta=172.9,151.0,139.5,116.9,116.7,73.6,52.1,18.5$. HRMS (ESI): $m / z$ calculated for $\mathrm{C}_{10} \mathrm{H}_{13} \mathrm{NO}_{3}$ $+\mathrm{H}^{+}\left[\mathrm{M}+\mathrm{H}^{+}\right]$: 196.0974. Found: 196.0950.

Methyl (S)-2-(3-aminophenoxy)propanoate ((S)-17). The similar treatment of methyl (S)-2-(3nitrophenoxy)propanoate $(S)-\mathbf{1 5}(490 \mathrm{mg}, 2.17 \mathrm{mmol})$ as that just described gave $(S)-\mathbf{1 7}(367 \mathrm{mg}, 87 \%)$. $[\alpha]_{\mathrm{D}}-23\left(\mathrm{c} 1, \mathrm{CHCl}_{3}\right) .{ }^{1} \mathrm{H}-\mathrm{NMR}\left(270 \mathrm{MHz}, \mathrm{CDCl}_{3}\right): \delta=7.01(\mathrm{t}, J=7.9 \mathrm{~Hz}, 1 \mathrm{H}), 6.28(\mathrm{dd}, J=7.9,1.0 \mathrm{~Hz}$, $1 \mathrm{H}), 6.23(\mathrm{~m}, 2 \mathrm{H}), 4.72(\mathrm{q}, J=6.8 \mathrm{~Hz}, 1 \mathrm{H}), 3.73(\mathrm{~s}, 3 \mathrm{H}), 3.68(\mathrm{~s}, 3 \mathrm{H}), 1.58(\mathrm{~d}, J=6.8 \mathrm{~Hz}, 3 \mathrm{H}) .{ }^{13} \mathrm{C}-\mathrm{NMR}$ $\left(67.5 \mathrm{MHz}, \mathrm{CDCl}_{3}\right): \delta=172.7,158.5,147.9,130.0,108.7,104.4,102.1,72.2,52.1,18.5$. HRMS (ESI): $\mathrm{m} / \mathrm{z}$ calculated for $\mathrm{C}_{10} \mathrm{H}_{13} \mathrm{NO}_{3}+\mathrm{H}^{+}\left[\mathrm{M}+\mathrm{H}^{+}\right]$: 196.0974. Found: 196.0980.

Methyl (R)-2-(3-aminophenoxy)propanoate ((R)-17). The similar treatment of methyl $(R)-2-(3-$ nitrophenoxy)propanoate $(R)-\mathbf{1 5}(628 \mathrm{mg}, 2.78 \mathrm{mmol})$ as that just described gave $(R)-\mathbf{1 7}$ (558 $\mathrm{mg}$, quant). $[\alpha]_{\mathrm{D}}+23\left(c 1, \mathrm{CHCl}_{3}\right) .{ }^{1} \mathrm{H}-\mathrm{NMR}\left(270 \mathrm{MHz}, \mathrm{CDCl}_{3}\right): \delta=7.05(\mathrm{t}, J=7.9 \mathrm{~Hz}, 1 \mathrm{H}), 6.37(\mathrm{~d}, J=7.9 \mathrm{~Hz}, 1 \mathrm{H})$, $6.25(\mathrm{~m}, 2 \mathrm{H}), 4.73(\mathrm{q}, J=6.8 \mathrm{~Hz}, 1 \mathrm{H}), 4.19(\mathrm{~s}, 2 \mathrm{H}), 3.75(\mathrm{~s}, 3 \mathrm{H}), 1.59(\mathrm{~d}, J=6.8 \mathrm{~Hz}, 3 \mathrm{H}) .{ }^{13} \mathrm{C}-\mathrm{NMR}$ (67.5 MHz, $\left.\mathrm{CDCl}_{3}\right): \delta=172.8,158.6,146.7,130.2,109.3,105.3,102.9,72.4,52.3,18.5$. HRMS (ESI): $\mathrm{m} / \mathrm{z}$ calculated for $\mathrm{C}_{10} \mathrm{H}_{13} \mathrm{NO}_{3}+\mathrm{H}^{+}\left[\mathrm{M}+\mathrm{H}^{+}\right]$: 196.0974. Found: 196.0960 .

Methyl (S)-2-(4-azidephenoxy)propanoate ((S)-18). Methyl (S)-2-(4-aminophenoxy)-propanoate (S)-14 $(607 \mathrm{mg}, 3.11 \mathrm{mmol})$ was dissolved in water $(6.78 \mathrm{~mL})$ and $37 \% \mathrm{HCl}(0.76 \mathrm{~mL})$ at $0{ }^{\circ} \mathrm{C}$. $\mathrm{NaNO}_{2}$ $(237 \mathrm{mg}, 3.44 \mathrm{mmol})$ in water $(2.26 \mathrm{~mL})$ was added slowly at $0{ }^{\circ} \mathrm{C}$, followed by $\mathrm{NaN}_{3}(381 \mathrm{mg}$, $5.87 \mathrm{mmol})$ in water $(2.26 \mathrm{~mL})$. After $30 \mathrm{~min}$ at $0{ }^{\circ} \mathrm{C}$ and $30 \mathrm{~min}$ at room temperature, the reaction mixture was extracted with ethyl acetate. The organic layer was washed by brine, dried over $\mathrm{MgSO}_{4}$, filtrated and concentrated to give (S)-18 (702 mg, quant). $[\alpha]_{\mathrm{D}}-45\left(c 1, \mathrm{CHCl}_{3}\right) .{ }^{1} \mathrm{H}-\mathrm{NMR}(270 \mathrm{MHz}$, $\left.\mathrm{CDCl}_{3}\right): \delta=6.94(\mathrm{~d}, J=9.2 \mathrm{~Hz}, 2 \mathrm{H}), 6.86(\mathrm{~d}, J=9.2 \mathrm{~Hz}, 2 \mathrm{H}), 4.72(\mathrm{q}, J=6.8 \mathrm{~Hz}, 1 \mathrm{H}), 3.76(\mathrm{~s}, 3 \mathrm{H})$, $1.61(\mathrm{~d}, J=6.8 \mathrm{~Hz}, 3 \mathrm{H}) .{ }^{13} \mathrm{C}-\mathrm{NMR}\left(67.5 \mathrm{MHz}, \mathrm{CDCl}_{3}\right): \delta=172.4,154.9,133.4,120.1,116.5,73.0,52.3$, 18.5. HRMS (ESI): $m / z$ calculated for $\mathrm{C}_{10} \mathrm{H}_{11} \mathrm{~N}_{3} \mathrm{O}_{3}+\mathrm{H}^{+}\left[\mathrm{M}+\mathrm{H}^{+}\right]: 222.0879$. Found: 222.0860. Chiral HPLC (n-hexane/2-propanol 99:1): $t_{\mathrm{R}} 20.5 \mathrm{~min}$.

Methyl (R)-2-(4-azidephenoxy)propanoate ( $(R)-18)$. The similar treatment of methyl $(R)-2-(4-$ aminophenoxy)propanoate $(R)-\mathbf{1 4}(500 \mathrm{mg}, 2.56 \mathrm{mmol})$ as that just described gave $(R)-\mathbf{1 8}(529 \mathrm{mg}, 93 \%)$. $[\alpha]_{\mathrm{D}}+45\left(c 1, \mathrm{CHCl}_{3}\right) .{ }^{1} \mathrm{H}-\mathrm{NMR}\left(270 \mathrm{MHz}, \mathrm{CDCl}_{3}\right): \delta=6.94(\mathrm{~d}, J=9.2 \mathrm{~Hz}, 2 \mathrm{H}), 6.86(\mathrm{~d}, J=9.2 \mathrm{~Hz}, 2 \mathrm{H})$, $4.73(\mathrm{q}, J=6.8 \mathrm{~Hz}, 1 \mathrm{H}), 3.76(\mathrm{~s}, 3 \mathrm{H}), 1.61(\mathrm{~d}, J=6.8 \mathrm{~Hz}, 3 \mathrm{H}) .{ }^{13} \mathrm{C}-\mathrm{NMR}\left(67.5 \mathrm{MHz}, \mathrm{CDCl}_{3}\right): \delta=172.4$, 154.9, 133.3, 120.1, 116.5, 73.0, 52.3, 18.5. HRMS (ESI): $m / z$ calculated for $\mathrm{C}_{10} \mathrm{H}_{11} \mathrm{~N}_{3} \mathrm{O}_{3}+\mathrm{H}^{+}\left[\mathrm{M}+\mathrm{H}^{+}\right]$: 222.0879. Found: 222.0870. Chiral HPLC (n-hexane/2-propanol 99:1): $t_{\mathrm{R}} 19.4 \mathrm{~min}$.

Methyl (S)-2-(3-azidophenoxy)propanoate ((S)-19). The similar treatment of methyl (S)-2-(3aminophenoxy)propanoate $(S)-\mathbf{1 7}(323 \mathrm{mg}, 1.65 \mathrm{mmol})$ as that just described gave $(S)-\mathbf{1 9}(336 \mathrm{mg}, 92 \%)$. $[\alpha]_{\mathrm{D}}-28\left(c 1, \mathrm{CHCl}_{3}\right) .{ }^{1} \mathrm{H}-\mathrm{NMR}\left(270 \mathrm{MHz}, \mathrm{CDCl}_{3}\right): \delta=7.24(\mathrm{t}, J=8.2 \mathrm{~Hz}, 1 \mathrm{H}), 6.65(\mathrm{t}, J=8.2 \mathrm{~Hz}$, 2H), $6.55(\mathrm{~s}, 1 \mathrm{H}), 4.76(\mathrm{q}, J=6.8 \mathrm{~Hz}, 1 \mathrm{H}), 3.76(\mathrm{~s}, 3 \mathrm{H}), 1.62(\mathrm{~d}, J=6.8 \mathrm{~Hz}, 3 \mathrm{H}) .{ }^{13} \mathrm{C}-\mathrm{NMR}(67.5 \mathrm{MHz}$, $\left.\mathrm{CDCl}_{3}\right): \delta=172.1,158.6,141.3,130.5,112.2,111.1,106.3,72.5,52.3,18.4$. HRMS (ESI): $m / z$ calculated for $\mathrm{C}_{10} \mathrm{H}_{11} \mathrm{~N}_{3} \mathrm{O}_{3}+\mathrm{H}^{+}\left[\mathrm{M}+\mathrm{H}^{+}\right]$: 222.0879. Found: 222.0880. Chiral HPLC (n-hexane/2-propanol 99:1): $t_{\mathrm{R}} 18.0 \mathrm{~min}$.

Methyl (R)-2-(3-azidophenoxy)propanoate ((R)-19). The similar treatment of methyl $(R)-2-(3-$ aminophenoxy)propanoate $(R)-\mathbf{1 7}(518 \mathrm{mg}, 2.65 \mathrm{mmol})$ as that just described gave $(R)-\mathbf{1 9}(497 \mathrm{mg}, 85 \%)$. $[\alpha]_{\mathrm{D}}+28\left(c 1, \mathrm{CHCl}_{3}\right) .{ }^{1} \mathrm{H}-\mathrm{NMR}\left(270 \mathrm{MHz}, \mathrm{CDCl}_{3}\right): \delta=7.24(\mathrm{t}, J=8.1 \mathrm{~Hz}, 1 \mathrm{H}), 6.65(\mathrm{t}, J=8.1 \mathrm{~Hz}$, $1 \mathrm{H}), 6.55(\mathrm{~s}, 1 \mathrm{H}), 4.76(\mathrm{q}, J=6.8 \mathrm{~Hz}, 1 \mathrm{H}), 3.76(\mathrm{~s}, 3 \mathrm{H}), 1.62(\mathrm{~d}, J=6.8 \mathrm{~Hz}, 3 \mathrm{H}) .{ }^{13} \mathrm{C}-\mathrm{NMR}(67.5 \mathrm{MHz}$, $\left.\mathrm{CDCl}_{3}\right): \delta=172.0,158.5,141.2,130.4,112.0,111.0,106.2,72.3,52.1,18.2$. HRMS (ESI): $\mathrm{m} / \mathrm{z}$ calculated for $\mathrm{C}_{10} \mathrm{H}_{11} \mathrm{~N}_{3} \mathrm{O}_{3}+\mathrm{H}^{+}\left[\mathrm{M}+\mathrm{H}^{+}\right]$: 222.0879. Found: 222.0860. Chiral HPLC (n-hexane/2-propanol 99:1): $t_{\mathrm{R}} 16.7 \mathrm{~min}$. 
(S)-2-(4-Azidophenoxy)propanoic acid ((S)-20). Methyl (S)-2-(4-azidophenoxy)propanoate $(S)$-18 (702 $\mathrm{mg}, 3.17 \mathrm{mmol})$ was dissolved in $\mathrm{MeOH}(15 \mathrm{~mL})$ and 2M NaOH $(3.2 \mathrm{~mL})$. After the reaction mixture was stirred at reflux for $2 \mathrm{~h}$, cooled to room temperature and then partitioned between ethyl acetate and water. The water layer was acidified by $1 \mathrm{M} \mathrm{HCl}$ aq and extracted by ethyl acetate. The organic layer was washed by $\mathrm{H}_{2} \mathrm{O}$ and brine, and dried over $\mathrm{MgSO}_{4}$, filtrated and concentrated to give $(S)-20(601 \mathrm{mg}, 91 \%) .[\alpha]_{\mathrm{D}}+27\left(c 1, \mathrm{CHCl}_{3}\right) .{ }^{1} \mathrm{H}-\mathrm{NMR}\left(270 \mathrm{MHz}, \mathrm{CDCl}_{3}\right): \delta=9.68(\mathrm{~s}, 1 \mathrm{H})$, $6.96(\mathrm{~d}, J=8.9 \mathrm{~Hz}, 4 \mathrm{H}), 6.89(\mathrm{~d}, J=8.9 \mathrm{~Hz}, 4 \mathrm{H}), 4.75(\mathrm{~d}, J=6.9 \mathrm{~Hz}, 1 \mathrm{H}), 1.66(\mathrm{~d}, J=6.9 \mathrm{~Hz}, 3 \mathrm{H})$. ${ }^{13} \mathrm{C}-\mathrm{NMR}\left(67.5 \mathrm{MHz}, \mathrm{CDCl}_{3}\right): \delta=177.6,154.5,133.7,120.2,116.6,72.5,18.4$. HRMS (ESI): $\mathrm{m} / z$ calculated for $\mathrm{C}_{9} \mathrm{H}_{9} \mathrm{~N}_{3} \mathrm{O}_{3}+\mathrm{H}^{+}\left[\mathrm{M}+\mathrm{H}^{+}\right]$: 208.0722. Found: 208.0720.

(R)-2-(4-Azidophenoxy)propanoic acid ((R)-20). The similar treatment of methyl $(R)-2-(4$-azido phenoxy)propanoate $(R)-\mathbf{1 8}(529 \mathrm{mg}, 2.39 \mathrm{mmol})$ as that just described gave $(R)-20(475 \mathrm{mg}, 96 \%)$. $\left.[\alpha]_{\mathrm{D}}-27(c), \mathrm{CHCl}_{3}\right) .{ }^{1} \mathrm{H}-\mathrm{NMR}\left(270 \mathrm{MHz}_{\mathrm{CDCl}}\right): \delta=11.71(\mathrm{~s}, 1 \mathrm{H}), 6.93(\mathrm{~d}, J=8.9 \mathrm{~Hz}, 2 \mathrm{H})$, $6.87(\mathrm{~d}, J=8.9 \mathrm{~Hz}, 2 \mathrm{H}), 4.74(\mathrm{q}, J=6.8 \mathrm{~Hz}, 1 \mathrm{H}), 1.65(\mathrm{~d}, J=6.8 \mathrm{~Hz}, 3 \mathrm{H}) .{ }^{13} \mathrm{C}-\mathrm{NMR}\left(67.5 \mathrm{MHz}, \mathrm{CDCl}_{3}\right)$ : $\delta=178.1,154.5,133.7,120.1,116.6,72.5,18.4$. HRMS (ESI): $m / z$ calculated for $\mathrm{C}_{9} \mathrm{H}_{9} \mathrm{~N}_{3} \mathrm{O}_{3}+\mathrm{H}^{+}\left[\mathrm{M}+\mathrm{H}^{+}\right]$: 208.0722. Found: 208.0710 .

(S)-2-(3-Azidophenoxy)propanoic acid ((S)-21). The similar treatment of methyl (S)-2-(3-azide phenoxy)propanoate $(S)-19(212 \mathrm{mg}, 0.96 \mathrm{mmol})$ as that just described gave $(S)-21(211 \mathrm{mg}$, quant). $[\alpha]_{\mathrm{D}}-5\left(c 1, \mathrm{CHCl}_{3}\right) .{ }^{1} \mathrm{H}-\mathrm{NMR}\left(270 \mathrm{MHz}, \mathrm{CDCl}_{3}\right): \delta=7.26(\mathrm{t}, J=8.1 \mathrm{~Hz}, 1 \mathrm{H}), 6.70(\mathrm{dd}, J=8.1,2.1 \mathrm{~Hz}$, $1 \mathrm{H}), 6.66(\mathrm{dd}, J=8.1,2.1 \mathrm{~Hz}, 1 \mathrm{H}), 6.57(\mathrm{t}, J=2.1 \mathrm{~Hz}, 1 \mathrm{H}), 4.80(\mathrm{q}, J=6.8 \mathrm{~Hz}, 1 \mathrm{H}), 1.67(\mathrm{~d}, J=6.6 \mathrm{~Hz}, 3 \mathrm{H})$. ${ }^{13} \mathrm{C}-\mathrm{NMR}\left(67.5 \mathrm{MHz} \mathrm{CDCl}_{3}\right): \delta=177.5,158.4,141.6,130.7,112.5,111.2,106.5,72.0,18.3$. HRMS (ESI): $m / z$ calculated for $\mathrm{C}_{9} \mathrm{H}_{9} \mathrm{~N}_{3} \mathrm{O}_{3}+\mathrm{H}^{+}\left[\mathrm{M}+\mathrm{H}^{+}\right]$: 208.0722. Found: 208.0750.

(R)-2-(3-Azidophenoxy)propanoic acid ((R)-21). The similar treatment of methyl (R)-2-(3-azido phenoxy)propanoate $(R)-\mathbf{1 9}(386 \mathrm{mg}, 1.74 \mathrm{mmol})$ as that just described gave $(R)-\mathbf{2 1}(294 \mathrm{mg}, 81 \%)$. $[\alpha]_{\mathrm{D}}+5\left(c 1, \mathrm{CHCl}_{3}\right) .{ }^{1} \mathrm{H}-\mathrm{NMR}\left(270 \mathrm{MHz}, \mathrm{CDCl}_{3}\right): \delta=7.25(\mathrm{t}, J=8.1 \mathrm{~Hz}, 1 \mathrm{H}), 6.69(\mathrm{dd}, J=8.1,2.1 \mathrm{~Hz}$, $2 \mathrm{H}), 6.65(\mathrm{dd}, J=8.1,2.1 \mathrm{~Hz}, 2 \mathrm{H}), 6.57(\mathrm{t}, J=2.1 \mathrm{~Hz}, 1 \mathrm{H}), 4.79(\mathrm{q}, J=6.8 \mathrm{~Hz}, 1 \mathrm{H}), 1.66(\mathrm{~d}, J=6.8 \mathrm{~Hz}, 3 \mathrm{H})$. ${ }^{13} \mathrm{C}-\mathrm{NMR}\left(67.5 \mathrm{MHz}, \mathrm{CDCl}_{3}\right): \delta=177.6,158.4,141.6,130.7,112.5,111.2,106.6,72.0,18.3$. HRMS (ESI): $m / z$ calculated for $\mathrm{C}_{9} \mathrm{H}_{9} \mathrm{~N}_{3} \mathrm{O}_{3}+\mathrm{H}^{+}\left[\mathrm{M}+\mathrm{H}^{+}\right]$: 208.0722. Found: 208.0710.

\subsection{Synthesis of 2-Azidephenoxy-Based Lactisole Derivatives}

Methyl (S)-2-(2-nitrophenoxy)propanoate ((S)-23). The similar treatment of Mitsunobu reaction for 2-nitrophenol $22(509 \mathrm{mg}, 3.66 \mathrm{mmol})$ and methyl D-(+)-lactate 4 (572 mg, $5.49 \mathrm{mmol})$ as that just described gave (S)-23 (952 mg, quant). [ $\alpha]_{\mathrm{D}}+106$ (c 1, $\left.\mathrm{CHCl}_{3}\right) .{ }^{1} \mathrm{H}-\mathrm{NMR}\left(270 \mathrm{MHz}, \mathrm{CDCl}_{3}\right)$ : $\delta=7.83(\mathrm{dd}, J=8.2,1.6 \mathrm{~Hz}, 1 \mathrm{H}), 7.49(\mathrm{td}, J=8.2,1.6 \mathrm{~Hz}, 1 \mathrm{H}), 7.08(\mathrm{td}, J=8.2,1.2 \mathrm{~Hz}, 1 \mathrm{H}), 6.96(\mathrm{dd}$, $J=8.2,1.2 \mathrm{~Hz}, 1 \mathrm{H}), 4.85(\mathrm{q}, J=6.8 \mathrm{~Hz}, 1 \mathrm{H}), 3.76(\mathrm{~s}, 3 \mathrm{H}), 1.69(\mathrm{~d}, J=6.8 \mathrm{~Hz}, 3 \mathrm{H}) .{ }^{13} \mathrm{C}-\mathrm{NMR}(67.5 \mathrm{MHz}$, $\left.\mathrm{CDCl}_{3}\right): \delta=171.1,150.6,140.5,133.7,125.4,121.4,115.6,74.2,52.3,18.1$. HRMS (ESI): $m / z$ calculated for $\mathrm{C}_{10} \mathrm{H}_{11} \mathrm{NO}_{5}+\mathrm{H}^{+}\left[\mathrm{M}+\mathrm{H}^{+}\right]: 226.0715$. Found: 226.0705 .

Methyl (R)-2-(2-nitrophenoxy)propanoate ((R)-23). The similar treatment of 2-nitrophenol 22 (500 mg, $3.60 \mathrm{mmol}$ ) and methyl L-(-)-lactate $5(562 \mathrm{mg}, 5.40 \mathrm{mmol})$ as that just described gave $(R)-23$ (892 mg, quant). [ $\alpha]_{\mathrm{D}}-106\left(c \mathrm{c}, \mathrm{CHCl}_{3}\right)$. (ref. [ $\left.\alpha\right]_{\mathrm{D}}-126.86$ (c 1.0, EtOH) [28]). ${ }^{1} \mathrm{H}-\mathrm{NMR}(270 \mathrm{MHz}$, $\left.\mathrm{CDCl}_{3}\right): \delta=7.76(\mathrm{dd}, J=8.2,1.6 \mathrm{~Hz}, 1 \mathrm{H}), 7.41(\mathrm{td}, J=8.2,1.6 \mathrm{~Hz}, 1 \mathrm{H}), 7.01(\mathrm{td}, J=8.2,1.2 \mathrm{~Hz}, 1 \mathrm{H})$, $6.89(\mathrm{td}, J=8.2,1.2 \mathrm{~Hz}, 1 \mathrm{H}), 4.79(\mathrm{q}, J=6.8 \mathrm{~Hz}, 1 \mathrm{H}), 3.69(\mathrm{~s}, 3 \mathrm{H}), 1.62(\mathrm{~d}, J=6.8 \mathrm{~Hz}, 3 \mathrm{H}) .{ }^{13} \mathrm{C}-\mathrm{NMR}$ $\left(67.5 \mathrm{MHz}, \mathrm{CDCl}_{3}\right): \delta=171.3,150.8,140.7,133.8,125.6,121.5,115.8,74.5,52.5,18.3$. HRMS (ESI): $m / z$ calculated for $\mathrm{C}_{10} \mathrm{H}_{11} \mathrm{NO}_{5}+\mathrm{H}^{+}\left[\mathrm{M}+\mathrm{H}^{+}\right]$: 226.0715. Found: 226.0710 .

(S)-2-(2-Nitrophenoxy)propanoic acid ((S)-24). Methyl (S)-2-(2-nitrophenoxy)propanoate $(S)$-23 (261 $\mathrm{mg}, 1.16 \mathrm{mmol})$ was dissolved in $\mathrm{MeOH}(15 \mathrm{~mL})$ and $2 \mathrm{M} \mathrm{NaOH}(1.5 \mathrm{~mL})$. After the reaction mixture was stirred at reflux for $1 \mathrm{~h}$, cooled to room temperature and then partitioned between ethyl acetate and water. The water layer was acidified by $1 \mathrm{M} \mathrm{HCl}$ and extracted by ethyl acetate. The organic layer was washed by $\mathrm{H}_{2} \mathrm{O}$ and brine, and dried over $\mathrm{MgSO}_{4}$, filtrated and concentrated to give $(S)-24$ (251 mg, quant). $[\alpha]_{\mathrm{D}}+5$ (c 1, $\left.\mathrm{CHCl}_{3}\right) .{ }^{1} \mathrm{H}-\mathrm{NMR}\left(270 \mathrm{MHz}, \mathrm{CDCl}_{3}\right): \delta=7.84(\mathrm{~d}, J=8.2 \mathrm{~Hz}, 1 \mathrm{H}), 7.49$ $(\mathrm{t}, J=8.2 \mathrm{~Hz}, 1 \mathrm{H}), 7.07(\mathrm{t}, J=8.2 \mathrm{~Hz}, 1 \mathrm{H}), 6.97(\mathrm{~d}, J=8.2 \mathrm{~Hz}, 1 \mathrm{H}), 4.88(\mathrm{q}, J=6.8 \mathrm{~Hz}, 1 \mathrm{H}), 1.68(\mathrm{~d}$, 
$J=6.8 \mathrm{~Hz}, 3 \mathrm{H}) .{ }^{13} \mathrm{C}-\mathrm{NMR}\left(67.5 \mathrm{MHz}, \mathrm{CDCl}_{3}\right): \delta=174.4,150.4,140.3,134.4,126.1,122.2,115.8,74.4$, 18.2. HRMS (ESI): $m / z$ calculated for $\mathrm{C}_{9} \mathrm{H}_{9} \mathrm{NO}_{5}+\mathrm{H}^{+}\left[\mathrm{M}+\mathrm{H}^{+}\right]$: 212.0559. Found: 212.0540 .

(R)-2-(2-Nitrophenoxy)propanoic acid ((R)-24). The similar treatment of methyl (R)-2-(2-nitrop henoxy)propanoate $(R)-23(632 \mathrm{mg}, 2.81 \mathrm{mmol})$ as that just described gave $(R)-24(752 \mathrm{mg}$, quant). $[\alpha]_{\mathrm{D}}-5\left(c 1, \mathrm{CHCl}_{3}\right) .{ }^{1} \mathrm{H}-\mathrm{NMR}\left(270 \mathrm{MHz}, \mathrm{CDCl}_{3}\right): \delta=7.79(\mathrm{~d}, J=8.2 \mathrm{~Hz}, 1 \mathrm{H}), 7.45(\mathrm{t}, J=8.2 \mathrm{~Hz}$, $1 \mathrm{H}), 7.04(\mathrm{t}, J=8.2 \mathrm{~Hz}, 1 \mathrm{H}), 6.95(\mathrm{~d}, J=8.2 \mathrm{~Hz}, 1 \mathrm{H}), 4.85(\mathrm{q}, J=6.8 \mathrm{~Hz}, 1 \mathrm{H}), 1.66(\mathrm{~d}, J=6.8 \mathrm{~Hz}, 3 \mathrm{H})$. ${ }^{13} \mathrm{C}-\mathrm{NMR}\left(67.5 \mathrm{MHz}, \mathrm{CDCl}_{3}\right): \delta=175.5,150.5,140.4,134.3,126.0,122.0,115.8,74.1,18.1$. HRMS (ESI): $m / z$ calculated for $\mathrm{C}_{9} \mathrm{H}_{9} \mathrm{NO}_{5}+\mathrm{H}^{+}\left[\mathrm{M}+\mathrm{H}^{+}\right]: 212.0559$. Found: 212.0560 .

tert-Butyl (S)-2-(2-nitrophenoxy)propanoate ((S)-25). To a solution of (S)-2-(2-nitrophenoxy)pro panoic acid (S)-24 $(251 \mathrm{mg}, 1.19 \mathrm{mmol})$, potassium carbonate anhydride $(4.11 \mathrm{~g}, 29.7 \mathrm{mmol})$ and tetrabutylammonium bromide $(384 \mathrm{mg}, 1.19 \mathrm{mmol})$ in $N, N$-dimethylacetamide $(6 \mathrm{~mL})$, tert-butyl bromide $(7.81 \mathrm{~g}, 57.0 \mathrm{mmol})$ was added dropwise at $0{ }^{\circ} \mathrm{C}$. The reaction mixture was stirred at $55{ }^{\circ} \mathrm{C}$ for $2.5 \mathrm{~h}$. After cooling to room temperature, the mixture was poured into cold water and extracted with ethyl acetate. The organic layer was washed with $\mathrm{H}_{2} \mathrm{O}$, brine, dried over $\mathrm{MgSO}_{4}$, filtrated and evaporated. The residue was purified by column chromatography (ethyl acetate/ $n$-hexane, 1:6) to give (S)-25 (246 mg, 77\%). [ $\alpha]_{\mathrm{D}}+108\left(\mathrm{c} 1, \mathrm{CHCl}_{3}\right) .{ }^{1} \mathrm{H}-\mathrm{NMR}\left(270 \mathrm{MHz}, \mathrm{CDCl}_{3}\right): \delta=7.81(\mathrm{~d}, J=8.2 \mathrm{~Hz}$, $1 \mathrm{H}), 7.48(\mathrm{t}, J=8.2 \mathrm{~Hz}, 1 \mathrm{H}), 7.05(\mathrm{t}, J=8.2 \mathrm{~Hz}, 1 \mathrm{H}), 6.96(\mathrm{~d}, J=8.2 \mathrm{~Hz}, 1 \mathrm{H}), 4.75(\mathrm{q}, J=6.8 \mathrm{~Hz}, 1 \mathrm{H})$, $1.65(\mathrm{~d}, J=6.8 \mathrm{~Hz}, 3 \mathrm{H}), 1.42(\mathrm{~s}, 9 \mathrm{H}) .{ }^{13} \mathrm{C}-\mathrm{NMR}\left(67.5 \mathrm{MHz}, \mathrm{CDCl}_{3}\right): \delta=169.9,151.0,140.5,133.5,125.5$, 121.0, 115.4, 82.4, 74.6, 27.7, 18.1. HRMS (ESI): $m / z$ calculated for $\mathrm{C}_{13} \mathrm{H}_{17} \mathrm{NO}_{5}+\mathrm{H}^{+}\left[\mathrm{M}+\mathrm{H}^{+}\right]$: 268.1185 . Found: 268.1170 .

tert-Butyl (R)-2-(2-nitrophenoxy)propanoate $((R)-25)$. The similar treatment of $(R)-2$-(2-nitrophe noxy)propanoic acid $(R)-24(289 \mathrm{mg}, 1.37 \mathrm{mmol})$ as that just described gave $(R)-25(301 \mathrm{mg}$, 82\%). $[\alpha]_{\mathrm{D}}-108\left(c 1, \mathrm{CHCl}_{3}\right) .{ }^{1} \mathrm{H}-\mathrm{NMR}\left(270 \mathrm{MHz}, \mathrm{CDCl}_{3}\right): \delta=7.72(\mathrm{~d}, J=8.6 \mathrm{~Hz}, 1 \mathrm{H}), 7.40(\mathrm{t}$, $J=7.9 \mathrm{~Hz}, 1 \mathrm{H}), 6.97(\mathrm{t}, J=7.9 \mathrm{~Hz}, 1 \mathrm{H}), 6.87(\mathrm{~d}, J=8.6 \mathrm{~Hz}, 1 \mathrm{H}), 4.67(\mathrm{q}, J=6.8 \mathrm{~Hz}, 1 \mathrm{H}), 1.56(\mathrm{~d}, J=6.8 \mathrm{~Hz}$, $3 \mathrm{H}), 1.33(\mathrm{~s}, 9 \mathrm{H}) .{ }^{13} \mathrm{C}-\mathrm{NMR}\left(67.5 \mathrm{MHz}, \mathrm{CDCl}_{3}\right): \delta=169.9,151.0,140.5,133.5,125.5,121.0,115.4,82.4$, 74.5, 27.7, 18.1. HRMS (ESI): $\mathrm{m} / z$ calculated for $\mathrm{C}_{13} \mathrm{H}_{17} \mathrm{NO}_{5}+\mathrm{H}^{+}\left[\mathrm{M}+\mathrm{H}^{+}\right]$: 268.1185. Found: 268.1190.

tert-Butyl (S)-2-(2-aminophenoxy)propanoate ((S)-26). tert-Butyl (S)-2-(2-nitrophenoxy)-

propanoate $(S)-25(246 \mathrm{mg}, 0.92 \mathrm{mmol})$ and $5 \% \mathrm{Pd} / \mathrm{C}(12.3 \mathrm{mg})$ were suspended in $\mathrm{MeOH}(20 \mathrm{~mL})$. The reaction mixture was stirred vigorously at room temperature for 45 min under $\mathrm{H}_{2}$ atmosphere then was filtrated with Celite and concentrated. The residue was partitioned between ethyl acetate and $1 \mathrm{M}$ $\mathrm{HCl}$, and then $1 \mathrm{M} \mathrm{NaOH}$ was added to make $\mathrm{pH} 10$, then extracted by ethyl acetate. The organic layer was washed by brine and dried over $\mathrm{MgSO}_{4}$, filtrated, and concentrated to give (S)-26 (159 mg, 73\%). $[\alpha]_{\mathrm{D}}+11\left(c 1, \mathrm{CHCl}_{3}\right) .{ }^{1} \mathrm{H}-\mathrm{NMR}\left(270 \mathrm{MHz}, \mathrm{CDCl}_{3}\right): \delta=6.81(\mathrm{t}, J=7.6 \mathrm{~Hz}, 1 \mathrm{H}), 6.73(\mathrm{~d}, J=7.6 \mathrm{~Hz}$, $1 \mathrm{H}), 6.67(\mathrm{~m}, 2 \mathrm{H}), 4.62(\mathrm{q}, J=8 \mathrm{~Hz}, 1 \mathrm{H}), 3.83(\mathrm{~s}, 2 \mathrm{H}), 1.60(\mathrm{~d}, J=6.8 \mathrm{~Hz}, 3 \mathrm{H}), 1.44(\mathrm{~s}, 9 \mathrm{H}) .{ }^{13} \mathrm{C}-\mathrm{NMR}$ $\left(67.5 \mathrm{MHz}, \mathrm{CDCl}_{3}\right): \delta=171.5,145.5,137.2,122.2,118.1,115.6,113.5,81.7,74.0,27.9,18.6$. HRMS (ESI): $m / z$ calculated for $\mathrm{C}_{13} \mathrm{H}_{19} \mathrm{NO}_{3}+\mathrm{H}^{+}\left[\mathrm{M}+\mathrm{H}^{+}\right]$: 238.1443. Found: 238.1440 .

tert-Butyl (R)-2-(2-aminophenoxy)propanoate $((R)-26)$. The similar treatment of tert-butyl $(R)$-2-(2-nitrophenoxy)propanoate $(R)-25(666 \mathrm{mg}, 2.49 \mathrm{mmol})$ as that just described gave $(R)$-26 (524 mg, 89\%). [ $\alpha]_{\mathrm{D}}-11\left(\mathrm{c} 1, \mathrm{CHCl}_{3}\right) .{ }^{1} \mathrm{H}-\mathrm{NMR}\left(270 \mathrm{MHz}, \mathrm{CDCl}_{3}\right): \delta=6.80(\mathrm{t}, J=7.6 \mathrm{~Hz}, 1 \mathrm{H}), 6.68(\mathrm{~m}$, $3 \mathrm{H}), 4.62(\mathrm{q}, J=6.8 \mathrm{~Hz}, 1 \mathrm{H}), 3.92(\mathrm{~s}, 2 \mathrm{H}), 1.59(\mathrm{~d}, J=6.8 \mathrm{~Hz}, 3 \mathrm{H}), 1.43(\mathrm{~s}, 9 \mathrm{H}) .{ }^{13} \mathrm{C}-\mathrm{NMR}(67.5 \mathrm{MHz}$, $\left.\mathrm{CDCl}_{3}\right): \delta=171.5,145.5,137.2,122.2,118.1,115.5,113.5,81.7,74.00,27.9,18.6$. HRMS (ESI): $\mathrm{m} / \mathrm{z}$ calculated for $\mathrm{C}_{13} \mathrm{H}_{19} \mathrm{NO}_{3}+\mathrm{H}^{+}\left[\mathrm{M}+\mathrm{H}^{+}\right]$: 238.1443. Found: 238.1430 .

tert-Butyl (S)-2-(2-azidophenoxy)propanoate ((S)-27). tert-Butyl (S)-2-(2-aminophenoxy)-propanoate (S)-26 $(159 \mathrm{mg}, 0.67 \mathrm{mmol})$ was dissolved in water $(1.46 \mathrm{~mL})$ and $37 \%$ hydrochloric acid $(0.17 \mathrm{~mL})$ at $0{ }^{\circ} \mathrm{C}$. $\mathrm{NaNO}_{2}(51.3 \mathrm{mg}, 0.74 \mathrm{mmol})$ in water $(0.49 \mathrm{~mL})$ was added slowly at $0{ }^{\circ} \mathrm{C}$, followed by $\mathrm{NaN}_{3}(82.4 \mathrm{mg}$, $1.27 \mathrm{mmol})$ in water $(0.49 \mathrm{~mL})$. After $30 \mathrm{~min}$ at $0{ }^{\circ} \mathrm{C}$ and $30 \mathrm{~min}$ at room temperature, the reaction mixture was extracted with ethyl acetate. The organic layer was washed by brine, dried over $\mathrm{MgSO}_{4}$, filtrated and concentrated to give (S)-27 (194 mg, quant). $[\alpha]_{\mathrm{D}}+15$ (c 1, $\left.\mathrm{CHCl}_{3}\right) .{ }^{1} \mathrm{H}-\mathrm{NMR}(270 \mathrm{MHz}$, $\left.\mathrm{CDCl}_{3}\right): \delta=6.90(\mathrm{~m}, 3 \mathrm{H}), 6.72(\mathrm{~d}, J=7.9 \mathrm{~Hz}, 1 \mathrm{H}), 4.62(\mathrm{q}, J=6.8 \mathrm{~Hz}, 1 \mathrm{H}), 1.55(\mathrm{~d}, J=6.8 \mathrm{~Hz}, 3 \mathrm{H}), 1.34$ (s, 9H). ${ }^{13} \mathrm{C}-\mathrm{NMR}\left(67.5 \mathrm{MHz}, \mathrm{CDCl}_{3}\right): \delta=170.6,150.5,128.9,125.3,122.1,121.0,114.1,82.1,74.1,27.8$, 
18.1. HRMS (ESI): $m / z$ calculated for $\mathrm{C}_{13} \mathrm{H}_{17} \mathrm{~N}_{3} \mathrm{O}_{3}+\mathrm{H}^{+}\left[\mathrm{M}+\mathrm{H}^{+}\right]$: 264.1348. Found: 264.1360. Chiral HPLC (n-hexane/2-propanol 199:1): $t_{\mathrm{R}} 37.8 \mathrm{~min}$.

tert-Butyl $(R)$-2-(3-azidophenoxy)propanoate $((R)-27)$. The similar treatment of tert-butyl $(R)$-2-(2-aminophenoxy)propanoate $(R)-26(524 \mathrm{mg}, 2.21 \mathrm{mmol})$ as that just described gave $((R)-39)$ (517 mg, 89\%). [ $\alpha]_{\mathrm{D}}-15\left(\mathrm{c} 1, \mathrm{CHCl}_{3}\right) .{ }^{1} \mathrm{H}-\mathrm{NMR}\left(270 \mathrm{MHz}, \mathrm{CDCl}_{3}\right): \delta=6.92(\mathrm{~m}, 3 \mathrm{H}), 6.77(\mathrm{~d}, J=7.9 \mathrm{~Hz}$, $1 \mathrm{H}), 4.67(\mathrm{q}, J=6.8 \mathrm{~Hz}, 1 \mathrm{H}), 1.61(\mathrm{~d}, J=6.8 \mathrm{~Hz}, 3 \mathrm{H}), 1.39(\mathrm{~s}, 9 \mathrm{H}) .{ }^{13} \mathrm{C}-\mathrm{NMR}\left(67.5 \mathrm{MHz}, \mathrm{CDCl}_{3}\right): \delta=170.7$, $150.5,128.9,125.3,122.1,121.0,114.2,82.1,74.1,27.8,18.1$. HRMS (ESI): $m / z$ calculated for $\mathrm{C}_{13} \mathrm{H}_{17} \mathrm{~N}_{3} \mathrm{O}_{3}$ $+\mathrm{H}^{+}\left[\mathrm{M}+\mathrm{H}^{+}\right]: 264.1348$. Found: 264.1330 .

(S)-2-(2-Azidophenoxy)propanoic acid ((S)-28). tert-Butyl (S)-2-(2-azidophenoxy)-propanoate $((S)-27)(218 \mathrm{mg}, 0.83 \mathrm{mmol})$ was dissolved in $4 \mathrm{M} \mathrm{HCl}$ in dioxane $(7.5 \mathrm{~mL})$ and stirred at room temperature for $1 \mathrm{~h}$, poured into $1 \mathrm{M} \mathrm{NaOH}$ solution to make alkaline. The organic layer was dried over $\mathrm{MgSO}_{4}$, filtrated and concentrated, and then the residue was treated with the same reaction 2 times. The aqueous layer was extracted with ethyl acetate. The organic layer was dried over $\mathrm{MgSO}_{4}$, filtrated and concentrated to give (S)-28 (116.3 mg, 68\%). [ $\alpha]_{\mathrm{D}}+12\left(c 1, \mathrm{CHCl}_{3}\right) .{ }^{1} \mathrm{H}-\mathrm{NMR}(270 \mathrm{MHz}$, $\left.\mathrm{CDCl}_{3}\right): \delta=8,24(\mathrm{~s}, 1 \mathrm{H}), 7.02(\mathrm{~m}, 3 \mathrm{H}), 6.85(\mathrm{~d}, J=7.6 \mathrm{~Hz}, 1 \mathrm{H}), 4.81(\mathrm{q}, J=6.8 \mathrm{~Hz}, 1 \mathrm{H}), 1.71(\mathrm{~d}$, $J=6.8 \mathrm{~Hz}, 3 \mathrm{H}) .{ }^{13} \mathrm{C}-\mathrm{NMR}\left(67.5 \mathrm{MHz}, \mathrm{CDCl}_{3}\right): \delta=176.4,149.4,129.5,125.6,123.1,120.8,115.2,73.7$, 18.2. HRMS (ESI): $m / z$ calculated for $\mathrm{C}_{9} \mathrm{H}_{9} \mathrm{~N}_{3} \mathrm{O}_{3}+\mathrm{H}^{+}\left[\mathrm{M}+\mathrm{H}^{+}\right]$: 208.0722. Found: 208.0705. Chiral HPLC (n-hexane/2-propanol 199:1): $t_{\mathrm{R}} 42.9 \mathrm{~min}$.

(R)-2-(2-Azidophenoxy)propanoic acid $((R)-28)$. The similar treatment of tert-butyl $(R)$-2-(2-azidephenoxy)propanoate $((R)-27)(253 \mathrm{mg}, 0.96 \mathrm{mmol})$ as that just described gave $(R)$-28 (128.7 mg, 65\%). [ $\alpha]_{\mathrm{D}}-12\left(c 1, \mathrm{CHCl}_{3}\right) .{ }^{1} \mathrm{H}-\mathrm{NMR}\left(270 \mathrm{MHz}, \mathrm{CDCl}_{3}\right): \delta=9.31(\mathrm{~s}, 1 \mathrm{H}), 7.09-6.96(\mathrm{~m}$, $3 \mathrm{H}), 6.84(\mathrm{~d}, J=7.6 \mathrm{~Hz}, 1 \mathrm{H}), 4.81(\mathrm{q}, J=6.8 \mathrm{~Hz}, 1 \mathrm{H}), 1.70(\mathrm{~d}, J=6.8 \mathrm{~Hz}, 3 \mathrm{H}) .{ }^{13} \mathrm{C}-\mathrm{NMR}(67.5 \mathrm{MHz}$, $\mathrm{CDCl}_{3}$ ): $\delta=176.9,149.5,129.4,125.5,123.0,120.8,115.1,73.6,18.2$. HRMS (ESI): $m / z$ calculated for $\mathrm{C}_{9} \mathrm{H}_{9} \mathrm{~N}_{3} \mathrm{O}_{3}+\mathrm{H}^{+}\left[\mathrm{M}+\mathrm{H}^{+}\right]$: 208.0722. Found: 208.0715.

\subsection{Synthesis of Trifluoromethyldiazirine-Based Lactisole Derivatives}

2,2,2-Trifluoro-1-(4-hydroxyphenyl)ethan-1-one 31. 2,2,2-Trifluoro-1-(4-methoxyphenyl)-ethan-1 -one 29 (493 mg, $2.41 \mathrm{mmol}$ ) and lithium chloride $(950 \mathrm{mg}, 22.4 \mathrm{mmol})$ was dissolved in dry DMF $(7.5 \mathrm{~mL})$. After the reaction mixture was stirred at reflux for $6 \mathrm{~h}$, the mixture was cooled to room temperature and $1 \mathrm{M} \mathrm{HCl}$ was added, and then extracted with ethyl acetate. The organic layer was washed with brine and dried over $\mathrm{MgSO}_{4}$, filtrated and concentrated. The residue was purified by column chromatography (ethyl acetate/ $n$-hexane, 1:8) to give 31 (376 mg, 82\%). ${ }^{1} \mathrm{H}-\mathrm{NMR}(270 \mathrm{MHz}$, $\left.\mathrm{CDCl}_{3}\right): \delta=8.04(\mathrm{~d}, J=8.9 \mathrm{~Hz}, 2 \mathrm{H}), 6.96(\mathrm{~d}, J=8.9 \mathrm{~Hz}, 2 \mathrm{H}), 5.71(\mathrm{~s}, 1 \mathrm{H}) .{ }^{13} \mathrm{C}-\mathrm{NMR}\left(67.5 \mathrm{MHz}, \mathrm{CDCl}_{3}\right)$ : $\delta=179.0\left(\mathrm{q},{ }^{2} J_{C F}=34.6 \mathrm{~Hz}\right), 133.1,123.1,116.9\left(\mathrm{q},{ }^{1} J_{C F}=291.6 \mathrm{~Hz}\right), 116.0$. HRMS (ESI): $m / z$ calculated for $\mathrm{C}_{8} \mathrm{H}_{5} \mathrm{~F}_{3} \mathrm{O}_{2}+\mathrm{H}^{+}\left[\mathrm{M}+\mathrm{H}^{+}\right]$: 191.0320. Found: 191.0317.

2,2,2-Trifluoro-1-(3-hydroxyphenyl)ethan-1-one 32. 2,2,2-Trifluoro-1-(4-methoxyphenyl)-ethan-1 -one 30 (1.052 g, $5.15 \mathrm{mmol})$ was dissolved in $\mathrm{CH}_{2} \mathrm{Cl}_{2}(30 \mathrm{~mL})$ and cooled to $-78{ }^{\circ} \mathrm{C}$. $\mathrm{BBr}_{3}$ was added dropwise at $-78{ }^{\circ} \mathrm{C}$ and the reaction mixture stirred at room temperature for $5 \mathrm{~h}$. The mixture was cooled to $0{ }^{\circ} \mathrm{C}$ and $10 \% \mathrm{NaOH}(30 \mathrm{~mL})$ was added slowly, and then $\mathrm{HCl}$ was added to make $\mathrm{pH} 1$ at same temperature. $\mathrm{NH}_{4} \mathrm{OH}$ was also added to make $\mathrm{pH} 7$ at room temperature, then extracted by ethyl acetate. The organic layer was dried over $\mathrm{MgSO}_{4}$, filtrated and concentrated to give 31 (1.018 g, quant). ${ }^{1} \mathrm{H}-\mathrm{NMR}$ $\left(270 \mathrm{MHz}, \mathrm{CDCl}_{3}\right): \delta=7.63(\mathrm{~d}, J=7.8 \mathrm{~Hz}, 1 \mathrm{H}), 7.50(\mathrm{~s}, 1 \mathrm{H}), 7.41(\mathrm{t}, J=7.8 \mathrm{~Hz}, 1 \mathrm{H}), 7.18(\mathrm{dd}, J=7.8$, $2.6 \mathrm{~Hz}, 1 \mathrm{H}) .{ }^{13} \mathrm{C}-\mathrm{NMR}\left(67.5 \mathrm{MHz}, \mathrm{CDCl}_{3}\right): \delta=180.3\left(\mathrm{q},{ }^{2} J_{\mathrm{CF}}=35.2 \mathrm{~Hz}\right), 156.1,131.2,130.5,123.0,122.8$, $116.6\left(\mathrm{q},{ }^{1} J_{C F}=291.6 \mathrm{~Hz}\right), 116.2$. HRMS $(\mathrm{ESI}): \mathrm{m} / z$ calculated for $\mathrm{C}_{8} \mathrm{H}_{5} \mathrm{~F}_{3} \mathrm{O}_{2}+\mathrm{H}^{+}\left[\mathrm{M}+\mathrm{H}^{+}\right]: 191.0320$. Found: 191.0316.

Methyl (S)-2-(4-(2,2,2-trifluoroacetyl)phenoxy)propanoate (S)-33. To 2,2,2-trifluoro-1-(4-hydro xyphenyl)ethanone 31 (1.175 g, $7.25 \mathrm{mmol})$ in dry $\mathrm{CH}_{2} \mathrm{Cl}_{2}(30 \mathrm{~mL})$, D-(+)-lactate $4(1.132 \mathrm{~g}, 10.9 \mathrm{mmol})$ and $\mathrm{PPh}_{3}(2.282 \mathrm{~g}, 8.70 \mathrm{mmol})$ was added at $0{ }^{\circ} \mathrm{C}$. After the reaction mixture was stirred for $10 \mathrm{~min}$ at $0{ }^{\circ} \mathrm{C}, \mathrm{DEAD}(1.891 \mathrm{~g}, 10.9 \mathrm{mmol})$ was slowly added at same temperature. The reaction mixture was stirred overnight at room temperature and partitioned between water and $\mathrm{CH}_{2} \mathrm{Cl}_{2}$. The organic 
layer was washed with brine, dried over $\mathrm{MgSO}_{4}$, filtered and concentrated. The residue was purified by column chromatography (ethyl acetate/n-hexane, 1:9) to give $(S)-33(1.560 \mathrm{~g}, 78 \%)$. [ $\alpha]_{\mathrm{D}}-48(c$ 1, $\left.\mathrm{CHCl}_{3}\right) .{ }^{1} \mathrm{H}-\mathrm{NMR}\left(270 \mathrm{MHz}, \mathrm{CDCl}_{3}\right): \delta=7.96(\mathrm{~d}, J=8.2 \mathrm{~Hz}, 2 \mathrm{H}), 6.88(\mathrm{~d}, J=8.2 \mathrm{~Hz}, 2 \mathrm{H}), 4.82$ $(\mathrm{q}, J=6.8 \mathrm{~Hz}, 1 \mathrm{H}), 3.70(\mathrm{~s}, 3 \mathrm{H}), 1.59(\mathrm{~d}, J=6.8 \mathrm{~Hz}, 3 \mathrm{H}) .{ }^{13} \mathrm{C}-\mathrm{NMR}\left(67.5 \mathrm{MHz}, \mathrm{CDCl}_{3}\right): \delta=178.8(\mathrm{q}$, $\left.{ }^{2} J_{C F}=34.6 \mathrm{~Hz}\right), 171.4,163.2,132.7,123.4,116.8\left(\mathrm{q},{ }^{1} J_{C F}=291.4 \mathrm{~Hz}\right), 115.2,72.5,52.5,18.3$. HRMS (ESI): $m / z$ calculated for $\mathrm{C}_{12} \mathrm{H}_{11} \mathrm{~F}_{3} \mathrm{O}_{4}+\mathrm{H}^{+}\left[\mathrm{M}+\mathrm{H}^{+}\right]$: 277.0688. Found: 277.0674 .

Methyl (R)-2-(4-(2,2,2-trifluoroacetyl)phenoxy)propanoate $(R)-33$. The similar treatment of 2,2,2-trifluoro-1-(4-hydroxyphenyl)ethenone 31 (484 mg, $2.99 \mathrm{mmol})$ and methyl L-(-)-lactate 5 (466 mg, $4.48 \mathrm{mmol})$ as that just described gave $(R)-33(614 \mathrm{mg}, 74 \%) .[\alpha]_{\mathrm{D}}+48\left(c 1, \mathrm{CHCl}_{3}\right) .{ }^{1} \mathrm{H}-\mathrm{NMR}$ $\left(270 \mathrm{MHz} \mathrm{CDCl}_{3}\right): \delta=8.04(\mathrm{~d}, J=8.2 \mathrm{~Hz}, 2 \mathrm{H}), 6.97(\mathrm{~d}, J=8.2 \mathrm{~Hz}, 2 \mathrm{H}), 4.91(\mathrm{q}, J=6.8 \mathrm{~Hz}, 1 \mathrm{H}), 3.78$ $(\mathrm{s}, 3 \mathrm{H}), 1.68(\mathrm{~d}, J=6.8 \mathrm{~Hz}, 3 \mathrm{H}) .{ }^{13} \mathrm{C}-\mathrm{NMR}\left(67.5 \mathrm{MHz}, \mathrm{CDCl}_{3}\right): \delta=178.8\left(\mathrm{q},{ }^{2} J_{C F}=34.6 \mathrm{~Hz}\right), 171.4$, 163.2, 132.7, 123.4, $116.8\left(q,{ }^{1} J_{C F}=291.4 \mathrm{~Hz}\right), 115.2,72.5,52.5,18.3$. HRMS (ESI): $\mathrm{m} / z$ calculated for $\mathrm{C}_{12} \mathrm{H}_{11} \mathrm{~F}_{3} \mathrm{O}_{4}+\mathrm{H}^{+}\left[\mathrm{M}+\mathrm{H}^{+}\right]$: 277.0688. Found: 277.0660.

Methyl (S)-2-(3-(2,2,2-trifluoroacetyl)phenoxy)propanoate (S)-34. The similar treatment of 2,2,2-trifluoro-1-(3-hydroxyphenyl)ethanone 32 (248 mg, $1.53 \mathrm{mmol})$ and methyl D-(-)-lactate 4 $(248 \mathrm{mg}, 2.30 \mathrm{mmol})$ as that just described gave $(S)-34(300 \mathrm{mg}, 71 \%) .[\alpha]_{\mathrm{D}}-45\left(\mathrm{c} 1, \mathrm{CHCl}_{3}\right) .{ }^{1} \mathrm{H}-\mathrm{NMR}$ $\left(270 \mathrm{MHz}_{\mathrm{CDCl}}\right): \delta=7.69(\mathrm{~d}, J=7.8 \mathrm{~Hz}, 1 \mathrm{H}), 7.52(\mathrm{~s}, 1 \mathrm{H}), 7.46(\mathrm{t}, J=7.8 \mathrm{~Hz}, 1 \mathrm{H}), 7.23(\mathrm{~d}, J=7.8 \mathrm{~Hz}$, $1 \mathrm{H}), 4.84(\mathrm{q}, J=6.8 \mathrm{~Hz}, 1 \mathrm{H}), 3.78(\mathrm{~s}, 3 \mathrm{H}), 1.66(\mathrm{~d}, J=6.8 \mathrm{~Hz}, 3 \mathrm{H}) .{ }^{13} \mathrm{C}-\mathrm{NMR}\left(67.5 \mathrm{MHz}, \mathrm{CDCl}_{3}\right): \delta=180.1$ $\left(\mathrm{q},{ }^{2} J_{C F}=35.2 \mathrm{~Hz}\right), 171.9,157.9,131.2,130.3,123.5,123.0,118.7,116.6\left(\mathrm{q},{ }^{1} J_{C F}=291.1 \mathrm{~Hz}\right), 115.5,72.7$, 52.5, 18.4. HRMS (ESI): $m / z$ calculated for $\mathrm{C}_{12} \mathrm{H}_{11} \mathrm{~F}_{3} \mathrm{O}_{4}+\mathrm{H}^{+}\left[\mathrm{M}+\mathrm{H}^{+}\right]: 277.0688$. Found: 277.0688 .

Methyl (R)-2-(3-(2,2,2-trifluoroacetyl)phenoxy)propanoate (R)-34. The similar treatment of 2,2,2-trifluoro-1-(3-hydroxyphenyl)ethanone $32(655 \mathrm{mg}, 4.04 \mathrm{mmol})$ and methyl L-(-)-Lactate 5 $(631 \mathrm{mg}, 6.06 \mathrm{mmol})$ as that just described gave $(R)-34(835 \mathrm{mg}, 75 \%)$. $[\alpha]_{\mathrm{D}}+45\left(c 1, \mathrm{CHCl}_{3}\right) .{ }^{1} \mathrm{H}-\mathrm{NMR}$ $\left(270 \mathrm{MHz}_{\mathrm{CDCl}}\right): \delta=7.69(\mathrm{~d}, J=7.8 \mathrm{~Hz}, 1 \mathrm{H}), 7.53(\mathrm{~s}, 1 \mathrm{H}), 7.46(\mathrm{t}, J=7.8 \mathrm{~Hz}, 1 \mathrm{H}), 7.24(\mathrm{~d}, J=7.8 \mathrm{~Hz}$, $1 \mathrm{H}), 4.85(\mathrm{q}, J=6.8 \mathrm{~Hz}, 1 \mathrm{H}), 3.78(\mathrm{~s}, 3 \mathrm{H}), 1.67(\mathrm{~d}, J=6.8 \mathrm{~Hz}, 3 \mathrm{H}) .{ }^{13} \mathrm{C}-\mathrm{NMR}\left(67.5 \mathrm{MHz}, \mathrm{CDCl}_{3}\right): \delta=180.0$ $\left(q^{2} J_{C F}=35.2 \mathrm{~Hz}\right), 171.8,157.9,131.1,130.3,123.4,122.9,118.7,116.5\left(\mathrm{q},{ }^{2} J_{C F}=291.1 \mathrm{~Hz}\right), 115.4,72.7$, 52.4, 18.3. HRMS (ESI): $m / z$ calculated for $\mathrm{C}_{12} \mathrm{H}_{11} \mathrm{~F}_{3} \mathrm{O}_{4}+\mathrm{H}^{+}\left[\mathrm{M}+\mathrm{H}^{+}\right]:$277.0688. Found: 277.0685.

(S)-2-(4-(2,2,2-Trifluoroacetyl)phenoxy)propanoic acid ((S)-35). Methyl (S)-2-(4-(2,2,2-trifluoroa cetyl)phenoxy)propanoate $(S)-33(402 \mathrm{mg}, 1.46 \mathrm{mmol})$ was dissolved in $\mathrm{MeOH}(18 \mathrm{~mL})$ and $\mathrm{H}_{2} \mathrm{O}$ $(2 \mathrm{~mL})$, and then $\mathrm{K}_{2} \mathrm{CO}_{3}(605 \mathrm{mg}, 4.37 \mathrm{mmol})$ was added. After the reaction mixture was stirred at reflux for $2 \mathrm{~h}$, cooled to room temperature and then partitioned between ethyl acetate and water. The water layer was acidified by $1 \mathrm{M} \mathrm{HCl}$ and extracted by ethyl acetate. The organic layer was washed by $\mathrm{H}_{2} \mathrm{O}$ and brine, and dried over $\mathrm{MgSO}_{4}$, filtrated and concentrated to give (S)-35 (400 mg, quant). $[\alpha]_{\mathrm{D}}-31\left(c 1, \mathrm{CHCl}_{3}\right) .{ }^{1} \mathrm{H}-\mathrm{NMR}\left(270 \mathrm{MHz}, \mathrm{CDCl}_{3}\right): \delta=9.05(1 \mathrm{H}, \mathrm{s}), 7.97(\mathrm{~d}, J=8.9 \mathrm{~Hz}, 2 \mathrm{H}), 6.91(\mathrm{~d}$, $J=8.9 \mathrm{~Hz}, 2 \mathrm{H}), 4.85(\mathrm{q}, J=6.8 \mathrm{~Hz}, 1 \mathrm{H}), 1.65(\mathrm{~d}, J=6.8 \mathrm{~Hz}, 3 \mathrm{H}) .{ }^{13} \mathrm{C}-\mathrm{NMR}\left(67.5 \mathrm{MHz}, \mathrm{CDCl}_{3}\right): \delta=178.9$ $\left(\mathrm{q},{ }^{2} J_{C F}=35.2 \mathrm{~Hz}\right), 176.7,162.9,132.8,123.7,116.8\left(\mathrm{q},{ }^{1} J_{C F}=291.6 \mathrm{~Hz}\right), 115.2,72.0,18.2$. HRMS (ESI): $m / z$ calculated for $\mathrm{C}_{11} \mathrm{H}_{9} \mathrm{~F}_{3} \mathrm{O}_{4}+\mathrm{H}^{+}\left[\mathrm{M}+\mathrm{H}^{+}\right]$: 263.0531. Found: 263.0543 .

(R)-2-(4-(2,2,2-Trifluoroacetyl)phenoxy)propanoic acid ((R)-35). The similar treatment of methyl $(R)$-2-(4-(2,2,2-trifluoroacetyl)phenoxy)propanoate $(R)-33(476 \mathrm{mg}, 1.72 \mathrm{mmol})$ as that just described gave $(R)$-35 (428 mg, 95\%). $[\alpha]_{\mathrm{D}}+31\left(c \mathrm{1}, \mathrm{CHCl}_{3}\right) .{ }^{1} \mathrm{H}-\mathrm{NMR}\left(270 \mathrm{MHz}, \mathrm{CDCl}_{3}\right): \delta=7.99(\mathrm{~d}, J=8.9 \mathrm{~Hz}$, $2 \mathrm{H}), 6.92(\mathrm{~d}, J=8.9 \mathrm{~Hz}, 2 \mathrm{H}), 4.86(\mathrm{q}, J=6.8 \mathrm{~Hz}, 1 \mathrm{H}), 1.66(\mathrm{~d}, J=6.8 \mathrm{~Hz}, 3 \mathrm{H}) .{ }^{13} \mathrm{C}-\mathrm{NMR}(67.5 \mathrm{MHz}$, $\left.\mathrm{CDCl}_{3}\right): \delta=178.9\left(\mathrm{q},{ }^{2} J_{C F}=34.6 \mathrm{~Hz}\right), 176.4,162.9,132.8,123.8,116.8\left(\mathrm{q},{ }^{1} J_{C F}=291.3 \mathrm{~Hz}\right), 115.2,71.9$, 18.2. HRMS (ESI): $m / z$ calculated for $\mathrm{C}_{11} \mathrm{H}_{9} \mathrm{~F}_{3} \mathrm{O}_{4}+\mathrm{H}^{+}\left[\mathrm{M}+\mathrm{H}^{+}\right]$: 263.0531. Found: 263.0541.

(S)-2-(3-(2,2,2-Trifluoroacetyl)phenoxy)propanoic acid ((S)-36). The similar treatment of methyl (S)-2-(3-(2,2,2-trifluoroacetyl)phenoxy)propanoate $(S)-34(285 \mathrm{mg}, 1.03 \mathrm{mmol})$ as that just described gave (S)-36 (268 mg, 99\%). [ $\alpha]_{\mathrm{D}}-28\left(\mathrm{c} 1, \mathrm{CHCl}_{3}\right) .{ }^{1} \mathrm{H}-\mathrm{NMR}\left(270 \mathrm{MHz}, \mathrm{CDCl}_{3}\right): \delta=7.70(\mathrm{~d}, J=7.6 \mathrm{~Hz}, 1 \mathrm{H})$, $7.56(\mathrm{~s}, 1 \mathrm{H}), 7.47(\mathrm{t}, J=8.1 \mathrm{~Hz}, 1 \mathrm{H}), 7.25(\mathrm{~d}, J=8.6 \mathrm{~Hz}, 1 \mathrm{H}), 4.88(\mathrm{q}, J=6.8 \mathrm{~Hz}, 1 \mathrm{H}), 1.70(\mathrm{~d}, J=6.9 \mathrm{~Hz}$, $3 \mathrm{H}) .{ }^{13} \mathrm{C}-\mathrm{NMR}\left(67.5 \mathrm{MHz}, \mathrm{CDCl}_{3}\right): \delta=180.1\left(\mathrm{q},{ }^{2} J_{C F}=35.2 \mathrm{~Hz}\right), 177.4,157.7,131.2,130.4,123.7,122.8$, $116.5\left(\mathrm{q},{ }^{1} J_{C F}=291.3 \mathrm{~Hz}\right), 115.7,72.2,18.2$. HRMS (ESI): $m / z$ calculated for $\mathrm{C}_{11} \mathrm{H}_{9} \mathrm{~F}_{3} \mathrm{O}_{4}+\mathrm{H}^{+}\left[\mathrm{M}+\mathrm{H}^{+}\right]$: 263.0531. Found: 263.0543. 
(R)-2-(3-(2,2,2-Trifluoroacetyl)phenoxy)propanoic acid ((R)-36). The similar treatment of methyl $(R)$-2-(3-(2,2,2-trifluoroacetyl)phenoxy)propanoate $(R)-34(288 \mathrm{mg}, 1.04 \mathrm{mmol})$ as that just described gave $(R)$-36 (265 mg, 97\%). [ $[\alpha]_{\mathrm{D}}+28\left(\right.$ c 1, $\left.\mathrm{CHCl}_{3}\right) .{ }^{1} \mathrm{H}-\mathrm{NMR}\left(270 \mathrm{MHz}, \mathrm{CDCl}_{3}\right): \delta=7.59(\mathrm{~d}$, $J=7.6 \mathrm{~Hz}, 1 \mathrm{H}), 7.46(\mathrm{~s}, 1 \mathrm{H}), 7.36(\mathrm{t}, J=8.1 \mathrm{~Hz}, 1 \mathrm{H}), 7.14(\mathrm{~d}, J=8.2 \mathrm{~Hz}, 1 \mathrm{H}), 4.78(\mathrm{q}, J=6.8 \mathrm{~Hz}, 1 \mathrm{H})$, $1.60(\mathrm{~d}, J=6.8 \mathrm{~Hz}, 3 \mathrm{H}) .{ }^{13} \mathrm{C}-\mathrm{NMR}\left(67.5 \mathrm{MHz}, \mathrm{CDCl}_{3}\right): \delta=180.1\left(\mathrm{q},{ }^{2} J_{C F}=35.2 \mathrm{~Hz}\right), 177.3,157.7$, $131.1,130.4,123.6,122.8,116.5\left(q,{ }^{1} J_{C F}=291.6 \mathrm{~Hz}\right), 115.7,72.2,18.2$. HRMS (ESI): $m / z$ calculated for $\mathrm{C}_{11} \mathrm{H}_{9} \mathrm{~F}_{3} \mathrm{O}_{4}+\mathrm{H}^{+}\left[\mathrm{M}+\mathrm{H}^{+}\right]: 263.0531$. Found: 263.0538 .

tert-Butyl (S)-2-(4-(2,2,2-trifluoroacetyl)phenoxy)propanoate ((S)-37). To a solution of (S)-2-(4(2,2,2-trifluoroacetyl)phenoxy)propanoic acid $35(138 \mathrm{mg}, 0.53 \mathrm{mmol})$, potassium carbonate (1.816 $\mathrm{g}, 13.1 \mathrm{mmol})$ and tetrabutylammonium bromide $(169 \mathrm{mg}, 0.53 \mathrm{mmol})$ in $N, N$-dimethylacetamide $(2.6 \mathrm{~mL})$, tert-butyl bromide $(3.416 \mathrm{~g}, 24.9 \mathrm{mmol})$ was added dropwise at $0{ }^{\circ} \mathrm{C}$. The reaction mixture was stirred at $55^{\circ} \mathrm{C}$ for $2.5 \mathrm{~h}$. After cooling to room temperature, the mixture was poured into cold water and extracted with ethyl acetate. The water layer was added $1 \mathrm{M} \mathrm{HCl}$ to make pH 1 and extracted with ethyl acetate, washed with brine, dried, filtrated and concentrated to recover $(S)$-36 (21.8 $\mathrm{mg}, 16 \%)$. The organic layer was washed with $\mathrm{H}_{2} \mathrm{O}$, brine, dried over $\mathrm{MgSO} 4$, filtrated and evaporated. The residue was purified by column chromatography (ethyl acetate/ $n$-hexane, $1: 6$ ) to give (S)-37 (111 mg, 66\%). [ $\alpha]_{\mathrm{D}}-38\left(c 1, \mathrm{CHCl}_{3}\right) .{ }^{1} \mathrm{H}-\mathrm{NMR}\left(270 \mathrm{MHz}, \mathrm{CDCl}_{3}\right): \delta=8.04(\mathrm{~d}, J=8.9 \mathrm{~Hz}, 2 \mathrm{H})$, $6.96(\mathrm{~d}, J=8.9 \mathrm{~Hz}, 2 \mathrm{H}), 4.75(\mathrm{q}, J=6.8 \mathrm{~Hz}, 1 \mathrm{H}), 1.64(\mathrm{~d}, J=6.8 \mathrm{~Hz}, 3 \mathrm{H}), 1.45(\mathrm{~s}, 9 \mathrm{H}) .{ }^{13} \mathrm{C}-\mathrm{NMR}(67.5 \mathrm{MHz}$, $\left.\mathrm{CDCl}_{3}\right): \delta=178.9\left(\mathrm{q}^{2} J_{C F}=35.2 \mathrm{~Hz}\right), 170.1,163.5,132.7,123.3,116.9\left(\mathrm{q},{ }^{1} J_{C F}=291.1 \mathrm{~Hz}\right), 115.2,82.7$, 73.0, 27.9, 18.2. HRMS (ESI): $m / z$ calculated for $\mathrm{C}_{15} \mathrm{H}_{17} \mathrm{~F}_{3} \mathrm{O}_{4}+\mathrm{H}^{+}\left[\mathrm{M}+\mathrm{H}^{+}\right]$: 319.1157. Found: 319.1158 .

tert-Butyl (R)-2-(4-(2,2,2-trifluoroacetyl)phenoxy)propanoate ((R)-37). The similar treatment of (R)-2-(4-(2,2,2-trifluoroacetyl)phenoxy)propanoic acid (R)-35 (428 mg, $1.63 \mathrm{mmol})$ as that just described gave $(R)-37(363 \mathrm{mg}, 70 \%)$. $[\alpha]_{\mathrm{D}}+38\left(c \mathrm{c}, \mathrm{CHCl}_{3}\right) .{ }^{1} \mathrm{H}-\mathrm{NMR}\left(270 \mathrm{MHz}, \mathrm{CDCl}_{3}\right): \delta=7.96(\mathrm{~d}, J=8.9 \mathrm{~Hz}$, $2 \mathrm{H}), 6.88(\mathrm{~d}, J=8.9 \mathrm{~Hz}, 2 \mathrm{H}), 4.67(\mathrm{q}, J=6.8 \mathrm{~Hz}, 1 \mathrm{H}), 1.55(\mathrm{~d}, J=6.8 \mathrm{~Hz}, 3 \mathrm{H}), 1.36(\mathrm{~s}, 9 \mathrm{H}) .{ }^{13} \mathrm{C}-\mathrm{NMR}$ $\left(67.5 \mathrm{MHz} \mathrm{CDCl}_{3}\right): \delta=178.8\left(\mathrm{q}^{2} \mathrm{~J}_{\mathrm{CF}}=34.6 \mathrm{~Hz}\right), 170.1,163.5,132.6,123.2,116.8\left(\mathrm{q},{ }^{1} J_{C F}=291.1 \mathrm{~Hz}\right)$, 115.2, 82.6, 73.0, 27.8, 18.2. HRMS (ESI): $m / z$ calculated for $\mathrm{C}_{15} \mathrm{H}_{17} \mathrm{~F}_{3} \mathrm{O}_{4}+\mathrm{H}^{+}\left[\mathrm{M}+\mathrm{H}^{+}\right]: 319.1157$. Found: 319.1147.

tert-Butyl (S)-2-(3-(2,2,2-trifluoroacetyl)phenoxy)propanoate ((S)-38). The similar treatment of (S)-2-(3-(2,2,2-trifluoroacetyl)phenoxy)propanoic acid (S)-36 (310 mg, $1.18 \mathrm{mmol})$ as that just described

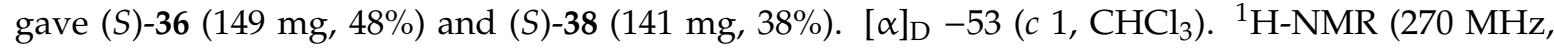
$\left.\mathrm{CDCl}_{3}\right): \delta=7.67(\mathrm{~d}, J=7.8 \mathrm{~Hz}, 1 \mathrm{H}), 7.51(\mathrm{~s}, 1 \mathrm{H}), 7.45(\mathrm{t}, J=7.8 \mathrm{~Hz}, 1 \mathrm{H}), 7.25(\mathrm{~d}, J=7.8 \mathrm{~Hz}, 1 \mathrm{H}), 4.69$ $(\mathrm{q}, J=6.8 \mathrm{~Hz}, 1 \mathrm{H}), 1.62(\mathrm{~d}, J=6.8 \mathrm{~Hz}, 3 \mathrm{H}), 1.45(\mathrm{~s}, 9 \mathrm{H}) .{ }^{13} \mathrm{C}-\mathrm{NMR}\left(67.5 \mathrm{MHz}, \mathrm{CDCl}_{3}\right): \delta=180.2(\mathrm{q}$, $\left.{ }^{2} J_{C F}=34.6 \mathrm{~Hz}\right), 170.6,158.2,131.0,130.2,123.3,123.2,116.6\left(\mathrm{q},{ }^{1} J_{C F}=291.1 \mathrm{~Hz}\right), 115.0,82.5,73.0,27.8$, 18.3. HRMS (ESI): $m / z$ calculated for $\mathrm{C}_{15} \mathrm{H}_{17} \mathrm{~F}_{3} \mathrm{O}_{4}+\mathrm{H}^{+}\left[\mathrm{M}+\mathrm{H}^{+}\right]$: 319.1157. Found: 319.1159 .

tert-Butyl (R)-2-(3-(2,2,2-trifluoroacetyl)phenoxy)propanoate((R)-38). The similar treatment of (R)-2-(3-(2,2,2-trifluoroacetyl)phenoxy)propanoic acid $(R)-36(344 \mathrm{mg}, 1.31 \mathrm{mmol})$ as that just described gave $(R)-36(167 \mathrm{mg}, 48 \%)$ and $\left.(R)-38(153 \mathrm{mg}, 37 \%) .[\alpha]_{\mathrm{D}}+53(c) 1, \mathrm{CHCl}_{3}\right) .{ }^{1} \mathrm{H}-\mathrm{NMR}(270 \mathrm{MHz}$, $\left.\mathrm{CDCl}_{3}\right): \delta=7.68(\mathrm{~d}, J=7.8 \mathrm{~Hz}, 1 \mathrm{H}), 7.51(\mathrm{~s}, 1 \mathrm{H}), 7.45(\mathrm{t}, J=7.8 \mathrm{~Hz}, 1 \mathrm{H}), 7.24(\mathrm{~d}, J=7.8 \mathrm{~Hz}, 1 \mathrm{H}), 4.69$ $(\mathrm{q}, J=6.8 \mathrm{~Hz}, 1 \mathrm{H}), 1.62(\mathrm{~d}, J=6.8 \mathrm{~Hz}, 3 \mathrm{H}), 1.45(\mathrm{~s}, 9 \mathrm{H}) .{ }^{13} \mathrm{C}-\mathrm{NMR}\left(67.5 \mathrm{MHz}, \mathrm{CDCl}_{3}\right): \delta=180.1(\mathrm{q}$, $\left.{ }^{2} J_{C F}=35.2 \mathrm{~Hz}\right), 170.6,158.2,131.0,130.2,123.3,123.2,116.6\left(q,{ }^{1} J_{C F}=291.1 \mathrm{~Hz}\right), 115.0,82.5,73.0,27.8$, 18.3. HRMS (ESI): $m / z$ calculated for $\mathrm{C}_{15} \mathrm{H}_{17} \mathrm{~F}_{3} \mathrm{O}_{4}+\mathrm{H}^{+}\left[\mathrm{M}+\mathrm{H}^{+}\right]$: 319.1157. Found: 319.1183 .

2-(1,3-Dithian-2-yl)phenol 40. Salicylaldehyde $39(0.62 \mathrm{~g}, 5.06 \mathrm{mmol})$ and iodine (130 mg, $0.51 \mathrm{mmol})$ were dissolved in $\mathrm{CH}_{2} \mathrm{Cl}_{2}(25 \mathrm{~mL})$ and then 1,3-propanedithiol $(0.65 \mathrm{~g}, 6.00 \mathrm{mmol})$ was added. After the reaction mixture was stirred at room temperature for $1 \mathrm{~h}$, then quenched aqueous sodium thiosulfate $(0.5 \mathrm{M}, 10 \mathrm{~mL})$. The mixture was extracted with $\mathrm{CH}_{2} \mathrm{Cl}_{2}$, washed with brine, dried over $\mathrm{MgSO}_{4}$, filtrated and concentrated to give 2-(1,3-dithian-2-yl)phenol 40 (1.02 g, 95\%). ${ }^{1} \mathrm{H}-\mathrm{NMR}$ $\left(270 \mathrm{MHz}, \mathrm{CDCl}_{3}\right): \delta=7.29(\mathrm{dd}, J=7.9,1.6 \mathrm{~Hz}, 1 \mathrm{H}), 7.21(\mathrm{td}, J=7.7,1.6 \mathrm{~Hz}, 1 \mathrm{H}), 6.88(\mathrm{dq}, J=7.4,2.0 \mathrm{~Hz}$, $2 \mathrm{H}), 6.33(\mathrm{~s}, 1 \mathrm{H}), 5.40(\mathrm{~s}, 1 \mathrm{H}), 3.07(\mathrm{td}, J=13.6,3.0 \mathrm{~Hz}, 2 \mathrm{H}), 2.91(\mathrm{dt}, J=14.2,3.6 \mathrm{~Hz}, 2 \mathrm{H}), 2.26-2.13(\mathrm{~m}$, 1H), 2.00-1.87 (m, 1H). ${ }^{13} \mathrm{C}-\mathrm{NMR}\left(67.5 \mathrm{MHz} \mathrm{CDCl}_{3}\right): \delta=154.5,130.1,129.1,123.5,120.8,117.3,47.4$, 31.6, 24.8. HRMS (ESI): $m / z$ calculated for $\mathrm{C}_{10} \mathrm{H}_{12} \mathrm{O}_{2} \mathrm{~S}_{2}+\mathrm{H}^{+}\left[\mathrm{M}+\mathrm{H}^{+}\right]:$213.0408. Found: 213.0383 . 
Methyl (S)-2-(2-(1,3-dithian-2-yl)phenoxy)propanoate ((S)-41). 2-(1,3-Dithian-2-yl)phenol 40 $(1.27 \mathrm{~g})$ phenol, methyl D-(+)-lactate $4(0.94 \mathrm{~g}, 8.99 \mathrm{mmol})$ and $\mathrm{PPh}_{3}(1.90 \mathrm{~g}, 7.22 \mathrm{mmol})$ were dissolved in dry $\mathrm{CH}_{2} \mathrm{Cl}_{2}(30 \mathrm{~mL})$. After stirring for $10 \mathrm{~min}$ at $0{ }^{\circ} \mathrm{C}$, DEAD $(1.57 \mathrm{~g}, 9.02 \mathrm{mmol})$ was slowly added. The reaction mixture was stirred overnight at room temperature, and then partitioned between water and $\mathrm{CH}_{2} \mathrm{Cl}_{2}$. The organic layer was washed with brine, dried over $\mathrm{MgSO}_{4}$, filtered and concentrated. The residue was purified by column chromatography (ethyl acetate/ $n$-hexane, 1:9) to give (S)-41 (1.48 g, 98\%). $[\alpha]_{\mathrm{D}}+31\left(c 1, \mathrm{CHCl}_{3}\right) .{ }^{1} \mathrm{H}-\mathrm{NMR}\left(270 \mathrm{MHz}, \mathrm{CDCl}_{3}\right): \delta=7.60(\mathrm{~d}, J=7.6 \mathrm{~Hz}, 1 \mathrm{H}), 7.19(\mathrm{t}, J=7.6 \mathrm{~Hz}$, $1 \mathrm{H}), 7.00(\mathrm{t}, J=7.6 \mathrm{~Hz}, 1 \mathrm{H}), 6.75(\mathrm{~d}, J=7.6 \mathrm{~Hz}, 1 \mathrm{H}), 5.76(\mathrm{~s}, 1 \mathrm{H}), 4.78(\mathrm{q}, J=6.8 \mathrm{~Hz}, 1 \mathrm{H}), 3.75(\mathrm{~s}, 3 \mathrm{H}), 3.11$ $(\mathrm{m}, 2 \mathrm{H}), 2.88(\mathrm{~m}, 2 \mathrm{H}), 2.16(\mathrm{~m}, 1 \mathrm{H}), 1.95(\mathrm{~m}, 1 \mathrm{H}), 1.67(\mathrm{~d}, J=6.8 \mathrm{~Hz}, 3 \mathrm{H}) .{ }^{13} \mathrm{C}-\mathrm{NMR}\left(67.5 \mathrm{MHz}, \mathrm{CDCl}_{3}\right)$ : $\delta=172.3,153.8,129.4,129.2,128.6,122.2,113.4,73.9,52.2,43.8,32.3,32.2,25.3,18.5$. HRMS (ESI): $\mathrm{m} / z$ calculated for $\mathrm{C}_{14} \mathrm{H}_{18} \mathrm{O}_{3} \mathrm{~S}_{2}+\mathrm{Na}^{+}\left[\mathrm{M}+\mathrm{Na}^{+}\right]$: 321.0595. Found: 321.0597.

Methyl (R)-2-(2-(1,3-dithian-2-yl)phenoxy)propanoate ((R)-41). 2-(1,3-Dithian-2-yl)phenol 40 $(1.27 \mathrm{~g})$ as that just described gave $(R)-41(1.47 \mathrm{~g}, 98 \%) .[\alpha]_{\mathrm{D}}-31\left(c 1, \mathrm{CHCl}_{3}\right) .{ }^{1} \mathrm{H}-\mathrm{NMR}(270 \mathrm{MHz}$, $\left.\mathrm{CDCl}_{3}\right): \delta=7.60(\mathrm{~d}, J=7.6 \mathrm{~Hz}, 1 \mathrm{H}), 7.19(\mathrm{t}, J=7.6 \mathrm{~Hz}, 1 \mathrm{H}), 7.00(\mathrm{t}, J=7.6 \mathrm{~Hz}, 1 \mathrm{H}), 6.75(\mathrm{~d}, J=7.6 \mathrm{~Hz}, 1 \mathrm{H})$, $5.76(\mathrm{~s}, 1 \mathrm{H}), 4.78(\mathrm{q}, J=6.8 \mathrm{~Hz}, 1 \mathrm{H}), 3.75(\mathrm{~s}, 3 \mathrm{H}), 3.11(\mathrm{~m}, 2 \mathrm{H}), 2.90(\mathrm{~m}, 2 \mathrm{H}), 2.16(\mathrm{~m}, 1 \mathrm{H}), 1.95(\mathrm{~m}, 1 \mathrm{H})$, $1.67(\mathrm{~d}, J=6.9 \mathrm{~Hz}, 3 \mathrm{H}) .{ }^{13} \mathrm{C}-\mathrm{NMR}\left(67.5 \mathrm{MHz}, \mathrm{CDCl}_{3}\right): \delta=172.3,153.8,129.4,129.2,128.7,122.3,113.4$, 74.0, 52.2, 43.8, 32.3, 32.2, 25.3, 18.6. HRMS (ESI): $m / z$ calculated for $\mathrm{C}_{14} \mathrm{H}_{18} \mathrm{O}_{3} \mathrm{~S}_{2}+\mathrm{Na}^{+}\left[\mathrm{M}+\mathrm{Na}^{+}\right]$: 321.0595. Found: 321.0598 .

(S)-2-(2-(1,3-Dithian-2-yl)phenoxy)propanoic acid (S)-42. Methyl (S)-2-(2-(1,3-dithian-2-yl)phen oxy)propanoate $(S)-41(1.51 \mathrm{~g}, 5.06 \mathrm{mmol})$ was dissolved in $\mathrm{MeOH}(30 \mathrm{~mL})$ and $\mathrm{H}_{2} \mathrm{O}(3.3 \mathrm{~mL})$, and then $\mathrm{K}_{2} \mathrm{CO}_{3}(700 \mathrm{mg}, 5.06 \mathrm{mmol})$ was added. After the reaction mixture was stirred at reflux for $2 \mathrm{~h}$, cooled to room temperature and then partitioned between ethyl acetate and water. The water layer was acidified by $1 \mathrm{M} \mathrm{HCl}$ aq and extracted by ethyl acetate. The organic layer was washed by $\mathrm{H}_{2} \mathrm{O}$ and brine, and dried over $\mathrm{MgSO}_{4}$, filtrated and concentrated to give (S)-42 (1.63 g, quant). $[\alpha]_{\mathrm{D}}+9$ (c 1, $\left.\mathrm{CHCl}_{3}\right) .{ }^{1} \mathrm{H}-\mathrm{NMR}\left(270 \mathrm{MHz}, \mathrm{CDCl}_{3}\right): \delta=7.55(\mathrm{~d}, J=7.6 \mathrm{~Hz}, 1 \mathrm{H}), 7.26(\mathrm{t}, J=7.6 \mathrm{~Hz}, 1 \mathrm{H}), 7.03(\mathrm{t}$, $J=7.6 \mathrm{~Hz}, 1 \mathrm{H}), 6.82(\mathrm{~d}, J=7.6 \mathrm{~Hz}, 1 \mathrm{H}), 5.62(\mathrm{~s}, 1 \mathrm{H}), 4.88(\mathrm{q}, J=6.8 \mathrm{~Hz}, 1 \mathrm{H}), 3.12(\mathrm{~m}, 2 \mathrm{H}), 2.92(\mathrm{~m}$, 2H), $2.19(\mathrm{~m}, 1 \mathrm{H}), 1.96(\mathrm{~m}, 1 \mathrm{H}), 1.71(\mathrm{~d}, J=6.8 \mathrm{~Hz}, 3 \mathrm{H}) .{ }^{13} \mathrm{C}-\mathrm{NMR}\left(67.5 \mathrm{MHz}, \mathrm{CDCl}_{3}\right): \delta=174.9$, 153.3, 129.6, 129.5, 128.1, 122.6, 112.8, 73.0, 45.4, 32.2, 32.1, 25.3, 18.0. HRMS (ESI): $m / z$ calculated for $\mathrm{C}_{13} \mathrm{H}_{16} \mathrm{O}_{3} \mathrm{~S}_{2}+\mathrm{H}^{+}\left[\mathrm{M}+\mathrm{H}^{+}\right.$]: 285.0619. Found: 285.0591.

(R)-2-(2-(1,3-dithian-2-yl)phenoxy)propanoic acid $(R)-42$. The similar treatment of methyl (R)-2-(2-(1,3-dithian-2-yl)phenoxy)propanoate $(R)-41(1.56 \mathrm{~g}, 5.22 \mathrm{mmol})$ as that just described gave (S)-42 (1.69 g, quant). $[\alpha]_{\mathrm{D}}-9\left(c 1, \mathrm{CHCl}_{3}\right) .{ }^{1} \mathrm{H}-\mathrm{NMR}\left(270 \mathrm{MHz}, \mathrm{CDCl}_{3}\right): \delta=7.56(\mathrm{~d}, J=7.6 \mathrm{~Hz}, 1 \mathrm{H})$, $7.24(\mathrm{t}, J=7.6 \mathrm{~Hz}, 1 \mathrm{H}), 7.02(\mathrm{t}, J=7.6 \mathrm{~Hz}, 1 \mathrm{H}), 6.81(\mathrm{~d}, J=7.6 \mathrm{~Hz}, 1 \mathrm{H}), 5.65(\mathrm{~s}, 1 \mathrm{H}), 4.85(\mathrm{q}, J=6.8 \mathrm{~Hz}$, $1 \mathrm{H}), 3.11(\mathrm{~m}, 2 \mathrm{H}), 2.90(\mathrm{~m}, 2 \mathrm{H}), 2.18(\mathrm{~m}, 1 \mathrm{H}), 1.95(\mathrm{~m}, 1 \mathrm{H}), 1.71(\mathrm{~d}, J=6.8 \mathrm{~Hz}, 3 \mathrm{H}) .{ }^{13} \mathrm{C}-\mathrm{NMR}(67.5 \mathrm{MHz}$, $\mathrm{CDCl}_{3}$ ): $\delta=175.8,153.3,129.5,129.5,128.2,122.5,112.9,73.1,45.0,32.2,32.1,25.2,18.1$. HRMS (ESI): $m / z$ calculated for $\mathrm{C}_{13} \mathrm{H}_{16} \mathrm{O}_{3} \mathrm{~S}_{2}+\mathrm{H}^{+}\left[\mathrm{M}+\mathrm{H}^{+}\right]$: 285.0619. Found: 285.0608 .

tert-Butyl (S)-2-(2-(1,3-dithian-2-yl)phenoxy)propanoate (S)-43. To a solution of (S)-2-(2-(1,3-dithian-2-yl)phenoxy)propanoic acid (1.63 g, $5.72 \mathrm{mmol})$ in $\mathrm{N}, \mathrm{N}$-dimethylacetamide $(29 \mathrm{~mL})$ in the presence of potassium carbonate $(19.8 \mathrm{~g}, 143 \mathrm{mmol})$ and tetrabutylammonium bromide $(1.85 \mathrm{~g}, 5.73 \mathrm{mmol})$ at $0{ }^{\circ} \mathrm{C}$, tert-butyl bromide $(37.6 \mathrm{~g}, 274 \mathrm{mmol})$ was added dropwise and the reaction mixture was stirred at $55^{\circ} \mathrm{C}$ for $2.5 \mathrm{~h}$. After cooling to room temperature, the mixture was added into cold water and extracted with ethyl acetate. The organic layer was washed with $\mathrm{H}_{2} \mathrm{O}$, brine, dried over $\mathrm{MgSO}_{4}$, filtrated and evaporated. The residue was purified by column chromatography (ethyl acetate $/ n$-hexane, 1:6) to give (S)-43 (1.61 g, 83\%). $[\alpha]_{\mathrm{D}}+25\left(c 1, \mathrm{CHCl}_{3}\right) .{ }^{1} \mathrm{H}-\mathrm{NMR}\left(270 \mathrm{MHz}, \mathrm{CDCl}_{3}\right)$ : $\delta=7.59(\mathrm{~d}, J=7.8 \mathrm{~Hz}, 1 \mathrm{H}), 7.18(\mathrm{t}, J=7.8 \mathrm{~Hz}, 1 \mathrm{H}), 6.97(\mathrm{t}, J=7.8 \mathrm{~Hz}, 1 \mathrm{H}), 6.74(\mathrm{~d}, J=7.8 \mathrm{~Hz}, 1 \mathrm{H}), 5.75(\mathrm{~s}$, $1 \mathrm{H}), 4.64(\mathrm{q}, J=6.8 \mathrm{~Hz}, 1 \mathrm{H}), 3.11(\mathrm{~m}, 2 \mathrm{H}), 2.88(\mathrm{~m}, 2 \mathrm{H}), 2.16(\mathrm{~m}, 1 \mathrm{H}), 1.93(\mathrm{~m}, 1 \mathrm{H}), 1.63(\mathrm{~d}, J=6.8 \mathrm{~Hz}, 3 \mathrm{H})$, $1.43(\mathrm{~s}, 9 \mathrm{H}) .{ }^{13} \mathrm{C}-\mathrm{NMR}\left(67.5 \mathrm{MHz}, \mathrm{CDCl}_{3}\right): \delta=171.0,153.9,129.3,129.0,128.3,121.8,112.8,81.8,73.9$, 43.8, 32.3, 32.2, 27.9, 25.4, 18.4. HRMS (ESI): $m / z$ calculated for $\mathrm{C}_{17} \mathrm{H}_{24} \mathrm{O}_{3} \mathrm{~S}_{2}+\mathrm{H}^{+}\left[\mathrm{M}+\mathrm{H}^{+}\right]: 341.1245$. Found: 341.1237. 
tert-Butyl (R)-2-(2-(1,3-dithian-2-yl)phenoxy)propanoate $(R)-43$. The similar treatment of (R)-2-(2-(1,3-dithian-2-yl)phenoxy)propanoic acid $42(1.69 \mathrm{~g}, 5.93 \mathrm{mmol})$ as that just described gave $(R)-43(1.65 \mathrm{~g}, 82 \%) .[\alpha]_{\mathrm{D}}-25\left(c 1, \mathrm{CHCl}_{3}\right) .{ }^{1} \mathrm{H}-\mathrm{NMR}\left(270 \mathrm{MHz}, \mathrm{CDCl}_{3}\right): \delta=7.59(\mathrm{~d}, J=7.8 \mathrm{~Hz}, 1 \mathrm{H})$, $7.18(\mathrm{t}, J=7.8 \mathrm{~Hz}, 1 \mathrm{H}), 6.97(\mathrm{t}, J=7.8 \mathrm{~Hz}, 1 \mathrm{H}), 6.73(\mathrm{~d}, J=7.8 \mathrm{~Hz}, 1 \mathrm{H}), 5.75(\mathrm{~s}, 1 \mathrm{H}), 4.64(\mathrm{q}, J=6.8 \mathrm{~Hz}$, $1 \mathrm{H}), 3.11(\mathrm{~m}, 2 \mathrm{H}), 2.88(\mathrm{~m}, 2 \mathrm{H}), 2.16(\mathrm{~m}, 1 \mathrm{H}), 1.95(\mathrm{~m}, 1 \mathrm{H}), 1.63(\mathrm{~d}, J=6.8 \mathrm{~Hz}, 3 \mathrm{H}), 1.43(\mathrm{~s}, 9 \mathrm{H}) .{ }^{13} \mathrm{C}-\mathrm{NMR}$ $\left(67.5 \mathrm{MHz}_{2} \mathrm{CDCl}_{3}\right): \delta=171.0,153.9,129.3,129.0,128.3,121.8,112.8,81.8,73.9,43.8,32.4,32.2,27.9,25.4$, 18.4. HRMS (ESI): $m / z$ calculated for $\mathrm{C}_{17} \mathrm{H}_{24} \mathrm{O}_{3} \mathrm{~S}_{2}+\mathrm{H}^{+}\left[\mathrm{M}+\mathrm{H}^{+}\right]$: 341.1245. Found: 341.1239 .

tert-Butyl (S)-2-(2-formylphenoxy)propanoate (S)-44. tert-Butyl (S)-2-(2-(1,3-dithian-2-yl)pheno xy)propanoate $(S)-43(94.3 \mathrm{mg}, 0.28 \mathrm{mmol})$ and sodium hydrogen carbonate $(465 \mathrm{mg}, 5.54 \mathrm{mmol})$ were dissolved in acetonitrile $(10 \mathrm{~mL})$ and water $(2 \mathrm{~mL})$, and then iodomethane $(392 \mathrm{mg}, 2.8 \mathrm{mmol})$ was added. After the reaction mixture was stirred at room temperature for $24 \mathrm{~h}$, iodomethane (196 mg, $1.4 \mathrm{mmol}$ ) was added. After stirred at room temperature for $24 \mathrm{~h}$, the reaction mixture extracted with ethyl acetate. The organic layer was washed with brine, dried over MgSO4, filtrated and concentrated. The residue was purified by column chromatography (ethyl acetate/n-hexane, 1:6) to give (S)-44 (52.3 mg, 78\%). [ $\alpha]_{\mathrm{D}}+14\left(\mathrm{c} 1, \mathrm{CHCl}_{3}\right) .{ }^{1} \mathrm{H}-\mathrm{NMR}\left(270 \mathrm{MHz}, \mathrm{CDCl}_{3}\right): \delta=10.57(\mathrm{~s}, 1 \mathrm{H}), 7.85(\mathrm{~d}, \mathrm{~J}=7.9 \mathrm{~Hz}$, $1 \mathrm{H}), 7.49(\mathrm{t}, J=7.9 \mathrm{~Hz}, 1 \mathrm{H}), 7.04(\mathrm{t}, J=7.9 \mathrm{~Hz}, 1 \mathrm{H}), 6.85(\mathrm{~d}, J=7.9 \mathrm{~Hz}, 1 \mathrm{H}), 4.77(\mathrm{q}, J=6.8 \mathrm{~Hz}, 1 \mathrm{H}), 1.66$ $(\mathrm{d}, J=6.8 \mathrm{~Hz}, 3 \mathrm{H}), 1.42(\mathrm{~s}, 9 \mathrm{H}) .{ }^{13} \mathrm{C}-\mathrm{NMR}\left(67.5 \mathrm{MHz}, \mathrm{CDCl}_{3}\right): \delta=189.7,170.4,160.2,135.5,128.2,125.4$, 121.4, 113.2, 82.3, 73.5, 27.8, 18.2. HRMS (ESI): $m / z$ calculated for $\mathrm{C}_{14} \mathrm{H}_{18} \mathrm{O}_{4}+\mathrm{H}^{+}\left[\mathrm{M}+\mathrm{H}^{+}\right]: 251.1283$. Found: 251.1312 .

tert-Butyl (R)-2-(2-formylphenoxy)propanoate $(R)-44$. The similar treatment of tert-butyl $(R)-2-(2-(1,3-$ dithian-2-yl)phenoxy)propanoate $(R)-43(156 \mathrm{mg}, 0.46 \mathrm{mmol})$ as that just described gave $(R)-44(90.4 \mathrm{mg}, 79 \%) .[\alpha]_{\mathrm{D}}-14\left(c 1, \mathrm{CHCl}_{3}\right) .{ }^{1} \mathrm{H}-\mathrm{NMR}\left(270 \mathrm{MHz}, \mathrm{CDCl}_{3}\right): \delta=10.58(\mathrm{~s}, 1 \mathrm{H})$, $7.84(\mathrm{~d}, J=7.6 \mathrm{~Hz}, 1 \mathrm{H}), 7.50(\mathrm{t}, J=7.6 \mathrm{~Hz}, 1 \mathrm{H}), 7.04(\mathrm{t}, J=7.6 \mathrm{~Hz}, 1 \mathrm{H}), 6.85(\mathrm{~d}, J=7.6 \mathrm{~Hz}, 1 \mathrm{H}), 4.78$ $(\mathrm{q}, J=6.8 \mathrm{~Hz}, 1 \mathrm{H}), 1.66(\mathrm{~d}, J=6.8 \mathrm{~Hz}, 3 \mathrm{H}), 1.42(\mathrm{~s}, 9 \mathrm{H}) .{ }^{13} \mathrm{C}-\mathrm{NMR}\left(67.5 \mathrm{MHz}, \mathrm{CDCl}_{3}\right): \delta=189.7$, $170.4,160.2,135.5,128.2,125.4,121.4,113.2,82.3,73.5,27.8,18.2$. HRMS (ESI): $m / z$ calculated for $\mathrm{C}_{14} \mathrm{H}_{18} \mathrm{O}_{4}+\mathrm{H}^{+}\left[\mathrm{M}+\mathrm{H}^{+}\right]:$251.1283. Found: 251.1292 .

tert-Butyl (S)-2-(2-(2,2,2-trifluoroacetyl)phenoxy)propanoate (S)-45. To the solution of tert-butyl (S)-2-(2-formylphenoxy)propanoate $(S)-44(591 \mathrm{mg}, 2.04 \mathrm{mmol})$ in dimethylacetamide $(7.9 \mathrm{~mL})$, (trifluoromethyl)trimetylsilane $(579 \mathrm{mg}, 4.07 \mathrm{mmol})$ and potassium carbonate $(16.3 \mathrm{mg}, 0.118 \mathrm{mmol})$ were added. The reaction mixture was and stirred at room temperature for $4 \mathrm{~h}$ and treated with $1 \mathrm{M} \mathrm{HCl}$ $(1 \mathrm{~mL})$ at room temperature for $4 \mathrm{~h}$, then extracted with ethyl acetate. The organic layer was washed with brine twice, dried over MgSO4, filtrated and concentrated to afford crude material. To crude phenylethanol derivative (784 mg) was dissolved in $\mathrm{CH}_{2} \mathrm{Cl}_{2}(13 \mathrm{~mL})$, Dess-Martin periodinane (1.096 g, $2.58 \mathrm{mmol}$ ) was added at room temperature. The reaction mixture was stirred at room temperature for $3 \mathrm{~h}$, then washed with water and brine. The organic layer was dried over $\mathrm{MgSO}_{4}$, filtrated and concentrated. The residue was subjected to column chromatography (hexane/AcOEt, 8:1) to give (S)-45 (636 mg, 85\%). [ $\alpha]_{\mathrm{D}}+25\left(\mathrm{c} 1, \mathrm{CHCl}_{3}\right) .{ }^{1} \mathrm{H}-\mathrm{NMR}\left(270 \mathrm{MHz}, \mathrm{CDCl}_{3}\right): \delta=7.54(\mathrm{~d}, J=7.6 \mathrm{~Hz}$, $1 \mathrm{H}), 7.41(\mathrm{t}, J=7.6 \mathrm{~Hz}, 1 \mathrm{H}), 6.95(\mathrm{t}, J=7.6 \mathrm{~Hz}, 1 \mathrm{H}), 6.71(\mathrm{~d}, J=7.6 \mathrm{~Hz}, 1 \mathrm{H}), 4.61(\mathrm{q}, J=6.8 \mathrm{~Hz}, 1 \mathrm{H})$, $1.51(\mathrm{~d}, J=6.8 \mathrm{~Hz}, 3 \mathrm{H}), 1.30(\mathrm{~s}, 9 \mathrm{H}) .{ }^{13} \mathrm{C}-\mathrm{NMR}\left(67.5 \mathrm{MHz}, \mathrm{CDCl}_{3}\right): \delta=183.6\left(\mathrm{q},{ }^{2} J_{C F}=37.4 \mathrm{~Hz}\right), 170.2$, $157.5,135.3,131.5,122.6,121.2,116.1\left(q,{ }^{1} J_{C F}=290.5 \mathrm{~Hz}\right), 112.8,82.4,73.7,27.8,17.8$. HRMS (ESI): $m / z$ calculated for $\mathrm{C}_{15} \mathrm{H}_{17} \mathrm{~F}_{3} \mathrm{O}_{4}+\mathrm{H}^{+}\left[\mathrm{M}+\mathrm{H}^{+}\right]$: 319.1157. Found: 319.1171 .

tert-Butyl (R)-2-(2-(2,2,2-trifluoroacetyl)phenoxy)propanoate $(R)-45$. The similar treatment of tert-butyl (R)-2-(2-formylphenoxy)propanoate $(R)-44(577 \mathrm{mg}, 2.30 \mathrm{mmol})$ as that just described gave (R)-45 (651 mg, 89\%). [ $\alpha]_{\mathrm{D}}-25\left(\mathrm{c} 1, \mathrm{CHCl}_{3}\right) .{ }^{1} \mathrm{H}-\mathrm{NMR}\left(270 \mathrm{MHz}, \mathrm{CDCl}_{3}\right): \delta=7.65(\mathrm{~d}, J=7.6 \mathrm{~Hz}$, $1 \mathrm{H}), 7.53(\mathrm{t}, J=7.6 \mathrm{~Hz}, 1 \mathrm{H}), 7.06(\mathrm{t}, J=7.6 \mathrm{~Hz}, 1 \mathrm{H}), 6.83(\mathrm{~d}, J=7.6 \mathrm{~Hz}, 1 \mathrm{H}), 4.72(\mathrm{q}, J=6.8 \mathrm{~Hz}, 1 \mathrm{H})$, $1.62(\mathrm{~d}, J=6.8 \mathrm{~Hz}, 3 \mathrm{H}), 1.41(\mathrm{~s}, 9 \mathrm{H}) .{ }^{13} \mathrm{C}-\mathrm{NMR}\left(67.5 \mathrm{MHz} \mathrm{CDCl}_{3}\right): \delta=183.6\left(\mathrm{q},{ }^{2} J_{C F}=37.4 \mathrm{~Hz}\right), 170.2$, $157.5,135.3,131.6,122.6,121.2,116.1\left(\mathrm{q},{ }^{1} J_{C F}=290.5 \mathrm{~Hz}\right), 112.8,82.4,73.7,27.8,17.8$. HRMS (ESI): $m / z$ calculated for $\mathrm{C}_{15} \mathrm{H}_{17} \mathrm{~F}_{3} \mathrm{O}_{4}+\mathrm{H}^{+}\left[\mathrm{M}+\mathrm{H}^{+}\right]$: 319.1157. Found: 319.1141 .

tert-Butyl (S)-2-(4-(2,2,2-trifluoro-1-(hydroxyimino)ethyl)phenoxy)propanoate ((S)-46). A solution of tert-butyl (S)-2-(4-(2,2,2-trifluoroacetyl)phenoxy)propanoate (S)-37 (252 mg, $0.79 \mathrm{mmol})$ and 
hydroxylamine hydrochloride $(60.7 \mathrm{mg}, 0.87 \mathrm{mmol})$ in ethanol $(0.44 \mathrm{~mL})$ and dry pyridine $(0.79 \mathrm{~mL})$ was heated at $60^{\circ} \mathrm{C}$ for $8 \mathrm{~h}$. The reaction mixture was partitioned between water and ether, and the organic layer was washed with $1 \mathrm{M} \mathrm{HCl}$, saturated $\mathrm{NaHCO}_{3}$ and brine. The organic layer was dried over $\mathrm{MgSO}_{4}$, filtrated and concentrated. The residue was purified by column chromatography (ethyl acetate $/ n$-hexane, 1:6) to give (S)-46 (275 mg, quant). The product was mixture of syn- and anti-isomers. $[\alpha]_{\mathrm{D}}-38\left(\mathrm{c} 1, \mathrm{CHCl}_{3}\right) .{ }^{1} \mathrm{H}-\mathrm{NMR}\left(270 \mathrm{MHz}, \mathrm{CDCl}_{3}\right): \delta=8.89$ and $8.75(\mathrm{~s}, 1 \mathrm{H}), 7.44$ and $7.34(\mathrm{~d} \times 2$, $J=8.9 \mathrm{~Hz}, 2 \mathrm{H}), 6.86$ and $6.81(\mathrm{~d} \times 2, J=8.9 \mathrm{~Hz}, 2 \mathrm{H}), 4.60$ and $4.59(\mathrm{q} \times 2, J=6.8 \mathrm{~Hz}, 1 \mathrm{H}), 1.53(\mathrm{~d}$, $J=6.8 \mathrm{~Hz}, 3 \mathrm{H}), 1.37(\mathrm{~s}, 9 \mathrm{H}) .{ }^{13} \mathrm{C}-\mathrm{NMR}\left(67.5 \mathrm{MHz}, \mathrm{CDCl}_{3}\right): \delta=171.0,159.3,146.9\left(\mathrm{q},{ }^{2} J_{\mathrm{CF}}=32.4 \mathrm{~Hz}\right)$, $130.5,120.8\left(\mathrm{q},{ }^{1} J_{C F}=274.9 \mathrm{~Hz}\right), 118.6,114.9,82.4,72.9,27.9,18.3$. HRMS (ESI): $\mathrm{m} / \mathrm{z}$ calculated for $\mathrm{C}_{15} \mathrm{H}_{18} \mathrm{~F}_{3} \mathrm{NO}_{4}+\mathrm{H}^{+}\left[\mathrm{M}+\mathrm{H}^{+}\right]$: 334.1266. Found: 334.1256.

tert-Butyl (R)-2-(4-(2,2,2-trifluoro-1-(hydroxyimino)ethyl)phenoxy)propanoate ((R)-46). The similar treatment of tert-butyl (R)-2-(4-(2,2,2-trifluoroacetyl)phenoxy)propanoate $(R)-37$ (459 mg, $1.44 \mathrm{mmol})$ as that just described gave (R)-46 (490 mg, quant). $[\alpha]_{\mathrm{D}}+38\left(\right.$ ( $\left.1, \mathrm{CHCl}_{3}\right) .{ }^{1} \mathrm{H}-\mathrm{NMR}\left(270 \mathrm{MHz}, \mathrm{CDCl}_{3}\right)$ : $\delta=8.36$ and $8.19(\mathrm{~s}, 1 \mathrm{H}), 7.50$ and $7.42(\mathrm{~d} \times 2, J=7.8 \mathrm{~Hz}, 2 \mathrm{H}), 6.93$ and $6.88(\mathrm{~d} \times 2, J=8.9 \mathrm{~Hz}, 2 \mathrm{H}), 4.67$ and $4.66(\mathrm{q} \times 2, J=6.8 \mathrm{~Hz}, 1 \mathrm{H}), 1.60(\mathrm{~d}, J=6.8 \mathrm{~Hz}, 3 \mathrm{H}), 1.44(\mathrm{~s}, 9 \mathrm{H}) .{ }^{13} \mathrm{C}-\mathrm{NMR}\left(67.5 \mathrm{MHz}, \mathrm{CDCl}_{3}\right)$ : $\delta=171.0,159.3,146.9\left(\mathrm{q},{ }^{2} J_{C F}=32.4 \mathrm{~Hz}\right), 130.5,120.8\left(\mathrm{q},{ }^{1} J_{C F}=274.9 \mathrm{~Hz}\right), 118.6,114.9,82.4,72.9,27.9$, 18.3. HRMS (ESI): $m / z$ calculated for $\mathrm{C}_{15} \mathrm{H}_{18} \mathrm{~F}_{3} \mathrm{NO}_{4}+\mathrm{H}^{+}\left[\mathrm{M}+\mathrm{H}^{+}\right]$: 334.1266. Found: 334.1236.

tert-Butyl (S)-2-(3-(2,2,2-trifluoro-1-(hydroxyimino)ethyl)phenoxy)propanoate ((S)-47). The similar treatment of tert-butyl (S)-2-(3-(2,2,2-trifluoroacetyl)phenoxy)propanoate $(S)-38(81.7 \mathrm{mg}, 0.26 \mathrm{mmol})$ as that just described gave (S)-47 (85.7 mg, quant). $[\alpha]_{\mathrm{D}}-40\left(\right.$ ( $\left.1, \mathrm{CHCl}_{3}\right) .{ }^{1} \mathrm{H}-\mathrm{NMR}\left(270 \mathrm{MHz}, \mathrm{CDCl}_{3}\right)$ : $\delta=7.36$ and $7.30 \mathrm{t} \times 2, J=7.8 \mathrm{~Hz}, 1 \mathrm{H}), 7.09(\mathrm{~d}, J=7.8 \mathrm{~Hz}, 1 \mathrm{H}), 6.97(\mathrm{~m}, 2 \mathrm{H}), 4.66(\mathrm{q}, J=6.8 \mathrm{~Hz}, 1 \mathrm{H})$, 1.60 and $1.59(\mathrm{~d} \times 2, J=6.8 \mathrm{~Hz}, 3 \mathrm{H}), 1.43$ and $1.42(\mathrm{~s} \times 2,9 \mathrm{H}) .{ }^{13} \mathrm{C}-\mathrm{NMR}\left(67.5 \mathrm{MHz}, \mathrm{CDCl}_{3}\right): \delta=171.3$, 157.6, $147.3\left(\mathrm{q},{ }^{2} J_{C F}=32.4 \mathrm{~Hz}\right), 129.7$ and 129.6, 127.2, 121.5, $120.6\left(\mathrm{q},{ }^{1} J_{C F}=274.3 \mathrm{~Hz}\right), 117.4$ and 117.0, 115.4 and $115.2,82.5,73.1,27.8,18.4$. HRMS (ESI): $m / z$ calculated for $\mathrm{C}_{15} \mathrm{H}_{18} \mathrm{~F}_{3} \mathrm{NO}_{4}+\mathrm{H}^{+}\left[\mathrm{M}+\mathrm{H}^{+}\right]$: 334.1266. Found: 334.1265.

tert-Butyl (R)-2-(3-(2,2,2-trifluoro-1-(hydroxyimino)ethyl)phenoxy)propanoate ((R)-47). The similar treatment of tert-butyl (R)-2-(3-(2,2,2-trifluoroacetyl)phenoxy)propanoate $(R)-38(97.2 \mathrm{mg}, 0.31 \mathrm{mmol})$ as that just described gave $(R)-47(86.6 \mathrm{mg}, 85 \%) .[\alpha]_{\mathrm{D}}+40\left(c 1, \mathrm{CHCl}_{3}\right) .{ }^{1} \mathrm{H}-\mathrm{NMR}\left(270 \mathrm{MHz}, \mathrm{CDCl}_{3}\right)$ : $\delta=7.37$ and $7.30(\mathrm{t} \times 2, J=7.8 \mathrm{~Hz}, 2 \mathrm{H}), 7.08(\mathrm{~d}, J=7.8 \mathrm{~Hz}, 1 \mathrm{H}), 6.97(\mathrm{~m}, 2 \mathrm{H}), 4.65(\mathrm{q}, J=6.8 \mathrm{~Hz}, 1 \mathrm{H})$, $1.60(\mathrm{~d}, J=6.8 \mathrm{~Hz}, 3 \mathrm{H}), 1.43$ and $1.42(\mathrm{~s} \times 2,9 \mathrm{H}) .{ }^{13} \mathrm{C}-\mathrm{NMR}\left(67.5 \mathrm{MHz}, \mathrm{CDCl}_{3}\right): \delta=171.1,157.6,147.6$ $\left(\mathrm{q},{ }^{2} J_{C F}=32.4 \mathrm{~Hz}\right), 129.7$ and 129.5, 127.1, 121.4, $120.5\left(\mathrm{q},{ }^{1} J_{C F}=274.9 \mathrm{~Hz}\right), 117.4$ and 117.1, 115.3 and 115.1, 82.3, 73.1, 27.8, 18.4. HRMS (ESI): $m / z$ calculated for $\mathrm{C}_{15} \mathrm{H}_{18} \mathrm{~F}_{3} \mathrm{NO}_{4}+\mathrm{H}^{+}\left[\mathrm{M}+\mathrm{H}^{+}\right]: 334.1266$. Found: 334.1257.

tert-Butyl (S)-2-(2-(2,2,2-trifluoro-1-(hydroxyimino)ethyl)phenoxy)propanoate ((S)-48). The similar treatment of tert-butyl (S)-2-(2-(2,2,2-trifluoroacetyl)phenoxy)propanoate $(S)-45$ (309 $\mathrm{mg}, 0.97 \mathrm{mmol}$ ) as that just described gave (S)-48 (331 mg, quant). $[\alpha]_{\mathrm{D}}+8\left(c 1, \mathrm{CHCl}_{3}\right) .{ }^{1} \mathrm{H}-\mathrm{NMR}\left(270 \mathrm{MHz}, \mathrm{CDCl}_{3}\right)$ : $\delta=7.37$ and $7.36(\mathrm{t} \times 2, J=7.6 \mathrm{~Hz}, 1 \mathrm{H}), 7.27$ and $7.21(\mathrm{~d} \times 2, J=7.6 \mathrm{~Hz}, 1 \mathrm{H}), 7.03$ and $6.99(\mathrm{t} \times 2, J=7.6 \mathrm{~Hz}$, $1 \mathrm{H}), 6.80$ and $6.75(\mathrm{~d} \times 2, J=7.6 \mathrm{~Hz}, 1 \mathrm{H}), 4.62(\mathrm{q}, J=6.8 \mathrm{~Hz}, 1 \mathrm{H}), 1.57$ and $1.54(\mathrm{~d} \times 2, J=6.8 \mathrm{~Hz}, 3 \mathrm{H})$, $1.41(\mathrm{~s}, 9 \mathrm{H}) .{ }^{13} \mathrm{C}-\mathrm{NMR}\left(67.5 \mathrm{MHz}, \mathrm{CDCl}_{3}\right): \delta=171.2$ and 171.0, 156.5, 155.1, 147.6 and $146.7(\mathrm{q} \times 2$, $\left.{ }^{2} J_{C F}=33.5 \mathrm{~Hz}\right), 131.6,131.0,129.8,121.0,117.9\left(\mathrm{q},{ }^{1} J_{C F}=287.2 \mathrm{~Hz}\right), 116.3,112.2$ and $111.7,82.3$ and 82.2, 73.5 and 73.4, 27.8, 18.2 and 18.0. HRMS (ESI): $\mathrm{m} / z$ calculated for $\mathrm{C}_{15} \mathrm{H}_{18} \mathrm{~F}_{3} \mathrm{NO}_{4}+\mathrm{H}^{+}\left[\mathrm{M}+\mathrm{H}^{+}\right]$: 334.1266. Found: 334.1246.

tert-Butyl (R)-2-(2-(2,2,2-trifluoro-1-(hydroxyimino)ethyl)phenoxy)propanoate ((R)-48). The similar treatment of tert-butyl (R)-2-(2-(2,2,2-trifluoroacetyl)phenoxy)propanoate $(R)-45(291 \mathrm{mg}, 0.92 \mathrm{mmol})$ as that just described gave $(R)-48(299 \mathrm{mg}, 98 \%) . \quad[\alpha]_{\mathrm{D}}-8\left(c \quad 1, \mathrm{CHCl}_{3}\right) .{ }^{1} \mathrm{H}-\mathrm{NMR}(270 \mathrm{MHz}$, $\left.\mathrm{CDCl}_{3}\right): \delta=7.37(\mathrm{~m}, 1 \mathrm{H}), 7.27$ and $7.21(\mathrm{~d}, J=7.6 \mathrm{~Hz}, 1 \mathrm{H}), 7.03$ and $6.98(\mathrm{t}, J=7.6 \mathrm{~Hz}, 1 \mathrm{H}), 6.80$ and $6.74(\mathrm{~d}, J=7.6 \mathrm{~Hz}, 1 \mathrm{H}), 4.62(\mathrm{q}, J=6.8 \mathrm{~Hz}, 1 \mathrm{H}), 1.57$ and $1.54(\mathrm{~d}, J=6.8 \mathrm{~Hz}, 3 \mathrm{H}), 1.41(\mathrm{~s}, 9 \mathrm{H}) .{ }^{13} \mathrm{C}-\mathrm{NMR}$ $\left(67.5 \mathrm{MHz}, \mathrm{CDCl}_{3}\right): \delta=171.2$ and 171.1, 156.5, 155.1, 147.5 and $146.5\left(\mathrm{q} \times 2,{ }^{2} J_{\mathrm{CF}}=34.1 \mathrm{~Hz}\right), 131.6$, 131.0, 129.8, 121.0, 120.5 and $118.2\left(\mathrm{q} \times 2,{ }^{1} J_{C F}=287.2 \mathrm{~Hz}\right), 116.3,112.2$ and $111.7,82.3$ and $82.2,73.5$ 
and 73.4, 27.8, 18.1 and 18.0. HRMS (ESI): $m / z$ calculated for $\mathrm{C}_{15} \mathrm{H}_{18} \mathrm{~F}_{3} \mathrm{NO}_{4}+\mathrm{H}^{+}\left[\mathrm{M}+\mathrm{H}^{+}\right]: 334.1266$. Found: 334.1261 .

tert-Butyl (S)-2-(4-(2,2,2-trifluoro-1-((tosyloxy)imino)ethyl)phenoxy)propanoate ((S)-49). tert-Butyl (S)-2-(4-(2,2,2-trifluoro-1-(hydroxyimino)ethyl)phenoxy)propanoate $(S)-46 \quad(268 \mathrm{mg}, 0.80 \mathrm{mmol}$ ), triethylamine $(203 \mathrm{mg}, 2.01 \mathrm{mmol})$ and DMAP $(4.9 \mathrm{mg}, 0.040 \mathrm{mmol})$ were suspended in $\mathrm{CH}_{2} \mathrm{Cl}_{2}$ $(1.5 \mathrm{~mL})$ at $0{ }^{\circ} \mathrm{C}$. $p$-Toluenesulfonyl chloride $(168 \mathrm{mg}, 0.88 \mathrm{mmol})$ was added at $0{ }^{\circ} \mathrm{C}$. The reaction mixture was stirred at room temperature for $45 \mathrm{~min}$, then washed with water. The organic layer was dried over $\mathrm{MgSO}_{4}$, filtrated and concentrated to give (S)-49 (418 mg, quant). The product was mixture of syn- and anti-isomers. $[\alpha]_{\mathrm{D}}-20\left(c 1, \mathrm{CHCl}_{3}\right) .{ }^{1} \mathrm{H}-\mathrm{NMR}\left(270 \mathrm{MHz}, \mathrm{CDCl}_{3}\right): \delta=7.88(\mathrm{~d}, J=8.2 \mathrm{~Hz}$, $2 \mathrm{H}), 7.45-7.35(\mathrm{~m}, 4 \mathrm{H}), 6.92$ and $6.87(\mathrm{~d}, J=8.2 \mathrm{~Hz}, 2 \mathrm{H}), 4.68(\mathrm{q}, J=6.8 \mathrm{~Hz}, 1 \mathrm{H}), 2.46$ and $2.45(\mathrm{~s} \times 2$, $3 \mathrm{H}), 1.61$ and $1.60(\mathrm{~d} \times 2, J=6.8 \mathrm{~Hz}, 3 \mathrm{H}), 1.44(\mathrm{~s}, 9 \mathrm{H}) .{ }^{13} \mathrm{C}-\mathrm{NMR}\left(67.5 \mathrm{MHz}, \mathrm{CDCl}_{3}\right): \delta=170.5$ and 170.4, 160.6 and $160.2,152.9\left(\mathrm{q},{ }^{2} J_{C F}=27.9 \mathrm{~Hz}\right), 146.0$ and $145.9,131.4$ and 131.1, 130.5, 129.8, 129.1, 129.0, 128.9, 120.3, 119.7 and 117.4 (q, $\left.{ }^{1} J_{C F}=276.0 \mathrm{~Hz}\right), 116.9,115.0,82.3,72.8$ and 72.7, 27.8 and 27.7, 21.6, 18.2. HRMS (ESI): $m / z$ calculated for $\mathrm{C}_{22} \mathrm{H}_{24} \mathrm{~F}_{3} \mathrm{NO}_{6} \mathrm{~S}+\mathrm{H}^{+}\left[\mathrm{M}+\mathrm{H}^{+}\right]$: 488.1355. Found: 488.1372 .

tert-Butyl (R)-2-(4-(2,2,2-trifluoro-1-((tosyloxy)imino)ethyl)phenoxy)propanoate ( $(R)-49)$. The similar treatment of tert-butyl ( $R$ )-2-(4-(2,2,2-trifluoro-1-(hydroxyimino)ethyl)phenoxy)-propanoate $(R)-46$ (331 mg, $0.99 \mathrm{mmol})$ as that just described gave $(R)-49(473 \mathrm{mg}, 98 \%) .[\alpha]_{\mathrm{D}}+20\left(c 1, \mathrm{CHCl}_{3}\right) .{ }^{1} \mathrm{H}-\mathrm{NMR}(270 \mathrm{MHz}$, $\left.\mathrm{CDCl}_{3}\right): \delta=7.89(\mathrm{~d}, J=7.8 \mathrm{~Hz}, 2 \mathrm{H}), 7.38(\mathrm{~m}, 4 \mathrm{H}), 6.87(\mathrm{~d}, J=7.8 \mathrm{~Hz}, 2 \mathrm{H}), 4.65(\mathrm{q}, J=6.8 \mathrm{~Hz}, 1 \mathrm{H}), 2.46$ $(\mathrm{s}, 3 \mathrm{H}), 1.60(\mathrm{~d}, J=6.8 \mathrm{~Hz}, 3 \mathrm{H}), 1.44(\mathrm{~s}, 9 \mathrm{H}) .{ }^{13} \mathrm{C}-\mathrm{NMR}\left(67.5 \mathrm{MHz}, \mathrm{CDCl}_{3}\right): \delta=170.5$ and $170.4,160.6$ and 160.2, $153.2\left(\mathrm{q},{ }^{2} J_{C F}=29.9 \mathrm{~Hz}\right), 146.0$ and $145.9,131.4$ and 131.1, 130.5, 129.8, 129.1, 128.9, 120.3 , $118.6\left(\mathrm{q},{ }^{1} J_{C F}=283.8 \mathrm{~Hz}\right), 116.9,115.0,82.3,72.8$ and $72.7,27.7$ and $27.8,21.6,18.2$. HRMS (ESI): $\mathrm{m} / \mathrm{z}$ calculated for $\mathrm{C}_{22} \mathrm{H}_{24} \mathrm{~F}_{3} \mathrm{NO}_{6} \mathrm{~S}+\mathrm{H}^{+}\left[\mathrm{M}+\mathrm{H}^{+}\right]$: 488.1355 . Found: 488.1380 .

tert-Butyl (S)-2-(3-(2,2,2-trifluoro-1-((tosyloxy)imino)ethyl)phenoxy)propanoate ((S)-50). The similar treatment of tert-butyl (S)-2-(3-(2,2,2-trifluoro-1-(hydroxyimino)ethyl)phenoxy)-propanoate (S)-47 (277 mg, $0.83 \mathrm{mmol})$ as that just described gave $(S)-50\left(431 \mathrm{mg}\right.$, quant). $[\alpha]_{\mathrm{D}}-34\left(c 1, \mathrm{CHCl}_{3}\right) .{ }^{1} \mathrm{H}-\mathrm{NMR}(270 \mathrm{MHz}$, $\left.\mathrm{CDCl}_{3}\right): \delta=7.88(\mathrm{~d}, J=8.6 \mathrm{~Hz}, 2 \mathrm{H}), 7.35(\mathrm{~m}, 3 \mathrm{H}), 7.00(\mathrm{~d}, J=7.8 \mathrm{~Hz}, 2 \mathrm{H}), 6.97(\mathrm{~d}, J=7.8 \mathrm{~Hz}, 2 \mathrm{H}), 6.85$ $(\mathrm{s}, 1 \mathrm{H}), 4.62(\mathrm{q}, J=6.8 \mathrm{~Hz}, 1 \mathrm{H}), 2.48(\mathrm{~s}, 3 \mathrm{H}), 1.60(\mathrm{~d}, J=6.8 \mathrm{~Hz}, 3 \mathrm{H}), 1.42(\mathrm{~s}, 9 \mathrm{H}) .{ }^{13} \mathrm{C}-\mathrm{NMR}(67.5 \mathrm{MHz}$, $\left.\mathrm{CDCl}_{3}\right): \delta=170.7,157.8$ and 157.7, $153.6\left(\mathrm{q},{ }^{2} J_{\mathrm{CF}}=32.4 \mathrm{~Hz}\right), 146.1$ and $146.0,131.5$ and 131.2, 130.0, 129.9 and $129.8,129.3$ and $129.1,128.8,125.6,121.8$ and $121.3,119.5\left(\mathrm{q},{ }^{1} J_{C F}=274.3 \mathrm{~Hz}\right), 118.4$ and $118.2,115.4$ and $114.9,82.3,73.0,27.8,21.7,18.3$. HRMS (ESI): $m / z$ calculated for $\mathrm{C}_{22} \mathrm{H}_{24} \mathrm{~F}_{3} \mathrm{NO}_{6} \mathrm{~S}+\mathrm{H}^{+}\left[\mathrm{M}+\mathrm{H}^{+}\right]$: 488.1355. Found: 488.1330.

tert-Butyl (R)-2-(3-(2,2,2-trifluoro-1-((tosyloxy)imino)ethyl)phenoxy)propanoate ((R)-50). The similar treatment of tert-butyl ( $R$ )-2-(3-(2,2,2-trifluoro-1-(hydroxyimino)ethyl)phenoxy)-propanoate $(R)-47$ (348 mg, $1.04 \mathrm{mmol})$ as that just described gave $(R)-50(471 \mathrm{mg}, 93 \%) .[\alpha]_{\mathrm{D}}+34\left(c 1, \mathrm{CHCl}_{3}\right) .{ }^{1} \mathrm{H}-\mathrm{NMR}(270 \mathrm{MHz}$, $\left.\mathrm{CDCl}_{3}\right): \delta=7.89(\mathrm{~d}, J=8.2 \mathrm{~Hz}, 2 \mathrm{H}), 7.35(\mathrm{~m}, 3 \mathrm{H}), 7.02(\mathrm{~m}, 2 \mathrm{H}), 6.93(\mathrm{~s}, 1 \mathrm{H}), 4.61(\mathrm{q}, J=6.7 \mathrm{~Hz}, 1 \mathrm{H})$, $2.46(\mathrm{~s}, 3 \mathrm{H}), 1.59(\mathrm{~d}, J=6.6 \mathrm{~Hz}, 3 \mathrm{H}), 1.42(\mathrm{~s}, 9 \mathrm{H}) .{ }^{13} \mathrm{C}-\mathrm{NMR}\left(67.5 \mathrm{MHz}, \mathrm{CDCl}_{3}\right): \delta=170.7,157.8$ and 157.7, $153.7\left(\mathrm{q},{ }^{2} J_{C F}=33.5 \mathrm{~Hz}\right), 146.1$ and $146.0,131.5$ and 131.2, 130.0, 129.9 and 129.8, 129.3 and 129.1, $127.8,125.6,121.8$ and $121.3,119.5\left(\mathrm{q},{ }^{1} J_{C F}=280.5 \mathrm{~Hz}\right), 118.4$ and $118.2,115.4$ and $114.9,82.3,73.1$ and 73.0, 27.8, 21.8, 18.3. HRMS (ESI): $m / z$ calculated for $\mathrm{C}_{22} \mathrm{H}_{24} \mathrm{~F}_{3} \mathrm{NO}_{6} \mathrm{~S}+\mathrm{H}^{+}\left[\mathrm{M}+\mathrm{H}^{+}\right]$: 488.1355. Found: 488.1330 .

tert-Butyl (S)-2-(2-(2,2,2-trifluoro-1-((tosyloxy)imino)ethyl)phenoxy)propanoate ((S)-51). The similar treatment of tert-butyl (S)-2-(2-(2,2,2-trifluoro-1-(hydroxyimino)ethyl)phenoxy)-propanoate (S)-48 (300 mg, $0.90 \mathrm{mmol})$ as that just described gave $(S)-51(412 \mathrm{mg}, 94 \%) .[\alpha]_{\mathrm{D}}+24\left(c 1, \mathrm{CHCl}_{3}\right) .{ }^{1} \mathrm{H}-\mathrm{NMR}(270 \mathrm{MHz}$, $\left.\mathrm{CDCl}_{3}\right): \delta=7.88(\mathrm{~d}, J=8.2 \mathrm{~Hz}, 2 \mathrm{H}), 7.39(\mathrm{~m}, 3 \mathrm{H}), 7.12(\mathrm{~d}, J=7.6 \mathrm{~Hz}, 1 \mathrm{H}), 6.97(\mathrm{t}, J=7.6 \mathrm{~Hz}, 1 \mathrm{H})$, $6.72(\mathrm{~d}, J=7.6 \mathrm{~Hz}, 1 \mathrm{H}), 4.56(\mathrm{q}, J=6.8 \mathrm{~Hz}, 1 \mathrm{H}), 2.45(\mathrm{~s}, 3 \mathrm{H}), 1.47(\mathrm{~d}, J=6.8 \mathrm{~Hz}, 3 \mathrm{H}), 1.39(\mathrm{~s}, 9 \mathrm{H})$. ${ }^{13} \mathrm{C}-\mathrm{NMR}\left(67.5 \mathrm{MHz}, \mathrm{CDCl}_{3}\right): \delta=170.3,156.6,155.3\left(\mathrm{q},{ }^{2} J_{\mathrm{CF}}=34.6 \mathrm{~Hz}\right), 145.7,132.9,132.4,131.7,131.1$, $129.8,129.0,121.1,117.8,116.8\left(\mathrm{q}^{1}{ }^{1} J_{\mathrm{CF}}=283.2 \mathrm{~Hz}\right), 111.8,82.2,73.6,27.7,21.7,17.8$. HRMS (ESI): $\mathrm{m} / \mathrm{z}$ calculated for $\mathrm{C}_{22} \mathrm{H}_{24} \mathrm{~F}_{3} \mathrm{NO}_{6} \mathrm{~S}+\mathrm{H}^{+}\left[\mathrm{M}+\mathrm{H}^{+}\right]$: 488.1355. Found: 488.1339 .

tert-Butyl (R)-2-(2-(2,2,2-trifluoro-1-((tosyloxy)imino)ethyl)phenoxy)propanoate ((R)-51). The similar treatment of tert-butyl (R)-2-(2-(2,2,2-trifluoro-1-(hydroxyimino)ethyl)phenoxy)-propanoate ( $R$ )-48 (254 mg, 
$0.76 \mathrm{mmol})$ as that just described gave $(R)-51$ (373 mg, quant). $[\alpha]_{\mathrm{D}}-24\left(\mathrm{c} 1, \mathrm{CHCl}_{3}\right) .{ }^{1} \mathrm{H}-\mathrm{NMR}$ $\left(270 \mathrm{MHz}, \mathrm{CDCl}_{3}\right): \delta=7.88(\mathrm{~d}, J=8.2 \mathrm{~Hz}, 2 \mathrm{H}), 7.39(\mathrm{~m}, 3 \mathrm{H}), 7.12(\mathrm{~d}, J=7.6 \mathrm{~Hz}, 1 \mathrm{H}), 6.97(\mathrm{t}, J=7.6 \mathrm{~Hz}$, $1 \mathrm{H}), 6.72(\mathrm{~d}, J=7.6 \mathrm{~Hz}, 1 \mathrm{H}), 4.55(\mathrm{q}, J=6.8 \mathrm{~Hz}, 1 \mathrm{H}), 2.46(\mathrm{~s}, 3 \mathrm{H}), 1.47(\mathrm{~d}, J=6.8 \mathrm{~Hz}, 3 \mathrm{H}), 1.39(\mathrm{~s}, 9 \mathrm{H})$. ${ }^{13} \mathrm{C}-\mathrm{NMR}\left(67.5 \mathrm{MHz}, \mathrm{CDCl}_{3}\right): \delta=170.3,156.6,155.3\left(\mathrm{q},{ }^{2} J_{\mathrm{CF}}=35.2 \mathrm{~Hz}\right), 145.7,132.9,132.4,131.7,131.1$, $129.8,129.1,121.1,117.8,116.8\left(\mathrm{q},{ }^{1} J_{C F}=282.7 \mathrm{~Hz}\right), 111.8,82.2,73.6,27.8,21.7,17.8$. HRMS (ESI): $\mathrm{m} / \mathrm{z}$ calculated for $\mathrm{C}_{22} \mathrm{H}_{24} \mathrm{~F}_{3} \mathrm{NO}_{6} \mathrm{~S}+\mathrm{H}^{+}\left[\mathrm{M}+\mathrm{H}^{+}\right]$: 488.1355 . Found: 488.1362 .

tert-Butyl (S)-2-(4-(3-(trifluoromethyl)diaziridin-3-yl)phenoxy)propanoate ((S)-52). To liquid $\mathrm{NH}_{3}(10 \mathrm{~mL})$ at $-78^{\circ} \mathrm{C}$ in a sealed tube, tert-butyl (S)-2-(2-(2,2,2-trifluoro-1-((tosyloxy)imino)-ethyl)phen oxy)propanoate $(S)-49(336 \mathrm{mg}, 0.69 \mathrm{mmol})$ in dry ether $(3 \mathrm{~mL})$ was added. The reaction mixture was stirred at room temperature for $3 \mathrm{~h}$. After evaporation of $\mathrm{NH}_{3}$ gas, the reaction mixture was partitioned between ether and water. The organic layer was dried over $\mathrm{MgSO}_{4}$, filtrated and concentrated. The residue was purified by column chromatography (ethyl acetate/ $n$-hexane, $1: 5$ ) to give (S)-52 (200 mg, 88\%). [ $\alpha]_{\mathrm{D}}-32$ (c 1, $\left.\mathrm{CHCl}_{3}\right) .{ }^{1} \mathrm{H}-\mathrm{NMR}\left(270 \mathrm{MHz}, \mathrm{CDCl}_{3}\right): \delta=7.51(\mathrm{~d}, J=8.6 \mathrm{~Hz}, 2 \mathrm{H}), 6.88$ $(\mathrm{d}, J=8.6 \mathrm{~Hz}, 2 \mathrm{H}), 4.64(\mathrm{q}, J=6.8 \mathrm{~Hz}, 1 \mathrm{H}), 2.76(\mathrm{~d}, J=8.6 \mathrm{~Hz}, 1 \mathrm{H}), 2.18(\mathrm{~d}, J=8.6 \mathrm{~Hz}, 1 \mathrm{H}), 1.59(\mathrm{~d}$, $J=6.8 \mathrm{~Hz}, 3 \mathrm{H}), 1.44(\mathrm{~s}, 9 \mathrm{H}) .{ }^{13} \mathrm{C}-\mathrm{NMR}\left(67.5 \mathrm{MHz}, \mathrm{CDCl}_{3}\right): \delta=170.9,159.0,129.4,124.3,123.6(\mathrm{q}$, $\left.{ }^{1} J_{C F}=278.2 \mathrm{~Hz}\right), 115.1,82.1,72.8,57.5\left(\mathrm{q},{ }^{2} J_{C F}=35.8 \mathrm{~Hz}\right), 27.9,18.3$. HRMS (ESI): $m / z$ calculated for $\mathrm{C}_{15} \mathrm{H}_{19} \mathrm{~F}_{3} \mathrm{~N}_{2} \mathrm{O}_{3}+\mathrm{H}^{+}\left[\mathrm{M}+\mathrm{H}^{+}\right]$: 333.1426. Found: 333.1414.

tert-Butyl (R)-2-(4-(3-(trifluoromethyl)diaziridin-3-yl)phenoxy)propanoate ((R)-52). The similar treatment of tert-butyl (R)-2-(4-(2,2,2-trifluoro-1-((tosyloxy)imino)ethyl)phenoxy)-propanoate $(R)-49$ (433 mg, $0.89 \mathrm{mmol})$ as that just described gave $(R)-52(259 \mathrm{mg}, 88 \%) .[\alpha]_{\mathrm{D}}+32\left(c 1, \mathrm{CHCl}_{3}\right) .{ }^{1} \mathrm{H}-\mathrm{NMR}(270 \mathrm{MHz}$, $\left.\mathrm{CDCl}_{3}\right): \delta=7.52(\mathrm{~d}, J=8.6 \mathrm{~Hz}, 2 \mathrm{H}), 6.88(\mathrm{~d}, J=8.6 \mathrm{~Hz}, 2 \mathrm{H}), 4.64(\mathrm{q}, J=6.8 \mathrm{~Hz}, 1 \mathrm{H}), 2.75(\mathrm{~s}, 1 \mathrm{H}), 2.16$ $(\mathrm{s}, 1 \mathrm{H}), 1.59(\mathrm{~d}, J=6.8 \mathrm{~Hz}, 3 \mathrm{H}), 1.44(\mathrm{~s}, 9 \mathrm{H}) .{ }^{13} \mathrm{C}-\mathrm{NMR}\left(67.5 \mathrm{MHz}, \mathrm{CDCl}_{3}\right): \delta=170.9,159.0,129.5$, 124.3, $123.6\left(\mathrm{q},{ }^{1} J_{C F}=277.7 \mathrm{~Hz}\right), 115.1,82.2,72.8,57.6\left(\mathrm{q},{ }^{2} J_{C F}=35.2 \mathrm{~Hz}\right), 27.9,18.3$. HRMS (ESI): $\mathrm{m} / \mathrm{z}$ calculated for $\mathrm{C}_{15} \mathrm{H}_{19} \mathrm{~F}_{3} \mathrm{~N}_{2} \mathrm{O}_{3}+\mathrm{H}^{+}\left[\mathrm{M}+\mathrm{H}^{+}\right]$: 333.1426. Found: 333.1416.

tert-Butyl (S)-2-(3-(3-(trifluoromethyl)diaziridin-3-yl)phenoxy)propanoate ((S)-53). The similar treatment of tert-butyl (S)-2-(3-(2,2,2-trifluoro-1-((tosyloxy)imino)ethyl)phenoxy)-propanoate (S)-50 (431 mg, $0.88 \mathrm{mmol}$ ) as that just described gave (S)-53 (269 mg, 92\%). [ $\alpha]_{\mathrm{D}}-38\left(c 1, \mathrm{CHCl}_{3}\right) .{ }^{1} \mathrm{H}-\mathrm{NMR}$ $\left(270 \mathrm{MHz}, \mathrm{CDCl}_{3}\right): \delta=7.32(\mathrm{t}, J=7.6 \mathrm{~Hz}, 1 \mathrm{H}), 7.21(\mathrm{~d}, J=7.6 \mathrm{~Hz}, 1 \mathrm{H}), 7.12(\mathrm{~s}, 1 \mathrm{H}), 6.94(\mathrm{~d}, J=7.6 \mathrm{~Hz}$, $1 \mathrm{H}), 4.64(\mathrm{q}, J=6.8 \mathrm{~Hz}, 1 \mathrm{H}), 2.75(\mathrm{~s}, 1 \mathrm{H}), 2.20(\mathrm{~s}, 1 \mathrm{H}), 1.59(\mathrm{~d}, J=6.8 \mathrm{~Hz}, 3 \mathrm{H}), 1.44(\mathrm{~s}, 9 \mathrm{H}) .{ }^{13} \mathrm{C}-\mathrm{NMR}$ $\left(67.5 \mathrm{MHz}, \mathrm{CDCl}_{3}\right): \delta=170.9,157.9,133.1,129.9,123.5\left(\mathrm{q},{ }^{1} J_{C F}=278.2 \mathrm{~Hz}\right), 120.9,116.9,114.6,82.2$, 72.9, $57.9\left(\mathrm{q},{ }^{2} J_{C F}=35.8 \mathrm{~Hz}\right), 27.9,18.3$. HRMS (ESI): $\mathrm{m} / z$ calculated for $\mathrm{C}_{15} \mathrm{H}_{19} \mathrm{~F}_{3} \mathrm{~N}_{2} \mathrm{O}_{3}+\mathrm{H}^{+}\left[\mathrm{M}+\mathrm{H}^{+}\right]$: 333.1426. Found: 333.1414.

tert-Butyl (R)-2-(3-(3-(trifluoromethyl)diaziridin-3-yl)phenoxy)propanoate $((R)-53)$. The similar treatment of tert-butyl (R)-2-(3-(2,2,2-trifluoro-1-((tosyloxy)imino)ethyl)phenoxy)-propanoate $(R)-50$ (471 mg, $0.97 \mathrm{mmol})$ as that just described gave $(R)-53\left(347 \mathrm{mg}\right.$, quant). $[\alpha]_{\mathrm{D}}+38\left(c 1, \mathrm{CHCl}_{3}\right) .{ }^{1} \mathrm{H}-\mathrm{NMR}(270 \mathrm{MHz}$, $\left.\mathrm{CDCl}_{3}\right): \delta=7.32(\mathrm{t}, J=7.6 \mathrm{~Hz}, 1 \mathrm{H}), 7.21(\mathrm{~d}, J=7.6 \mathrm{~Hz}, 1 \mathrm{H}), 7.12(\mathrm{~s}, 1 \mathrm{H}), 6.94(\mathrm{~d}, J=7.6 \mathrm{~Hz}, 1 \mathrm{H}), 4.64(\mathrm{q}$, $J=6.8 \mathrm{~Hz}, 1 \mathrm{H}), 2.74(\mathrm{~s}, 1 \mathrm{H}), 2.18(\mathrm{~s}, 1 \mathrm{H}), 1.59(\mathrm{~d}, J=6.8 \mathrm{~Hz}, 3 \mathrm{H}), 1.44(\mathrm{~s}, 9 \mathrm{H}) .{ }^{13} \mathrm{C}-\mathrm{NMR}(67.5 \mathrm{MHz}$, $\left.\mathrm{CDCl}_{3}\right): \delta=170.9,157.9,133.1,129.9,123.5\left(\mathrm{q},{ }^{1} J_{C F}=278.2 \mathrm{~Hz}\right), 120.9,116.8,114.6,82.1,72.8,57.9(\mathrm{q}$, $\left.{ }^{2} J_{C F}=35.8 \mathrm{~Hz}\right), 27.9,18.4$. HRMS (ESI): $m / z$ calculated for $\mathrm{C}_{15} \mathrm{H}_{19} \mathrm{~F}_{3} \mathrm{~N}_{2} \mathrm{O}_{3}+\mathrm{H}^{+}\left[\mathrm{M}+\mathrm{H}^{+}\right]: 333.1426$. Found: 333.1421.

tert-Butyl (S)-2-(2-(3-(trifluoromethyl)diaziridin-3-yl)phenoxy)propanoate ((S)-54). The similar treatment of tert-butyl (S)-2-(2-(2,2,2-trifluoro-1-((tosyloxy)imino)ethyl)phenoxy)-propanoate (S)-51 (354 mg, $0.73 \mathrm{mmol}$ ) as that just described gave (S)-54 (182 mg, 76\%). [ $\alpha]_{\mathrm{D}}-17\left(\mathrm{c} 1, \mathrm{CHCl}_{3}\right) .{ }^{1} \mathrm{H}-\mathrm{NMR}$ $\left(270 \mathrm{MHz}, \mathrm{CDCl}_{3}\right): \delta=7.54(\mathrm{~d}, J=7.6 \mathrm{~Hz}, 1 \mathrm{H}), 7.34(\mathrm{t}, J=7.6 \mathrm{~Hz}, 1 \mathrm{H}), 7.01(\mathrm{t}, J=7.6 \mathrm{~Hz}, 1 \mathrm{H}), 6.80$ $(\mathrm{d}, J=7.6 \mathrm{~Hz}, 1 \mathrm{H}), 4.79(\mathrm{q}, J=6.8 \mathrm{~Hz}, 1 \mathrm{H}), 1.63(\mathrm{~d}, J=6.8 \mathrm{~Hz}, 3 \mathrm{H}), 1.36(\mathrm{~s}, 9 \mathrm{H}) .{ }^{13} \mathrm{C}-\mathrm{NMR}(67.5 \mathrm{MHz}$, $\left.\mathrm{CDCl}_{3}\right): \delta=170.9,156.4,131.5,130.9,123.6\left(\mathrm{q},{ }^{1} J_{C F}=278.2 \mathrm{~Hz}\right), 121.1,120.8,111.9,82.3,72.7,55.8(\mathrm{q}$, $\left.{ }^{2} J_{C F}=37.6 \mathrm{~Hz}\right), 27.6,18.2$. HRMS (ESI): $m / z$ calculated for $\mathrm{C}_{15} \mathrm{H}_{19} \mathrm{~F}_{3} \mathrm{~N}_{2} \mathrm{O}_{3}+\mathrm{H}^{+}\left[\mathrm{M}+\mathrm{H}^{+}\right]: 333.1426$. Found: 333.1425 .

tert-Butyl (R)-2-(2-(3-(trifluoromethyl)diaziridin-3-yl)phenoxy)propanoate $((R)-54) . \quad$ The similar treatment of tert-butyl (R)-2-(2-(2,2,2-trifluoro-1-((tosyloxy)imino)ethyl)phenoxy)-propanoate ( $R$ )-51 (317 mg, 
$0.65 \mathrm{mmol})$ as that just described gave $(R)-54(173 \mathrm{mg}, 80 \%) .[\alpha]_{\mathrm{D}}+17\left(c 1, \mathrm{CHCl}_{3}\right) .{ }^{1} \mathrm{H}-\mathrm{NMR}(270 \mathrm{MHz}$, $\left.\mathrm{CDCl}_{3}\right): \delta=7.54(\mathrm{~d}, J=7.6 \mathrm{~Hz}, 1 \mathrm{H}), 7.34(\mathrm{t}, J=7.6 \mathrm{~Hz}, 1 \mathrm{H}), 7.01(\mathrm{t}, J=7.6 \mathrm{~Hz}, 1 \mathrm{H}), 6.80(\mathrm{~d}, J=7.6 \mathrm{~Hz}$, $1 \mathrm{H}), 4.79(\mathrm{q}, J=6.8 \mathrm{~Hz}, 1 \mathrm{H}), 1.63(\mathrm{~d}, J=6.8 \mathrm{~Hz}, 3 \mathrm{H}), 1.36(\mathrm{~s}, 9 \mathrm{H}) .{ }^{13} \mathrm{C}-\mathrm{NMR}\left(67.5 \mathrm{MHz}, \mathrm{CDCl}_{3}\right): \delta=170.9$, $156.4,131.5,130.9,123.6\left(\mathrm{q},{ }^{1} J_{C F}=278.8 \mathrm{~Hz}\right), 121.1,120.8,111.9,82.3,72.7,55.8\left(\mathrm{q},{ }^{2} J_{C F}=37.4 \mathrm{~Hz}\right), 27.6$, 18.2. HRMS (ESI): $m / z$ calculated for $\mathrm{C}_{15} \mathrm{H}_{19} \mathrm{~F}_{3} \mathrm{~N}_{2} \mathrm{O}_{3}+\mathrm{H}^{+}\left[\mathrm{M}+\mathrm{H}^{+}\right]:$333.1426. Found: 333.1415.

tert-Butyl (S)-2-(4-(3-(trifluoromethyl)-3H-diazirin-3-yl)phenoxy)propanoate ((S)-55). tert-Butyl (S)-2-(4-(3-(trifluoromethyl)diaziridin-3-yl)phenoxy)propanoate (S)-52 (151 mg, $0.45 \mathrm{mmol}$ ) was dissolved in $\mathrm{CH}_{2} \mathrm{Cl}_{2}(2 \mathrm{~mL}) . \mathrm{MnO}_{2}(197 \mathrm{mg}, 2.27 \mathrm{mmol})$ was added to the solution, and the reaction mixture was stirred at room temperature for $2 \mathrm{~h}$, followed by filtration and then concentrated. The residue was purified by column chromatography (ethyl acetate/n-hexane, 1:9) to give (S)-55 (136 mg, 91\%). $[\alpha]_{\mathrm{D}}-35\left(c 1, \mathrm{CHCl}_{3}\right) .{ }^{1} \mathrm{H}-\mathrm{NMR}\left(270 \mathrm{MHz}, \mathrm{CDCl}_{3}\right): \delta=7.12(\mathrm{~d}, J=8.6 \mathrm{~Hz}, 2 \mathrm{H}), 6.86(\mathrm{~d}, J=8.6 \mathrm{~Hz}$, $2 \mathrm{H}), 4.62(\mathrm{q}, J=6.8 \mathrm{~Hz}, 1 \mathrm{H}), 1.58(\mathrm{~d}, J=6.8 \mathrm{~Hz}, 3 \mathrm{H}), 1.43(\mathrm{~s}, 9 \mathrm{H}) .{ }^{13} \mathrm{C}-\mathrm{NMR}\left(67.5 \mathrm{MHz}, \mathrm{CDCl}_{3}\right)$ : $\delta=170.8,158.8,128.1,122.2\left(\mathrm{q},{ }^{1} J_{C F}=274.9 \mathrm{~Hz}\right), 121.6,115.3,82.2,72.9,28.2\left(\mathrm{q},{ }^{2} J_{C F}=40.8 \mathrm{~Hz}\right), 27.9$, 18.3. HRMS (ESI): $m / z$ calculated for $\mathrm{C}_{15} \mathrm{H}_{17} \mathrm{~F}_{3} \mathrm{~N}_{2} \mathrm{O}_{3}+\mathrm{H}^{+}\left[\mathrm{M}+\mathrm{H}^{+}\right]$: 331.1270. Found: 333.1261. Chiral HPLC (n-hexane/2-propanol 90:10): $t_{\mathrm{R}} 15.4 \mathrm{~min}$.

tert-Butyl (R)-2-(4-(3-(trifluoromethyl)-3H-diazirin-3-yl)phenoxy)propanoate $((R)-55)$. The similar treatment of tert-butyl (R)-2-(4-(3-(trifluoromethyl)diaziridin-3-yl)phenoxy)-propanoate $(R)-52$ (201 mg, $0.60 \mathrm{mmol})$ as that just described gave $(R)-55(184 \mathrm{mg}, 92 \%) .[\alpha]_{\mathrm{D}}+35\left(c 1, \mathrm{CHCl}_{3}\right) .{ }^{1} \mathrm{H}-\mathrm{NMR}(270 \mathrm{MHz}$, $\left.\mathrm{CDCl}_{3}\right): \delta=7.12(\mathrm{~d}, J=8.6 \mathrm{~Hz}, 2 \mathrm{H}), 6.86(\mathrm{~d}, J=8.6 \mathrm{~Hz}, 2 \mathrm{H}), 4.61(\mathrm{q}, J=6.8 \mathrm{~Hz}, 1 \mathrm{H}), 1.58(\mathrm{~d}, J=6.8 \mathrm{~Hz}$, $3 \mathrm{H}), 1.43(\mathrm{~s}, 9 \mathrm{H}) .{ }^{13} \mathrm{C}-\mathrm{NMR}\left(67.5 \mathrm{MHz}, \mathrm{CDCl}_{3}\right): \delta=170.8,158.8,128.1,122.2\left(\mathrm{q},{ }^{1} J_{C F}=274.9 \mathrm{~Hz}\right), 121.6$, $115.3,82.2,72.9,28.2\left(\mathrm{q},{ }^{2} J_{C F}=40.8 \mathrm{~Hz}\right), 27.9,18.3$. HRMS (ESI): $m / z$ calculated for $\mathrm{C}_{15} \mathrm{H}_{17} \mathrm{~F}_{3} \mathrm{~N}_{2} \mathrm{O}_{3}+\mathrm{H}^{+}$ $\left[\mathrm{M}+\mathrm{H}^{+}\right]$: 331.1270. Found: 333.1260. Chiral HPLC ( $n$-hexane/2-propanol 90:10): $t_{\mathrm{R}} 17.1 \mathrm{~min}$.

tert-Butyl (S)-2-(3-(3-(trifluoromethyl)-3H-diazirin-3-yl)phenoxy)propanoate ((S)-56). The similar treatment of tert-butyl (S)-2-(3-(3-(trifluoromethyl)diaziridin-3-yl)phenoxy)-propanoate (S)-53 (269 mg, $0.81 \mathrm{mmol})$ as that just described gave $(S)-56(220 \mathrm{mg}, 82 \%) .[\alpha]_{\mathrm{D}}-38\left(c 1, \mathrm{CHCl}_{3}\right) .{ }^{1} \mathrm{H}-\mathrm{NMR}(270 \mathrm{MHz}$, $\left.\mathrm{CDCl}_{3}\right): \delta=7.3(\mathrm{t}, J=7.6 \mathrm{~Hz}, 1 \mathrm{H}), 6.9(\mathrm{~d}, J=7.6 \mathrm{~Hz}, 1 \mathrm{H}), 6.8(\mathrm{~d}, J=7.6 \mathrm{~Hz}, 1 \mathrm{H}), 6.7(\mathrm{~s}, 1 \mathrm{H}), 4.6(\mathrm{q}$, $J=6.8 \mathrm{~Hz}, 1 \mathrm{H}), 1.6(\mathrm{~d}, J=6.8 \mathrm{~Hz}, 3 \mathrm{H}), 1.4(\mathrm{~s}, 9 \mathrm{H}) .{ }^{13} \mathrm{C}-\mathrm{NMR}\left(67.5 \mathrm{MHz}, \mathrm{CDCl}_{3}\right): \delta=170.8,158.0$, 130.5, 130.0, $122.1\left(\mathrm{q},{ }^{1} J_{C F}=274.9 \mathrm{~Hz}\right), 119.3,116.3,113.2,82.3,72.9,28.3\left(\mathrm{q},{ }^{2} J_{C F}=40.8 \mathrm{~Hz}\right), 27.9,18.3$. HRMS (ESI): $m / z$ calculated for $\mathrm{C}_{15} \mathrm{H}_{17} \mathrm{~F}_{3} \mathrm{~N}_{2} \mathrm{O}_{3}+\mathrm{H}^{+}\left[\mathrm{M}+\mathrm{H}^{+}\right]$: 331.1270. Found: 333.1268. Chiral HPLC (n-hexane/2-propanol 90:10): $t_{\mathrm{R}} 9.4 \mathrm{~min}$.

tert-Butyl (R)-2-(3-(3-(trifluoromethyl)-3H-diazirin-3-yl)phenoxy)propanoate $((R)-56)$. The similar treatment of tert-butyl (R)-2-(3-(3-(trifluoromethyl)diaziridin-3-yl)phenoxy)-propanoate $(R)-53(347 \mathrm{mg}$, $1.05 \mathrm{mmol})$ as that just described gave $(R)-56(283 \mathrm{mg}, 82 \%) .[\alpha]_{\mathrm{D}}+38\left(c 1, \mathrm{CHCl}_{3}\right) .{ }^{1} \mathrm{H}-\mathrm{NMR}(270 \mathrm{MHz}$, $\left.\mathrm{CDCl}_{3}\right): \delta=7.3(\mathrm{t}, J=7.6 \mathrm{~Hz}, 1 \mathrm{H}), 6.9(\mathrm{~d}, J=7.6 \mathrm{~Hz}, 1 \mathrm{H}), 6.8(\mathrm{~d}, J=7.6 \mathrm{~Hz}, 1 \mathrm{H}), 6.7(\mathrm{~s}, 1 \mathrm{H}), 4.6(\mathrm{q}$, $J=6.8 \mathrm{~Hz}, 1 \mathrm{H}), 1.6(\mathrm{~d}, J=6.8 \mathrm{~Hz}, 3 \mathrm{H}), 1.4(\mathrm{~s}, 9 \mathrm{H}) .{ }^{13} \mathrm{C}-\mathrm{NMR}\left(67.5 \mathrm{MHz}, \mathrm{CDCl}_{3}\right): \delta=170.8,158.0$, 130.5, 130.0, $122.1\left(\mathrm{q},{ }^{1} J_{C F}=274.9 \mathrm{~Hz}\right), 119.3,116.3,113.2,82.3,72.9,28.3\left(\mathrm{q},{ }^{2} J_{C F}=40.2 \mathrm{~Hz}\right), 27.9,18.3$. HRMS (ESI): $m / z$ calculated for $\mathrm{C}_{15} \mathrm{H}_{17} \mathrm{~F}_{3} \mathrm{~N}_{2} \mathrm{O}_{3}+\mathrm{H}^{+}\left[\mathrm{M}+\mathrm{H}^{+}\right]$: 331.1270. Found: 333.1263. Chiral HPLC (n-hexane/2-propanol 90:10): $t_{\mathrm{R}} 8.8 \mathrm{~min}$.

tert-Butyl (S)-2-(2-(3-(trifluoromethyl)-3H-diazirin-3-yl)phenoxy)propanoate ((S)-57). The similar treatment of tert-butyl (S)-2-(2-(3-(trifluoromethyl)diaziridin-3-yl)phenoxy)-propanoate (S)-54 (105 mg, $0.32 \mathrm{mmol})$ as that just described gave $(S)-57(93.4 \mathrm{mg}, 89 \%) .[\alpha]_{\mathrm{D}}-10\left(c 1, \mathrm{CHCl}_{3}\right) .{ }^{1} \mathrm{H}-\mathrm{NMR}(270 \mathrm{MHz}$, $\left.\mathrm{CDCl}_{3}\right): \delta=7.37(\mathrm{~d}, J=7.6 \mathrm{~Hz}, 1 \mathrm{H}), 7.24(\mathrm{t}, J=7.6 \mathrm{~Hz}, 1 \mathrm{H}), 6.87(\mathrm{t}, J=7.6 \mathrm{~Hz}, 1 \mathrm{H}), 6.66(\mathrm{~d}, J=7.6 \mathrm{~Hz}$, $1 \mathrm{H}), 4.60(\mathrm{q}, J=6.8 \mathrm{~Hz}, 1 \mathrm{H}), 1.61(\mathrm{~d}, J=6.8 \mathrm{~Hz}, 3 \mathrm{H}), 1.30(\mathrm{~s}, 9 \mathrm{H}) .{ }^{13} \mathrm{C}-\mathrm{NMR}\left(67.5 \mathrm{MHz}, \mathrm{CDCl}_{3}\right): \delta=170.7$, 158.0, 131.7, 131.1, $122.1\left(\mathrm{q},{ }^{1} J_{C F}=274.9 \mathrm{~Hz}\right), 121.3,117.1,112.2,82.1,73.3,27.8,26.4\left(\mathrm{q},{ }^{2} J_{C F}=43.0 \mathrm{~Hz}\right)$, 18.2. HRMS (ESI): $m / z$ calculated for $\mathrm{C}_{15} \mathrm{H}_{17} \mathrm{~F}_{3} \mathrm{~N}_{2} \mathrm{O}_{3}+\mathrm{H}^{+}\left[\mathrm{M}+\mathrm{H}^{+}\right]$: 331.1270. Found: 333.1285. Chiral HPLC (n-hexane/2-propanol 90:10): $t_{\mathrm{R}} 9.9 \mathrm{~min}$.

tert-Butyl (R)-2-(2-(3-(trifluoromethyl)-3H-diazirin-3-yl)phenoxy)propanoate ((R)-57). The similar treatment of tert-butyl (R)-2-(2-(3-(trifluoromethyl)diaziridin-3-yl)phenoxy)-propanoate $(R)-54(85.8 \mathrm{mg}$, $0.26 \mathrm{mmol})$ as that just described gave $(R)-57(81.7 \mathrm{mg}, 96 \%) .[\alpha]_{\mathrm{D}}+10\left(c 1, \mathrm{CHCl}_{3}\right) .{ }^{1} \mathrm{H}-\mathrm{NMR}(270 \mathrm{MHz}$, $\left.\mathrm{CDCl}_{3}\right): \delta=7.45(\mathrm{~d}, J=7.6 \mathrm{~Hz}, 1 \mathrm{H}), 7.33(\mathrm{t}, J=7.6 \mathrm{~Hz}, 1 \mathrm{H}), 6.96(\mathrm{t}, J=7.6 \mathrm{~Hz}, 1 \mathrm{H}), 6.74(\mathrm{~d}, J=7.6 \mathrm{~Hz}$, 
$1 \mathrm{H}), 4.68(\mathrm{q}, J=6.8 \mathrm{~Hz}, 1 \mathrm{H}), 1.69(\mathrm{~d}, J=6.8 \mathrm{~Hz}, 3 \mathrm{H}), 1.39(\mathrm{~s}, 9 \mathrm{H}) .{ }^{13} \mathrm{C}-\mathrm{NMR}\left(67.5 \mathrm{MHz}, \mathrm{CDCl}_{3}\right): \delta=170.7$, 158.0, 131.7, 131.1, $122.1\left(\mathrm{q},{ }^{1} J_{C F}=274.9 \mathrm{~Hz}\right), 121.3,117.1,112.2,82.1,73.2,27.8,26.4\left(\mathrm{q},{ }^{2} J_{C F}=43.0 \mathrm{~Hz}\right)$, 18.2. HRMS (ESI): $m / z$ calculated for $\mathrm{C}_{15} \mathrm{H}_{17} \mathrm{~F}_{3} \mathrm{~N}_{2} \mathrm{O}_{3}+\mathrm{H}^{+}\left[\mathrm{M}+\mathrm{H}^{+}\right]$: 331.1270. Found: 333.1276. Chiral HPLC (n-hexane/2-propanol 90:10): $t_{\mathrm{R}} 10.3 \mathrm{~min}$.

(S)-2-(4-(3-(Trifluoromethyl)-3H-diazirin-3-yl)phenoxy)propanoic acid ((S)-58). tert-Butyl (S)-2-(4-(3(trifluoromethyl)-3H-diazirin-3-yl)phenoxy)propanoate (S)-55 (165 mg, $0.50 \mathrm{mmol}$ ) was dissolved in $\mathrm{CH}_{2} \mathrm{Cl}_{2}(1 \mathrm{~mL})$ and then trifluoroacetic acid $(2 \mathrm{~mL})$ was added to the solution. After the reaction mixture was stirred at room temperature for $2 \mathrm{~h}$, the reaction mixture was poured into the cold water and extracted by $\mathrm{CH}_{2} \mathrm{Cl}_{2}$. The organic layer was dried over $\mathrm{MgSO}_{4}$, filtrated and concentrated to give $(S)$-58 (135 mg, 98\%). [ $\alpha]_{\mathrm{D}}-20\left(c 1, \mathrm{CHCl}_{3}\right) .{ }^{1} \mathrm{H}-\mathrm{NMR}\left(270 \mathrm{MHz}, \mathrm{CDCl}_{3}\right): \delta=11.33(\mathrm{~s}, 1 \mathrm{H})$, $7.14(\mathrm{~d}, J=8.6 \mathrm{~Hz}, 2 \mathrm{H}), 6.89(\mathrm{~d}, J=8.6 \mathrm{~Hz}, 2 \mathrm{H}), 4.79(\mathrm{q}, J=6.8 \mathrm{~Hz}, 1 \mathrm{H}), 1.66(\mathrm{~d}, J=6.8 \mathrm{~Hz}, 3 \mathrm{H})$. ${ }^{13} \mathrm{C}-\mathrm{NMR}\left(67.5 \mathrm{MHz}, \mathrm{CDCl}_{3}\right): \delta=177.8,158.2,128.3,122.3,122.2\left(\mathrm{q}^{1}{ }^{1} J_{\mathrm{CF}}=274.3 \mathrm{~Hz}\right), 115.4,71.9,28.1(\mathrm{q}$, ${ }^{2} J_{C F}=40.8 \mathrm{~Hz}$ ), 18.3. HRMS (ESI): $m / z$ calculated for $\mathrm{C}_{11} \mathrm{H}_{9} \mathrm{~F}_{3} \mathrm{~N}_{2} \mathrm{O}_{3}+\mathrm{H}^{+}\left[\mathrm{M}+\mathrm{H}^{+}\right]: 275.0644$. Found: 275.0648 .

(R)-2-(4-(3-(Trifluoromethyl)-3H-diazirin-3-yl)phenoxy)propanoic acid ((R)-58). The similar treatment of tert-butyl (R)-2-(4-(3-(trifluoromethyl)-3H-diazirin-3-yl)phenoxy)-propanoate ( $R$ )-55 (201 mg, $0.61 \mathrm{mmol})$ as that just described gave $(R)-58(184 \mathrm{mg}, 92 \%) .[\alpha]_{\mathrm{D}}+20\left(c 1, \mathrm{CHCl}_{3}\right) .{ }^{1} \mathrm{H}-\mathrm{NMR}(270 \mathrm{MHz}$, $\left.\mathrm{CDCl}_{3}\right): \delta=10.28(\mathrm{~s}, 1 \mathrm{H}), 7.15(\mathrm{~d}, J=8.6 \mathrm{~Hz}, 2 \mathrm{H}), 6.89(\mathrm{~d}, J=8.6 \mathrm{~Hz}, 2 \mathrm{H}), 4.79(\mathrm{q}, J=6.8 \mathrm{~Hz}, 1 \mathrm{H}), 1.67(\mathrm{~d}$, $J=6.8 \mathrm{~Hz}, 3 \mathrm{H}) .{ }^{13} \mathrm{C}-\mathrm{NMR}\left(67.5 \mathrm{MHz}, \mathrm{CDCl}_{3}\right): \delta=177.4,158.2,128.3,122.3,122.2\left(\mathrm{q},{ }^{1} J_{C F}=274.3 \mathrm{~Hz}\right)$, 115.4, 72.0, $28.1\left(\mathrm{q},{ }^{2} J_{C F}=40.8 \mathrm{~Hz}\right), 18.3$. HRMS (ESI): $m / z$ calculated for $\mathrm{C}_{11} \mathrm{H}_{9} \mathrm{~F}_{3} \mathrm{~N}_{2} \mathrm{O}_{3}+\mathrm{H}^{+}\left[\mathrm{M}+\mathrm{H}^{+}\right]$: 275.0644. Found: 275.0614 .

(S)-2-(3-(3-(Trifluoromethyl)-3H-diazirin-3-yl)phenoxy)propanoic acid ((S)-59). The similar treatment of tert-butyl (S)-2-(3-(3-(trifluoromethyl)-3H-diazirin-3-yl)phenoxy)-propanoate (S)-56 (220 mg, $0.67 \mathrm{mmol})$ as that just described gave $(S)-59\left(209 \mathrm{mg}\right.$, quant). $[\alpha]_{\mathrm{D}}-13\left(\mathrm{c} 1, \mathrm{CHCl}_{3}\right) .{ }^{1} \mathrm{H}-\mathrm{NMR}$ $\left(270 \mathrm{MHz} \mathrm{CDCl}_{3}\right): \delta=11.47(\mathrm{~s}, 1 \mathrm{H}), 7.29(\mathrm{t}, J=7.8 \mathrm{~Hz}, 1 \mathrm{H}), 6.89(\mathrm{~d}, J=7.8 \mathrm{~Hz}, 1 \mathrm{H}), 6.79(\mathrm{~d}, J=7.8 \mathrm{~Hz}$, $1 \mathrm{H}), 6.74(\mathrm{~s}, 1 \mathrm{H}), 4.78(\mathrm{q}, J=6.8 \mathrm{~Hz}, 1 \mathrm{H}), 1.66(\mathrm{~d}, J=6.8 \mathrm{~Hz}, 3 \mathrm{H}) .{ }^{13} \mathrm{C}-\mathrm{NMR}\left(67.5 \mathrm{MHz}, \mathrm{CDCl}_{3}\right): \delta=178.0$, $157.5,130.9,130.2,122.0\left(\mathrm{q},{ }^{1} J_{C F}=274.7 \mathrm{~Hz}\right), 119.8,115.7,114.0,72.1,28.3\left(\mathrm{q},{ }^{2} J_{C F}=39.9 \mathrm{~Hz}\right), 18.2$. HRMS (ESI): $m / z$ calculated for $\mathrm{C}_{11} \mathrm{H}_{9} \mathrm{~F}_{3} \mathrm{~N}_{2} \mathrm{O}_{3}+\mathrm{H}^{+}\left[\mathrm{M}+\mathrm{H}^{+}\right]$: 275.0644. Found: 275.0661 .

(R)-2-(3-(3-(Trifluoromethyl)-3H-diazirin-3-yl)phenoxy)propanoic acid ((R)-59). The similar treatment of tert-butyl (R)-2-(3-(3-(trifluoromethyl)-3H-diazirin-3-yl)phenoxy)-propanoate $(R)-56$ $(283 \mathrm{mg}, 0.86 \mathrm{mmol})$ as that just described gave $(R)-59(208 \mathrm{mg}, 89 \%) . \quad[\alpha]_{\mathrm{D}}+13\left(c 1, \mathrm{CHCl}_{3}\right)$. ${ }^{1} \mathrm{H}-\mathrm{NMR}\left(270 \mathrm{MHz}, \mathrm{CDCl}_{3}\right): \delta=11.32(\mathrm{~s}, 1 \mathrm{H}), 7.30(\mathrm{t}, J=8 \mathrm{~Hz}, 1 \mathrm{H}), 6.90(\mathrm{~d}, J=7.8 \mathrm{~Hz}, 1 \mathrm{H})$, $6.80(\mathrm{~d}, J=7.8 \mathrm{~Hz}, 1 \mathrm{H}), 6.74(\mathrm{~s}, 1 \mathrm{H}), 4.78(\mathrm{q}, J=6.8 \mathrm{~Hz}, 1 \mathrm{H}), 1.66(\mathrm{~d}, J=6.8 \mathrm{~Hz}, 3 \mathrm{H}) .{ }^{13} \mathrm{C}-\mathrm{NMR}$ $\left(67.5 \mathrm{MHz}, \mathrm{CDCl}_{3}\right): \delta=177.9,157.5,130.9,130.2,122.0\left(\mathrm{q},{ }^{1} J_{C F}=274.5 \mathrm{~Hz}\right), 119.8,115.7,114.0,72.1$, $28.3\left(\mathrm{q},{ }^{2} J_{C F}=39.7 \mathrm{~Hz}\right), 18.2$. HRMS (ESI): $\mathrm{m} / z$ calculated for $\mathrm{C}_{11} \mathrm{H}_{9} \mathrm{~F}_{3} \mathrm{~N}_{2} \mathrm{O}_{3}+\mathrm{H}^{+}\left[\mathrm{M}+\mathrm{H}^{+}\right]: 275.0644$. Found: 275.0627.

(S)-2-(2-(3-(Trifluoromethyl)-3H-diazirin-3-yl)phenoxy)propanoic acid ((S)-60). The similar treatment of tert-butyl (S)-2-(2-(3-(trifluoromethyl)-3H-diazirin-3-yl)phenoxy)-propanoate (S)-57 (95.4 mg, $0.29 \mathrm{mmol}$ ) as that just described gave (S)-60 (89.0 mg, quant). $[\alpha]_{\mathrm{D}}-10\left(c 1, \mathrm{CHCl}_{3}\right) .{ }^{1} \mathrm{H}-\mathrm{NMR}\left(270 \mathrm{MHz}, \mathrm{CDCl}_{3}\right)$ : $\delta=7.49(\mathrm{~d}, J=7.6 \mathrm{~Hz}, 1 \mathrm{H}), 7.37(\mathrm{t}, J=7.6 \mathrm{~Hz}, 1 \mathrm{H}), 7.02(\mathrm{t}, J=7.6 \mathrm{~Hz}, 1 \mathrm{H}), 6.78(\mathrm{~d}, J=7.6 \mathrm{~Hz}, 1 \mathrm{H})$, $4.86(\mathrm{q}, J=6.8 \mathrm{~Hz}, 1 \mathrm{H}), 1.78(\mathrm{~d}, J=6.8 \mathrm{~Hz}, 3 \mathrm{H}) .{ }^{13} \mathrm{C}-\mathrm{NMR}\left(67.5 \mathrm{MHz}, \mathrm{CDCl}_{3}\right): \delta=177.1,157.5,132.0$, $131.4122 .0\left(\mathrm{q},{ }^{1} J_{C F}=275.4 \mathrm{~Hz}\right), 122.0,117.4,112.4,72.3,26.3\left(\mathrm{q},{ }^{2} J_{C F}=42.5 \mathrm{~Hz}\right), 18.2$. HRMS (ESI): $\mathrm{m} / \mathrm{z}$ calculated for $\mathrm{C}_{11} \mathrm{H}_{9} \mathrm{~F}_{3} \mathrm{~N}_{2} \mathrm{O}_{3}+\mathrm{H}^{+}\left[\mathrm{M}+\mathrm{H}^{+}\right]$: 275.0644. Found: 275.0663 .

(R)-2-(2-(3-(Trifluoromethyl)-3H-diazirin-3-yl)phenoxy)propanoic acid ((R)-60). The similar treatment of tert-butyl (R)-2-(2-(3-(trifluoromethyl)-3H-diazirin-3-yl)phenoxy)-propanoate ( $R$ )-57 (166 mg, $0.50 \mathrm{mmol}$ ) as that just described gave (R)-60 (151 mg, quant). $[\alpha]_{\mathrm{D}}+10\left(c 1, \mathrm{CHCl}_{3}\right) \cdot{ }^{1} \mathrm{H}-\mathrm{NMR}\left(270 \mathrm{MHz}, \mathrm{CDCl}_{3}\right)$ : $\delta=7.50(\mathrm{~d}, J=7.6 \mathrm{~Hz}, 1 \mathrm{H}), 7.38(\mathrm{t}, J=7.6 \mathrm{~Hz}, 1 \mathrm{H}), 7.03(\mathrm{t}, J=7.6 \mathrm{~Hz}, 1 \mathrm{H}), 6.80(\mathrm{~d}, J=7.6 \mathrm{~Hz}, 1 \mathrm{H})$, $4.88(\mathrm{q}, J=6.8 \mathrm{~Hz}, 1 \mathrm{H}), 1.77(\mathrm{~d}, J=6.8 \mathrm{~Hz}, 3 \mathrm{H}) .{ }^{13} \mathrm{C}-\mathrm{NMR}\left(67.5 \mathrm{MHz}, \mathrm{CDCl}_{3}\right): \delta=176.6,157.4,132.0$, 131.3, 122.0, $122.0\left(\mathrm{q},{ }^{1} J_{C F}=274.9 \mathrm{~Hz}\right), 117.3,112.3,72.2,26.3\left(\mathrm{q},{ }^{2} J_{C F}=42.5 \mathrm{~Hz}\right), 18.1$. HRMS (ESI): $\mathrm{m} / \mathrm{z}$ calculated for $\mathrm{C}_{11} \mathrm{H}_{9} \mathrm{~F}_{3} \mathrm{~N}_{2} \mathrm{O}_{3}+\mathrm{H}^{+}\left[\mathrm{M}+\mathrm{H}^{+}\right]$: 275.0644. Found: 275.0654 . 


\subsection{Cell-Based Sweet Taste Assay for Photoreactive Lactisole Derivatives}

Construction of cell lines stably expressing the sweet taste receptor. The previously reported method to construct a cell line stably expressing the human sweet taste receptor [37,38] was also used in this study. The genes encoding T1R2, T1R3, and G $\alpha 16$ gust44 were incorporated into a modified version of the pcDNA5/FRT vector (Thermo Fisher Scientific, Waltham, MA, USA.). Following the Flp-In System protocol (Thermo Fisher Scientific, Waltham, MA, USA.), this construct was transfected into Flp-In 293 cells.

Measurement of cellular responses. Measurements of cellular responses were performed as described previously $[5,37,38]$. At first, all synthesized compounds were prepared in $1 \mathrm{M}$ solution using dimethyl sulfoxide, and diluted by assay buffer. Cellular responses administrated mixtures containing both $1 \mathrm{mM}$ aspartame and various concentrations of inhibitors were measured. Flp-In 293 cells stably expressing the sweet taste receptor were seeded in 96-well plates and incubated for an additional $23 \mathrm{~h}$. The cells were washed with assay buffer and loaded using the FRIPR Calcium 4 Assay Kit (Molecular Devices, San Jose, CA, USA.). Measurement was performed on FlexStation 3 (Molecular Devices, San Jose, CA, USA.) after the samples were incubated at $37^{\circ} \mathrm{C}$ for $1 \mathrm{~h}$. The temperature of the FlexStation 3 was also maintained at $37^{\circ} \mathrm{C}$.

Data analysis. All data were normalized by the cellular response against $1 \mathrm{mM}$ aspartame and were fitted to Hill's equation, which was drawn using Clampfit 9.2 (Molecular Devices, Palo Alto, CA, USA), and $\mathrm{IC}_{50}$ values were calculated from a dose-response curve.

Supplementary Materials: The following are available online, ${ }^{1} \mathrm{H}$ - and ${ }^{13} \mathrm{C}$ - data for synthetic compounds, Cellular response of each photophore containing lactisole derivatives.

Author Contributions: Conceptualization, T.N., T.M. and M.H.; organic synthesis, A.I., Z.P.T., L.W. and M.H.; biochemical analysis, T.N., T.M.; data curation, T.N., A.I. and M.H.; writing-original draft preparation, T.N., M.H. All authors have read and agreed to the published version of the manuscript.

Funding: This research was partially supported by the Ministry of Education, Science, Sports, and Culture Grant-in-Aid for Scientific Research (C), (17K0194007 M.H.). Part of this work was performed under the Cooperative Research Program of "Network Joint Research Center for Materials and Devices". Cross-ministerial Strategic Innovation Promotion Program (SIP) "Technologies for creating next-generation agriculture, forestry and fisheries" (T.M.).

Conflicts of Interest: The authors declare no conflict of interest.

\section{References}

1. Rathbone, E.B.; Patel, G.D.; Butters, R.W.; Cookson, D.; Robinson, J.L. Occurrence of 2-(4-methoxyphenoxy)propanoic acid in roasted coffee beans: Analysis by gas-liquid chromatography and by high-performance liquid chromatography. J. Agr. Food Chem. 1989, 37, 54-58. [CrossRef]

2. Rathbone, E.B.; Butters, R.W.; Cookson, D.; Robinson, J.L. Chirality of 2-(4-methoxyphenoxy)propanoic acid in roasted coffee beans: Analysis of the methyl esters by chiral high-performance liquid chromatography. J. Agr. Food Chem. 1989, 37, 58-60. [CrossRef]

3. Jiang, P.; Cui, M.; Zhao, B.; Liu, Z.; Snyder, L.A.; Benard, L.M.J.; Osman, R.; Margolskee, R.F.; Max, M. Lactisole interacts with the transmembrane domains of human T1R3 to inhibit sweet taste. J. Biol. Chem. 2005, 280, 15238-15246. [CrossRef]

4. Maillet, E.L.; Margolskee, R.F.; Mosinger, B. Phenoxy herbicides and fibrates potently inhibit the human chemosensory receptor subunit T1R3. J. Med. Chem. 2009, 52, 6931-6935. [CrossRef]

5. Nakagita, T.; Ishida, A.; Matsuya, T.; Kobayashi, T.; Narukawa, M.; Hirokawa, T.; Hashimoto, M.; Misaka, T. Structural insights into the differences among lactisole derivatives in inhibitory mechanisms against the human sweet taste receptor. PLoS ONE 2019, 14, e0213552. [CrossRef]

6. Aaberg, B. Plant growth regulators. XXXIX. Some nitro- and chloro-nitro-phenoxyacetic and optically active-phenoxypropionic acids. Swed. J. Agric. Res. 1980, 10, 101-106.

7. Tomohiro, T.; Hashimoto, M.; Hatanaka, Y. Cross-linking chemistry and biology: Development of multifunctional photoaffinity probes. Chem. Record 2005, 5, 385-395. [CrossRef] 
8. Hashimoto, M.; Hatanaka, Y. Recent progress in diazirine-based photoaffinity labeling. Eur. J. Org. Chem. 2008, 2513-2523. [CrossRef]

9. Hatanaka, Y. Development and leading-edge application of innovative photoaffinity labeling. Chem. Pharm. Bull. 2015, 63, 1-12. [CrossRef]

10. Hatanaka, Y.; Hashimoto, M. Photoaffinity Labeling for Structural Probing within Protein; Springer: Tokyo, Japan, 2017. [CrossRef]

11. Brunner, J. New photolabeling and crosslinking methods. Annu. Rev. Biochem. 1993, 62, 483-514. [CrossRef]

12. Masuda, K.; Koizumi, A.; Misaka, T.; Hatanaka, Y.; Abe, K.; Tanaka, T.; Ishiguro, M.; Hashimoto, M. Photoactive ligands probing the sweet taste receptor. Design and synthesis of highly potent diazirinyl D-phenylalanine derivatives. Bioorg. Med. Chem. Lett. 2010, 20, 1081-1083. [CrossRef]

13. Murai, Y.; Masuda, K.; Sakihama, Y.; Hashidoko, Y.; Hatanaka, Y.; Hashimoto, M. Comprehensive synthesis of photoreactive (3-trifluoromethyl)diazirinyl indole derivatives from 5- and 6-trifluoroacetylindoles for photoaffinity labeling. J. Org. Chem. 2012, 77, 8581-8587. [CrossRef]

14. Tsunekawa, Y.; Masuda, K.; Muto, M.; Muto, Y.; Murai, Y.; Hashidoko, Y.; Orikasa, Y.; Oda, Y.; Hatanaka, Y.; Hashimoto, M. Chemo-enzymatic synthesis of $1^{\prime}$-photoreactive sucrose derivatives via ether linkage. Heterocycles 2012, 84, 283-290. [CrossRef]

15. Sakurai, M.; Masuda, K.; Wang, L.; Murai, Y.; Sakihama, Y.; Hashidoko, Y.; Hatanaka, Y.; Hashimoto, M. Synthesis of methoxy-substituted diazirinyl phenylalanine-A novel photoreactive aspartame derivative for functional analysis of sweet receptors. Heterocycles 2014, 88, 629-637. [CrossRef]

16. Sakurai, M.; Yoshida, T.; Wang, L.; Murai, Y.; Masuda, K.; Sakihama, Y.; Hashidoko, Y.; Hatanaka, Y.; Hashimoto, M. Synthesis of photoreactive diazirinyl salicin derivative to elucidate functional analysis of the bitter taste receptor. Heterocycles 2015, 90, 698-705. [CrossRef]

17. Wang, L.; Yoshida, T.; Muto, Y.; Murai, Y.; Tachrim, Z.P.; Ishida, A.; Nakagawa, S.; Sakihama, Y.; Hashidoko, Y.; Masuda, K.; et al. Synthesis of diazirine-based photoreactive saccharin derivatives for the photoaffinity labeling of gustatory receptors. Eur. J. Org. Chem. 2015, 3129-3134. [CrossRef]

18. Wang, L.; Hashidoko, Y.; Hashimoto, M. Cosolvent-promoted O-benzylation with silver(i) oxide: Synthesis of 1'-benzylated sucrose derivatives, mechanistic studies, and scope investigation. J. Org. Chem. 2016, 81, 4464-4474. [CrossRef]

19. Yoshida, T.; Hashidoko, Y.; Hashimoto, M. Synthesis of benzophenone and phenylazide derivatives of salicin for functional analysis of the bitter taste receptor using photoaffinity labeling. Heterocycles 2016, 93, 355-361. [CrossRef]

20. Ishida, A.; Wang, L.; Tachrim, Z.P.; Suzuki, T.; Sakihama, Y.; Hashidoko, Y.; Hashimoto, M. Comprehensive Synthesis of Photoreactive Phenylthiourea Derivatives for the Photoaffinity Labeling. Chemistryselect 2017, 2, 160-164. [CrossRef]

21. Walsh, D.A.; Sleevi, M.C.; Sancilio, L.F. Antiinflammatory activity of N-(2-benzoylphenyl)alanine derivatives. J. Med. Chem. 1984, 27, 1317-1321. [CrossRef]

22. Azzolina, O.; Vercesi, D.; Ghislandi, V. Optical resolution, asymmetric synthesis and absolute configuration of m-benzoyl-2-phenoxypropionic acids. Farmaco 1988, 43, 469-478.

23. Azzolina, O.; Collina, S.; Ghislandi, V. Optical resolution of aryloxypropionic acids and their esters by HPLC on cellulose tris(3,5-dimethyltriphenylcarbamate) derivative. Farmaco 1993, 48, 1401-1416.

24. Azzolina, O.; Vercesi, D.; Collina, S.; Ghislandi, V. Chiral resolution of methyl 2-aryloxypropionates by biocatalytic stereospecific hydrolysis. Farmaco 1995, 50, 221-226.

25. Vinkovic, V.; Kontrec, D.; Sunjic, V.; Navarini, L.; Zanetti, F.; Azzolina, O. Mechanism of chiral recognition in the enantioseparation of 2-aryloxypropionic acids on new brush-type chiral stationary phases. Chirality 2001, 13, 581-587. [CrossRef]

26. Biagi, G.; Livi, O.; Scartoni, V.; Verugi, E. 1,2,3-Triazoles: Structural changes on two effective inhibitors of prostaglandin synthesis in vitro. Farmaco 1988, 43, 597-611. [CrossRef]

27. Akazome, M.; Sukegawa, J.; Goto, Y.; Matsumoto, S. A cyclic trimer of 2-(2-aminophenoxy)propionic acid with a bowl-shaped structure. Tetrahedron Lett. 2009, 50, 5382-5385. [CrossRef]

28. Akazome, M.; Ishii, Y.; Nireki, T.; Ogura, K. Induced helix of 2-(2-aminophenoxy)alkanoic acid oligomers as a $\delta$-peptidomimetic foldamer. Tetrahedron Lett. 2008, 49, 4430-4433. [CrossRef] 
29. Akazome, M.; Hamada, N.; Takagi, K.; Yagyu, D.; Matsumoto, S. Binding of acetylcholine and quaternary ammonium compounds to a C3-symmetric bowl-shaped tripeptide of 2-(3-aminophenoxy)propanoic acids acting as a ditopic receptor. Tetrahedron Lett. 2014, 55, 2226-2229. [CrossRef]

30. Lu, X.; Cseh, S.; Byun, H.-S.; Tigyi, G.; Bittman, R. Total Synthesis of Two Photo-Activatable Analogues of the Growth-Factor-Like Mediator Sphingosine 1-Phosphate: Differential Interaction with Protein Targets. J. Org. Chem. 2003, 68, 7046-7050. [CrossRef]

31. Murai, Y.; Yoshida, T.; Wang, L.; Masuda, K.; Hashidoko, Y.; Monde, K.; Hatanaka, Y.; Hashimoto, M. Efficient Synthesis of Photoreactive 2-Propoxyaniline Derivatives as Artificial Sweeteners. Synlett 2016, 27, 946-950. [CrossRef]

32. Hatanaka, Y.; Hashimoto, M.; Kurihara, H.; Nakayama, H.; Kanaoka, Y. Novel family of aromatic diazirines for photoaffinity-labeling. J. Org. Chem. 1994, 59, 383-387. [CrossRef]

33. Liu, H.-J.; Sabesan, S.I. Direct transformation of carboxylic acids to thiol esters induced by phenyl dichlorophosphate. Can. J. Chem. 1980, 58, 2645-2648. [CrossRef]

34. Sevenard, D.V.; Vorobyev, M.; Sosnovskikh, V.Y.; Wessel, H.; Kazakova, O.; Vogel, V.; Shevchenko, N.E.; Nenajdenko, V.G.; Lork, E.; Roeschenthaler, G.-V. Halogenation of fluorinated cyclic 1,3-dicarbonyl compounds: New aspects of synthetic application. Tetrahedron 2009, 65, 7538-7552. [CrossRef]

35. Neogi, A.; Majhi, T.P.; Achari, B.; Chattopadhyay, P. Palladium-catalyzed intramolecular C-O bond formation: An approach to the synthesis of chiral benzodioxocines. Eur. J. Org. Chem. 2008, 330-336. [CrossRef]

36. Wang, L.; Murai, Y.; Yoshida, T.; Ishida, A.; Masuda, K.; Sakihama, Y.; Hashidoko, Y.; Hatanaka, Y.; Hashimoto, M. Alternative One-pot synthesis of (trifluoromethyl)phenyldiazirines from tosyloxime derivatives: Application for new synthesis of optically pure diazirinylphenylalanines for photoaffinity labeling. Org. Lett. 2015, 17, 616-619. [CrossRef]

37. Fujiwara, S.; Imada, T.; Nakagita, T.; Okada, S.; Nammoku, T.; Abe, K.; Misaka, T. Sweeteners interacting with the transmembrane domain of the human sweet-taste receptor induce sweet-taste synergisms in binary mixtures. Food Chem. 2012, 130, 561-568. [CrossRef]

38. Imada, T.; Misaka, T.; Fujiwara, S.; Okada, S.; Fukuda, Y.; Abe, K. Amiloride reduces the sweet taste intensity by inhibiting the human sweet taste receptor. Biochem. Biophys. Res. Comm. 2010, 397, 220-225. [CrossRef]

Sample Availability: Samples of the compounds are available from the authors.

(C) 2020 by the authors. Licensee MDPI, Basel, Switzerland. This article is an open access article distributed under the terms and conditions of the Creative Commons Attribution (CC BY) license (http://creativecommons.org/licenses/by/4.0/). 